\title{
Counseling and clinical psychology doctoral students' perceptions of their faculty's ethical behavior
}

Philip W. Cromer

West Virginia University

Follow this and additional works at: https://researchrepository.wvu.edu/etd

\section{Recommended Citation}

Cromer, Philip W., "Counseling and clinical psychology doctoral students' perceptions of their faculty's ethical behavior" (2005). Graduate Theses, Dissertations, and Problem Reports. 2238.

https://researchrepository.wvu.edu/etd/2238

This Dissertation is protected by copyright and/or related rights. It has been brought to you by the The Research Repository @ WVU with permission from the rights-holder(s). You are free to use this Dissertation in any way that is permitted by the copyright and related rights legislation that applies to your use. For other uses you must obtain permission from the rights-holder(s) directly, unless additional rights are indicated by a Creative Commons license in the record and/ or on the work itself. This Dissertation has been accepted for inclusion in WVU Graduate Theses, Dissertations, and Problem Reports collection by an authorized administrator of The Research Repository @ WVU.

For more information, please contact researchrepository@mail.wvu.edu. 
Counseling and Clinical Psychology Doctoral Students' Perceptions of Their Faculty’s Ethical Behavior

\author{
Philip W. Cromer
}

Dissertation submitted to the College of Human Resources and Education at West Virginia University in partial fulfillment of the requirements of the degree of

Doctor of Philosophy

In

Counseling Psychology

Robert P. Marinelli, Ed.D., Chairperson

William J. Fremouw, Ph.D.

Richard T. Walls, Ph.D.

Margaret K. Glenn, Ed.D.

David J. Srebalus, Ed.D.

Department of Counseling, Rehabilitation Counseling, and Counseling Psychology

Morgantown, West Virginia

2005

Keywords: Psychology Doctoral Students, Perceptions, Ethical Behavior 


\begin{abstract}
Counseling and Clinical Psychology Doctoral Students’ Perceptions of Their Faculty’s Ethical Behavior
\end{abstract}

Philip W. Cromer

The purpose of this study was to examine the perceptions of psychology doctoral students with regard to their faculty's ethical behavior. A review of the literature suggested that research on the perception of ethical behavior in academia has been narrowly focused on undergraduate students. Furthermore, many of the studies did not convey a comprehensive picture of the students' perceptions of their faculty's ethical behavior. A survey instrument was adapted from a survey used in a study of students' view of their undergraduate professors' actions (Keith-Spiegel, Tabachnick, \& Allen, 1993). A randomized sample of 50 accredited counseling psychology doctoral programs and 50 accredited clinical psychology doctoral programs were chosen from the American Psychological Association's Graduate Study in Psychology (2004). A complete list of non-accredited counseling psychology programs (5 total) and clinical psychology doctoral programs (13 total) were also acquired from the same source. Six surveys were sent to each program totaling 708 surveys. One hundred and twenty five usable surveys were returned after a follow-up notice was sent to the training directors of each program. Data analyses revealed statistically significant differences across counseling psychology and clinical psychology doctoral students in areas related to the perception and occurrence of a variety of behaviors including hugging a student, criticizing all theoretical approaches except those the professor personally prefers and insulting or ridiculing a student in the student's presence. Although these differences were statistically significant, there are few practical differences between them. Anecdotal findings have also been categorized and discussed. Suggestions for future research are based on these findings. 
This work is dedicated to my wife Julie and my son Kai. Having them in my life is a true blessing and inspiration. I love you both very much. 


\section{ACKNOWLEDGEMENTS}

I am truly thankful for the help that was provided to me by my advisor Robert P. Marinelli, Ed.D. Throughout the entire process he was patient, thoughtful and considerate. I would also like to thank Richard T. Walls, Ph.D. for helping with the statistical analyses and results section. I am grateful to William J. Fremouw, Ph.D., David Srebalus, Ed.D. and Margaret K. Glenn, Ed.D. for their constructive comments and support as committee members. I am also thankful to my peers who participated in this survey and for sharing their personal experiences. 


\section{TABLE OF CONTENTS}

Abstract................................................................. ii

Dedication........................................................ iii

Acknowledgements............................................. iv

Table of Contents..................................................v

List of Tables..................................................viii

Chapter I

Introduction................................................1

Counseling and Clinical Psychology.................... 1

Training in Ethics....................................4

Ethics of Training................................... 7

Research...........................................8

Sexual Boundary Crossings............................. 8

Other Multiple Relationships............................. 14

Student-Faculty Dual Relationship Guidelines............. 14

Student Perceptions....................................16

Statement of the Problem................................19

Purpose of the Study.....................................19

Research Questions....................................20

Definitions............................................22

Chapter II

Method.................................................... 24

Participants...................................... 24 
Procedure................................................ 24

Survey Instrument..................................... 25

Demographics......................................... 28

Research Design and Analysis..............................29

Chapter III

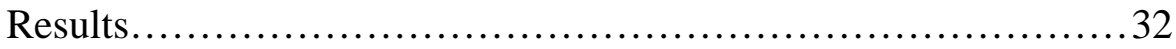

Sample Characteristics.................................... 32

Research Questions................................... 34

Chapter IV

Discussion, and Limitations of the Study $\ldots \ldots \ldots \ldots \ldots \ldots \ldots \ldots \ldots \ldots . . . \ldots 9$

Discussion and Implications of Research Findings................... 89

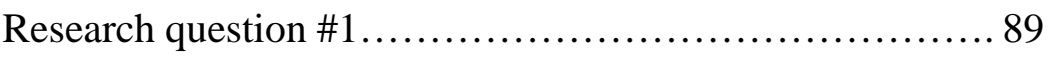

Research question $\# 2 \ldots \ldots \ldots \ldots \ldots \ldots \ldots \ldots \ldots \ldots \ldots \ldots \ldots . . . . . . . . \ldots 1$

Research question \#3........................................ 93

Research question \#4..................................... 94

Research question \#5..................................... 95

Research question \#6..................................... 96

Research question \#7..................................... 97

Research question \#8.................................... 98

Anecdotal Findings...................................... 100

General Comments................................101

Personal Experiences................................ 101

Clarifications......................................103 
Suggestions...................................105

Limitations and Future Research.........................107

REFERENCES................................................ 112

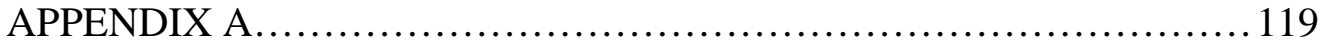




\section{LIST OF TABLES}

Table 1- $\quad$ Frequency and Percent of Doctoral Students’ Demographic Information...

Table 2- $\quad$ Frequency and Percent of Doctoral Students’ Educational Experiences

Table 3- $\quad$ Means and Standard Deviations of the Estimated Number of Faculty by Full-Time, Part-Time, Gender violations of Ethics, Number of Students in Program, and Years of Clinical Experience.

Table 4a- $\quad$ Frequency and Percent of “Occurs in program” Ethics Questions by Program.

Table 4b- $\quad$ Frequency and Percent of "Is it ethical” Ethics Questions by Program....

Table 4c- $\quad$ Means and Standard Deviations of each Ethics Question by Counseling and Clinical Program. 58

Table 5a- $\quad$ Significant ANOVA's on Ethics Questions (Occurs in program) by Program (counseling vs. clinical)......................... 66

Table 5b- $\quad$ Means and Standard Deviations on Ethics Questions (Occurs in program) by program.

Table 6a- $\quad$ Significant ANOVA's on Ethics Questions (Is it ethical) by Program (counseling vs. clinical)

Table 6b- Means and Standard Deviations on Ethics Questions (Is it ethical) by Program.

Table 7a- $\quad$ Significant ANOVA's on Ethics Questions (Occurs in program) by APA Accreditation (Yes vs. No).

Table 7b- $\quad$ Means and Standard Deviations on Ethics Questions (Occurs in program) by APA Accreditation

Table 8a- $\quad$ Significant ANOVA's on Ethics Questions (Is it ethical) by APA Accreditation (Yes vs. No).

Table 8b- $\quad$ Means and Standard Deviations on Ethics Questions (Is it ethical) by APA Accreditation... 
Table 9a- Significant ANOVA's on Ethics Questions (Occurs in program) by Ethics Course Taken (Yes vs. No)............................ 75

Table 9b- $\quad$ Means and Standard Deviations on Ethics Questions (Occurs in program) by Ethics Course Taken.......................76

Table 10a- Significant ANOVA's on Ethics Questions (Is it ethical) by Ethics Course Taken (Yes vs. No)................................77

Table 10b- Means and Standard Deviations on Ethics Questions (Is it ethical) by Ethics Course Taken (Yes vs. No)..............................78

Table 11a- Significant ANOVAs on Matched Categories (Is it ethical) by program (Clinical vs. Counseling).............................. 79

Table 11b- Means and Standard Deviations on Competence/Impairment and Unprofessional Behavior Composite Scores by Program.............80

Table 12a- Significant ANOVAs on Matched Categories (Is it ethical) by APA Accreditation (yes vs. no)............................. 81

Table 12b- Means and Standard Deviations on Composite Scores

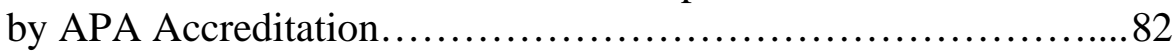

Table 13a- Significant ANOVAs on Matched Categories (Is it ethical) by Ethics Courses Taken (yes vs. no). 83

Table 13b- Means and Standard Deviations on Composite Scores by Ethic Courses Taken.............................................. 84

Table 14a Means and Standard Deviations of the top 10 Ethics Behaviors (Occurs in program) ranked by Counseling Psychology Students... 85

Table 14b Means and Standard Deviations of the top 10 Ethics Behaviors (Is it ethical) ranked by Counseling Psychology Students........... 86

Table 15a Means and Standard Deviations of the top 10 Ethics Behaviors (Occurs in program) ranked by Clinical Psychology Students....... 87

Table 15b Means and Standard Deviations of the top 10 Ethics Behaviors (Is it ethical) ranked by Clinical Psychology Students. ... 88 


\section{CHAPTER 1}

\section{INTRODUCTION}

Formal attention to ethical issues in psychology started in 1938. At this time a special committee of the American Psychological Association (APA) considered writing the first ethical code (Kimmel, 1988). In 1947 work on a formal code of ethics began, and in 1953 the first formal code of ethics was formulated (APA, 1990). Since the conception of the ethics code, literature on ethical issues in psychology has grown significantly. The majority of the literature has focused primarily on issues related to clinical practice and basic research. Although there has been a gradual increase in the literature pertaining to ethics in education, (DePalma \& Drake, 1956; Jorgensen \& Weigel, 1973; Newmark, \& Hutchins, 1981; Tymchuk, Drapkin, Major-Kingsley, Ackerman, Coffman, \& Baum, 1979; Holmes, Rupert, Ross, \& Shapera,1999), issues related to psychology doctoral students' perceptions of ethical training and the ethical behavior of their faculty has not.

\section{Counseling and Clinical Psychology}

The majority of psychology students applying to graduate school are interested in becoming clinicians, and approximately half of all degrees awarded in psychology are in subfields of clinical and counseling psychology (Mayne, Norcross, \& Sayette, 2000). Controversy exists about whether clinical and counseling psychologists are more similar or dissimilar in the training they receive, the type of work they do, and the characteristics of both students and faculty members (Brems \& Johnson, 1996; Norcross, Sayette, Mayne, \& Turkson, 1998; Tipton, 1983; Zook, 1989). Norcross and colleagues (1998) reported several differences. For example, counseling psychology programs accept a 
significantly higher percentage of ethnic minorities than did clinical programs (25\% vs. 18\% respectively). Counseling psychology programs also accepted a far higher proportion of students who had already attained their masters degree than PsyD programs, which in turn accepted more master's candidates than $\mathrm{PhD}$ clinical programs ( $67 \%$ vs. $40 \%$ vs. $21 \%)$.

The largest differences found between counseling and clinical psychology programs are the areas of research in which they focus. Counseling psychology programs focus more on minority/cross-cultural issues and vocational assessment, $69 \%$ and $62 \%$ respectively, when compared to only 32\% and 1\% of the clinical programs (Norcross et al., 1998). Norcross and colleagues (1998) also found that counseling psychology programs provide more research training and mentorship in areas of professional issues and human diversity. Professional issues include psychology ethics and professional training, whereas human diversity issues include women's studies and gender differences. Conversely, clinical psychology programs offer their students more research opportunities in the areas of psychopathological populations and in activities that are more likely found in more medical settings. Psychopathological populations include personality disorders and posttraumatic stress disorder, whereas activities associated with hospital/medical settings include pain management and neuropsychology.

Brems and Johnson (1997) also revealed differences on three types of service activities performed by counseling and clinical psychologists. Counseling psychologists, when compared to their clinical counterparts, reported higher rates of group therapy, career counseling, and testing. A salient reason for this discrepancy is that counseling psychologists reported more employment at university counseling centers, which tend to 
emphasize these activities. Conversely, these activities are not emphasized in medical settings where clinical psychologists are typically employed. (Brems \& Johnson, 1997).

A recent study of the theoretical orientations and employment settings of APA's Division 12 (Clinical) and Division 17 (Counseling) revealed differences among the 1,389 psychologist participants (Bechtoldt, Wyckoff, Pokrywa, Campbell, \& Norcross, 2000). While both divisions embrace an eclectic/integrative orientation and cognitive orientation, $29 \%$ and $26 \%$ respectively, counseling psychologists identified more with a client-centered and humanistic approach. Clinical psychologists identified more with a behavioral and psychoanalytic approach (Bechtoldt, Wyckoff, Pokrywa, Campbell, \& Norcross, 2000).

Despite their differences, counseling psychologists and clinical psychologists have many similarities. Accepted applicants in counseling and clinical psychology programs have similar grade point averages as well as Graduate Record Examination (GRE) scores. Graduates from doctoral-level counseling and clinical psychology programs are also eligible for the same professional benefits. These benefits include insurance reimbursement, psychology licensure, and independent practice (Norcross, Sayette, Mayne, Karg, \& Turkson, 1998). Furthermore, the American Psychological Association (APA) stopped distinguishing between clinical and counseling psychology internships. Presently there is just one list of accredited internships for both counseling and clinical psychology students, although internship sites may indicate a preference for either clinical and/or counseling students. 


\section{Training in Ethics}

In 1979 the APA accreditation policy required students in doctoral training programs to have instruction in ethics (APA, 1979). Since that time other programs in the field of mental health, such as counseling, have also started to require their students to have training in ethics (Kitchener, 1992). Despite the accreditation policy, many programs vary in the way they carry out their ethics education because currently there is no mandate that programs have to teach a separate course in ethics (APA, 2003). While there are psychology programs that do offer a separate course in the instruction of professional ethics, other programs take a more informal approach to teaching ethics by incorporating ethical issues into already existing courses.

Although there is a paucity of research with regard to the outcomes of accredited and non-accredited doctoral programs in professional psychology, difference has been found between the two. McGaha and Minder (1993) compared the performance of clinical, counseling, and school psychology graduates on the Examination for Professional Practice in Psychology. They found that graduates of fully accredited programs in clinical, counseling, and school psychology achieved higher exam scores than did graduates of probationary or non-accredited programs.

In 1981 a study by Newmark and Hutchins investigated if clinical psychology internships sites were offering training in ethics. The investigators of this study surveyed 185 internship sites by using a modified survey that was originally developed by Tymchuk et al., 1979. They found that $79 \%$ did provide some training in professional ethics. They also reported that when these sites were asked whether they had any formal training in ethics for their interns only $45 \%$ of the sites reported having such training. 
Seventy-five percent of these sites required such training of all of their interns. The authors of this study also suggested the possibility that the training directors of these internship sites are putting too much faith in the ethical knowledge of their interns, and that these sites might not have been truly compliant with the APA accreditation criteria for internships.

Another study by Tymchuk (1985) found that though the majority of psychology clinical doctoral students (92\%) in his study were receiving their training in university settings, only $55 \%$ of them reported that their program had a specific course in ethics. Ninety-four percent of the students, who were APA student members, believed that graduate programs should require a formal course in ethics. Furthermore, in Wilson and Ranft’s (1993) study of the state of ethical training for counseling psychology doctoral students they assert, "Direct information related to students' perceptions, needs, and opinions about the efficacy of ethical training has been negligible. Thus input from the consumers of graduate training in ethics is lacking” (p.448).

A study by Stadler and Paul (1986) also provided some interesting facts regarding counselor educators' preparation in ethics. In their study of 248 department heads in counseling and counseling psychology they found that with regard to their preparation in ethics, out of those who graduated in the 1970's only $16.4 \%$ reported having formal coursework in professional ethics. Stadler and Paul reported that this figure rose to $77.8 \%$ for graduates in the 1980 's. This figure likely rose in response to the 1979 APA requirement for ethics education in training programs.

In 1993, Wilson and Ranft surveyed 50 student representatives from APAaccredited doctoral programs in counseling psychology on the type of ethics education 
they received, as well as the perception of their readiness to cope with ethical dilemmas in the future. Results of the study indicated that the majority of the programs (94\%) stated that they required ethics training. This figure is surprising considering at the time of this survey it had been 12 years since the APA had mandated that accredited doctoral training programs teach professional ethics and standards.

Another interesting result of the Wilson and Ranft study was the format in which the training of ethics was conveyed to the students. For example, $64 \%$ of the programs indicated that they had a formal course to ensure that graduate students learned professional ethics. Forty-eight percent stated that they use seminars. Integrating ethical issues into preexisting courses was the format used by $44 \%$ of the programs. Furthermore, Wilson and Ranft (1993) stated, “Of the respondents, 86\% reported receiving content instruction compared to $44 \%$ having instruction in the process of legal and ethical decision making” (p.452). This finding was particularly interesting when considering most of the students in this study (76\%) felt as if they were prepared to handle problem solving with regard to ethics even though the majority of their training did not focus on these skills. It is also helpful for investigators to inquire about the way students receive their training in ethics, such as ethics material being integrated into a course or taking a separate course in ethics, as it relates to their ethical decision making skills. Although ethics education has steadily increased throughout the years since DePalma and Drake (1956) revealed that only 9.6\% of schools offered some type of ethical training for graduate students in psychology, concerns regarding the teaching of ethics continue. 


\section{Ethics of Training}

Those who teach professional psychology at the graduate level have a tremendous responsibility to their students, particularly to provide a model of ethical appropriateness to their students (Keith-Spiegel, 1994; Kitchener, 1992; Pittenger, 1994; Jordan \& Meara, 1990). However, the profession of psychology has often lacked empirical data with regard to the ethical behavior of academic psychologists.

In an early study Goodstein (1981) reported that he had been under the false pretense that academic psychologists rarely, if ever, have ethical complaints filed against them. Goodstein (1981) discussed how ethical guidelines are also for academic psychologists and stated, "I have found that my assumptions were naïve and that academic psychologists were as likely to offend the ethical code as any other kind of psychologist” (p.191). He reiterated this point when he reported that 13 or $36 \%$ out of the 36 cases that were under review by the American Psychological Association’s Committee on Scientific and Professional Ethics and Conduct at its spring 1980 meeting involved academic issues. Goodstein (1981) also proposed that many of the violations being charged against academic psychologists differed somewhat in content from the violations being charged against nonacademic psychologists. For example, Goodstein stated that for a nonacademic psychologist the charges that are typically brought against them deal with such issues like having sex with clients or Medicaid fraud, but that academic psychologists deal with such issues like plagiarism and ethical issues concerning the supervision of student research. 


\section{Research}

Goodyear, Crego, and Johnston (1992) conducted a study that discusses ethical issues in the supervision of student research. There were 57 participants in this study (66\% male; 34\% female) chosen from editorial board members of the Journal of Counseling Psychology, Psychological Assessment, and Professional Psychology: Research and Practice. Each author was asked to recall up to three instances of ethical problems that related to the supervision of student research. The respondents reported 114 such incidents. The majority of them (79\%) had at least one critical incident, with a mean number of two being reported by each respondent (Goodyear et al., 1992).

Categories that were identified as ethical issues in the supervision of student research were as follows: Incompetent supervision, inadequate supervision, supervision abandonment, intrusion of supervisor values, abusive supervision, exploitive supervision, and dual relationships. Although the frequencies of these behaviors were not assessed in this research, it is clear that there is the possibility of pervasive problems with regard to research and supervision, and should be investigated in greater detail. In fact, this is further corroborated by research conducted by Pope and Vetter's (1992) national survey that examined ethical dilemmas encountered by members of the APA. In their reply from 679 psychologists, they found dilemmas focusing on research mentioned pressures to misstate research procedures or findings.

\section{Sexual Boundary Crossings}

Despite the ethical problems that exist in the supervision of student research issues, sexual boundary crossings are often considered to be more pervasive and prevalent. In 1991 Tabachnick, Keith-Spiegel, and Pope conducted a study regarding the 
belief and behaviors of psychologists as educators. These investigators collected survey data from 482 APA members whose work setting was primarily in institutions of higher learning. The specialty of psychology reported most frequently was clinical (23.6\%), experimental (17.7\%), social (16.3\%), developmental (14.0\%), and counseling (8.6\%). With regard to the gender of the respondents, $46.1 \%$ were male and $53.9 \%$ were female. There were several statistically significant relationships between male and female respondents. For example, 26\% of the males in this study report sexual involvement with a student after the completion of the course compared to $12 \%$ of the women. Other behaviors in which men were statistically higher than women related to being sexually attracted to a student (93\% vs. $64 \%)$, engaging in sexual fantasies about students (84\% vs. $39 \%$ ), and encouraging competition among students ( $85 \%$ vs. $63 \%$ ). These findings were consistent with earlier research done by Pope, Tabachnick, and Keith-Spiegel in their 1986 study of sexual attraction to clients, as well as Pope Tabachnick, and KeithSpiegel's (1987) study of the beliefs and behaviors of psychologists as therapists. In fact, when investigators sought to expose sexual relationships between faculty and their students (Glaser \& Thorpe, 1986; Hammel, Olkin, \& Taube, 1996; Lamb \& Catanzaro, 1998), several important findings were revealed.

In Glaser and Thorpe’s (1986) study of sexual contact and advances between psychology educators and female graduate students, they surveyed 464 of the female members of APA Division 12 (Clinical Psychology) that lived in the United States and Canada. Results of this study revealed "Seventeen percent $(\mathrm{n}=80)$ of the respondents indicate that they engaged in intimate sexual contact with one or more psychology educators during graduate training” (p.45). Furthermore, the percentage of sexual contact 
reported by recent doctoral recipients increased to 22\%, and 34\% among students who were either divorced or separated during graduate training respectively. Not surprisingly though, 95\% of all respondents stated that they thought sexual contact between psychology educators and themselves was harmful, with the majority of them thinking that it was very harmful. In addition, $88 \%$ of those surveyed stated that their training in professional ethical issues, particularly in the area of sexual involvements with educators, was not covered at all. In fact, only $3 \%$ of the respondents stated that this particular ethical issue was covered "thoroughly" while 9\% stated that there was "some” coverage.

It is interesting to note how these statistics changed when the respondents were asked about their training in ethical issues regarding sexual contact between therapists and their clients. Compared to the previous $3 \%$, this figure rose to $22 \%$ of the respondents saying that the issue of sexual contact between therapist and client was covered "thoroughly", 45\% said that the issue was "somewhat" covered, and 33\% said that it was not covered at all (Glaser \& Thorpe, 1986).

Hammel, Olkin, and Taube’s (1996) study also examined student-educator sex, but the setting was in clinical and counseling psychology doctoral training programs. Out of the 1,000 male and female APA members that were sent surveys, $52 \%$ of the women and $49 \%$ of the men responded. Results from this study revealed several important factors about sexual relationships among the faculty and students. The first being that $15 \%$ of the women in this study stated that they had a sexual contact with an educator, compared to only $2 \%$ of the men. Furthermore, the majority of the respondents (86\%) reported that the sexual contact occurred either prior to, or during a working relationship, whereas $14 \%$ stated that sexual contact occurred after the conclusion of one (Hammel et 
al., 1996). There was no association between program status, APA-accredited or not, and the frequency of sexual encounters between students and educators.

Despite all of the statistics on student-educator sexual encounters, information collected from the respondents with regard to their past and current perceptions of their faculty’s ethical behavior proved to be very compelling. Hammel et al., 1996 stated, “Though $47 \%$ of the respondents indicate that they recall perceiving ethical problems at the time of contact, 84\% currently perceived such difficulties” (p.96). There are several possibilities for the difference between the changes in students' perceptions from the past to the present. However, one of the more salient reasons for this difference is the power that a faculty member has over the student when they are in a direct, or even indirect working relationship. In retrospect, many students have changed their opinions of the sexual relationship they encountered with one of their faculty and are now able to say that the relationship was problematic, coercive, and a hindrance to the working relationship.

Hammel and colleagues (1996) also found that with regard to educator characteristics: 1) The majority of boundary violations (86\%) were committed by men, 2) Most of these men (45\%) were married at the time of the violation, (32\%) were either divorced or separated, 3) The violator was often the student's clinical supervisor (36\%) and 4) The majority of sexual boundary crossings that occurred typically did not happen when there was not a current or past working relationship. As important as it is to know who may be committing a sexual violation, it is also important to know the characteristics of those being violated. Such characteristics, as revealed in Hammel et al., 1996 are as follows: 1) At the time of the sexual boundary crossing both males and females were 
typically 30 years of age, and 2) The majority of the students (67\%) were single, divorced, or separated.

In 1998, Lamb and Catanzaro examined the relationship between sexual, as well as nonsexual, boundary violations involving psychologists, clients, supervisees, and students. What makes their study stand out is that Lamb and Catanzaro also focused on how these boundary violations have serious implications for professional practice. Out of the 1,000 practitioners that were randomly selected from the APA, 596 surveys were returned. Overall, the response from males was 52\% $(n=309)$ and $48 \%(n=287)$ for females. The most common work setting (75\%) was private practice, $8 \%$ were in a university counseling center, (6\%), were in community mental health centers, and (11\%) were listed as other. Academics who were not involved in clinical practice were not included in their study.

Although Lamb and Catanzaro (1998) have found evidence to the contrary, they stated that other authors such as Jackson and Nuttall (2001) and Bartell and Rubin (1990) have revealed that, "Professionals who were involved with their own therapists, supervisors, or educators at an earlier time have an increased probability of becoming offending therapists, supervisors, or educators themselves” (p.498). Therefore, the modeling effect that someone of power has over their student, supervisee, or client may have a tremendous impact on the way that person will behave towards others in the future. For students, particularly females, it is important to know the characteristics of those who are likely to commit such a sexual boundary violation.

A more recent study by Lamb, Catanzaro, and Moorman (2003) investigated the reflections of psychologists on their sexual relationships with clients, supervisees, and 
students. A six page questionnaire was sent to 1,000 psychologists (500 clinical and 500 counseling). Of the 1,000 surveys sent out, a total of 368 surveys were returned. With regard to sexual involvement, results reveal the incidences of such relationships are as follows: $3.5 \%$ overall, $2 \%$ with clients, $1 \%$ with supervisees, and $3 \%$ with students. These figures are similar to Lamb \& Catanzaro’s 1998 findings, using similar methodologies, in that overall violations were reported as $8 \%, 6 \%$ with clients, $1.5 \%$ with supervisees, and $1.7 \%$ with students. With the exception of sexual violations with students, the 2003 figures are lower.

Professionals who engaged in prohibited behaviors with students, clients or supervisors note that the dissatisfaction in their own lives could have served as a cue for their increased risk for this type of behavior (Lamb et al., 2003). Since most of the violations took place after the professional relationship, the timing of the relationship could also be a cue for increased risk for psychologists who may be vulnerable (Lamb et al., 2003). Results from this study also reveal that the majority of men who engaged in a sexual boundary violation did so as professionals. In contrast, women reported such involvement as clients, supervisees, or students.

One of the more staggering results of this study revealed that $40 \%$ of the supervisors did not view their involvement as harmful to the other individual. This clearly indicates a need for more educative actions. In fact, Lamb et al., 2003 suggested that graduate student groups, among others, provide psychologists with an open forum to discuss what constitutes harm, as well as how to process ethical decision making. 


\section{Other Multiple Relationships}

At the center of most ethical dilemmas is the issue of having to identify what are appropriate ethical boundaries, and how to make the right ethical decisions regarding those boundaries. This is further corroborated by research on master's degree students in counseling psychology by Podbelski and Weisgerber (1989). They found that $44 \%$ of their sample $(\mathrm{N}=50)$ were not able to identify ethical issues concerning multiple relationships (sexual and non-sexual), nor were $24 \%$ able to identify these issues with

prompting. Both of these issues are important since boundary violations can frequently be ambiguous and, as Lamb et al., 1998 revealed in their study of sexual and nonsexual boundary violations, they can also be influenced by previous training experiences.

\section{Student-Faculty Dual Relationship Guidelines}

Over the years, several guidelines have been established to manage facultystudent dual relationships (Biaggio, Paget, \& Chenoweth, 1997; Blevins-Knabe, 1992; Gottlieb, 1993; Kitchener, 1988; Rest, 1982; Woody, 1990). Before discussing these studies, it is important to review what the current revision of the 2002 APA ethical principles and code of conduct states about multiple relationships:

A multiple relationship occurs when a psychologist is in a professional role with a person and (1) at the same time is in another role with the same person, (2) at the same time is in a relationship with a person closely associated with or related to the person with whom the psychologist has the professional relationship, or (3) promises to enter into another relationship in the future with the person or a person closely associated with or related to the person. 
A psychologist refrains from entering into a multiple relationship if the multiple relationship could reasonably be expected to impair the psychologist's objectivity, competence, or effectiveness in performing his or her functions as a psychologist, or otherwise risks exploitation or harm to the person with whom the professional relationship exist. Multiple relationships that would not be expected to cause impairment or risk exploitation or harm are not unethical (p.1065). Biaggio et al., 1997 formulated general guidelines for faculty members to consider when trying to maintain appropriate ethical boundaries with students. First, faculty members need to acknowledge the power and responsibility that they hold. This is crucial to remember and is emphasized by previous studies that have shown a rampant misuse of power during, and after working relationships between students and educators (Glaser \& Thorpe, 1986; Hammel et al., 1996; Pope et al., 1986; Pope et al., 1987; Tabachnick et al. 1991). In graduate training programs it can often be difficult to assess what is a boundary violation versus what is in the best interest of the student. What adds to the confusion in these doctoral training programs is that there are often ambiguous areas of multiple relationships such as mentoring, graduate assistantships in which the faculty are employing the student, and social relationships (Bowman, Hatley, and Bowman, 1995). The second guideline, when evaluating faculty-student relationships, is to develop a framework that puts educational goals of the student first. When developing this framework the authors of this article had to first define what an ethical relationship with a student was. Biaggio et al., 1997 stated, "We contend that an ethical relationship with a student is one in which three conditions are met: (a) educational standards are maintained, (b) educational experiences are provided for the student, and (c) exploitative 
practices are absent” (p.187). Therefore, in student-faculty working relationships, educational goals take priority and there must be no exploitation or coercion. The third and final guideline is to foster a climate for ethical relationships, which is seen as one of the best ways to prevent problematic ethical violations (Biaggio et al., 1997). In order to establish this climate, faculty members must remember that professional behavior is an ongoing process that requires attention, as well as consultation with colleagues.

\section{Student Perceptions}

The research conducted on the ethical management of dual relationships has grown throughout the years yet, research that investigates faculty and student perceptions have been sparse (Biaggio et al., 1997). In fact, after a thorough search of the literature it is apparent that there are no broad studies that identify doctoral students' perceptions of their faculty's ethical behavior, and none comparing counseling psychology and clinical psychology doctoral student perceptions.

Kolbert, Morgan and Brendel (2002) did conduct a qualitative analysis of faculty and student perceptions of dual relationships within counselor education. The population for this study was composed of 16 graduate students earning their master's degrees in school counseling and 6 of their full-time faculty. There were no doctoral students in this study, but those that did participate had completed approximately half of the required 45 credit hours of the counselor preparation program.

A positive result of this study suggests that both students and their faculty recognize that there is definitely a power differential between the two. When it came to deciding who had the primary obligation to maintain professional boundaries, the students in this study stated that it is the responsibility of the professor (Kolbert et al., 
2002). Many students reported "They trusted the professor to maintain objectivity, to avoid exploiting the student, and to preserve boundaries by clarifying the expectations” (p.204). Other concerns were that the students believed their professors would not fairly assess their performance, there could be unfair learning advantages, and students would gain unfair professional advancement if there were boundary violations. Despite the themes of unfairness and favoritism being recognized by the students, the faculty in this study failed to see that favoritism could cause difficulties for their students. There is a possibility that the faculty in this department, as well as in other academic departments, may not be aware of their students' perceptions and concerns of their ethical behavior. Another study that focused on ethics in academia, from a student's perspective, was conducted by Keith-Spiegel, Tabachnick, and Allen (1993). In their study, a sample of 482 undergraduates were asked to complete a survey regarding their professors' behaviors. The responses of these students were then compared to previous research by Tabachnick et al. 1991, where the same survey was used but the respondents in the study were professors. The investigators found an interesting pattern. The results revealed that rather than expecting their professors to behave ethically, students viewed them more like allies (Keith-Spiegel et al., 1993). The investigators found that when they compared the two studies, "Students were generally less condemnatory than teaching psychologists were towards themselves” (p.466). For example, 36.5\% of the students felt that it was not unethical, or unethical under rare circumstances for professors to date a student (Keith-Spiegel et al., 1993). In the Tabachnick and colleagues (1991) study, 79.8\% of the professors felt that it was unethical, or unethical under rare circumstances for professors to date a student. 
Considering the difference in results between graduate and undergraduate psychology students, it may be that education plays an important role on the impact of student opinion with regard to faculty professional ethical behavior. This may be particularly true considering the APA's ethical principles of psychologists and code of conduct. Most psychology or other human service undergraduate students would not have as in depth knowledge of the professional ethics code when compared to doctoral students. Therefore, it is important to consider the possibility that with an increase in students' level of education, there would also be a similar increase in knowing what appropriate professional ethical boundaries are.

A final study of student perceptions of dual relationships between faculty and students was conducted by Holmes, Rupert, Ross, and Shapera (1999). In this study a total of 160 general undergraduate students agreed to complete the student/faculty relationship survey. Of the 160 students, 136 filled out the survey in its entirety. The survey had 109 different one-sentence descriptions of various dual relationships that could occur between students and faculty members. The results were consistent with earlier research on dual relationships (Biaggio et al., 1997; Gottlieb, 1993; Kitchener, 1992; Pope, Schover, \& Levenson, 1980; Pope, 1991; Tabachnick et al., 1991). It was apparent to the students that engaging in a relationship with a faculty member, particularly one that is sexual in nature is inappropriate, unethical, and often fraught with danger. The results revealed that men tend to rate ambiguous situations more sexual than women. However, women were far more likely to perceive many of the situations on the survey as being sexually harassing or offensive. Even though male students in this study appear to perceive sexual innuendoes in ambiguous situations, it is the female students 
who tend to perceive those situations as unethical, inappropriate, and harassing (Holmes et al., 1999).

\section{Statement of the Problem}

The difficulty with many of the previous investigations that studied students' perceptions of their faculty's ethical behavior are as follows: 1) Many were narrow in focus, and did not convey a comprehensive picture of students' perceptions of their faculty's ethical behavior; 2) The populations used for these investigations were primarily composed of general undergraduate students who have not had a separate course in ethics. This is problematic because it makes it difficult to investigate the effect of ethics training on a student's ability to identify unethical behavior; and 3) The majority of these investigations have used general undergraduate students, not doctoral level psychology students enrolled in either APA accredited or non-accredited programs. This may make it difficult to investigate the effect of doctoral level education in professional psychology or accreditation on faculty's ethical behavior, as well as the student's ability to identify unethical behavior.

\section{Purpose of the Study}

This investigation addresses the previous issues that have been neglected, and furthers the knowledge of ethics education by investigating doctoral students’ perceptions of their faculty's ethical behavior. Improving the understanding of how students view their educators may help to guide faculty as role models. This is important considering the impact that unethical educators have on their students, and the subsequent harm that an unethical professional may have on their clients (Bartell and Rubin, 1990). Further, comparing the responses of the respondents, with regard to the following variables, could 
reveal important facts about the environment in which these respondents are being trained: 1) Being in a counseling psychology program vs. clinical psychology program 2) Having taken a doctoral level ethics course vs. not taken and 3) Being enrolled in an accredited doctoral program vs. non-accredited program.

\section{Research Questions}

\section{Research Question 1}

What are the perceptions of psychology doctoral students with regard to the report of possible unethical behavior by their program faculty? The means, standard deviations, frequencies, and percentages of all questions will be reported. No hypotheses were made due to the limited literature in this area but it is expected that doctoral students, with regard to the 67 behaviors listed in the survey, would find that most of the behaviors are not ethical or are ethical only under rare circumstances.

\section{Research Question 2}

What are the perceptions of psychology doctoral students with regard to whether or not the specific behaviors listed in the survey are unethical? The means, standard deviations, frequencies, and percentages of all questions will be reported. No hypotheses were made due to the lack of literature in this area but it is expected that doctoral students, with regard to the 67 behaviors listed in the survey, would find that most of the behaviors are not ethical or are ethical only under rare circumstances.

\section{Research Question 3}

What are the differences in perceptions of counseling psychology doctoral students, versus the perceptions of clinical psychology doctoral students, with regard to the report of possible unethical behavior by their program faculty? It is hypothesized that 
counseling psychology students will have a higher report rate on questions relating to cultural diversity, which are questions 13 and 17.

\section{Research Question 4}

What are the differences in perceptions of counseling doctoral students, versus the perceptions of clinical psychology doctoral students', with regard to whether or not the behaviors listed on the survey are unethical? It is hypothesized that counseling psychology students will rate behaviors on the survey less ethical when compared to clinical students on questions relating to cultural diversity, which are questions 13 and 17.

\section{Research Question 5}

Are there differences in the perceptions of psychology doctoral students enrolled in APA accredited doctoral programs, versus those enrolled in non-accredited doctoral programs, with regard to the report of possible unethical behavior by their program faculty? It is hypothesized that psychology doctoral students, who are enrolled in APA accredited doctoral programs, will have a higher report rate across all behaviors when compared to students enrolled in non-accredited doctoral programs.

\section{Research Question 6}

Are there differences in the perceptions of psychology doctoral students who are enrolled in APA accredited doctoral programs, versus those enrolled in non-accredited doctoral programs, with regard to whether or not the behaviors listed on the survey are unethical? It is hypothesized that psychology doctoral students, who are enrolled in APA accredited doctoral programs, will rate behaviors on the survey more unethical when compared to students enrolled in non-accredited doctoral programs. 


\section{Research Question 7}

Are there differences in the perceptions of psychology doctoral students, who have had a doctoral level ethics course, with regard to the report of possible unethical behavior by their program faculty? It is hypothesized that psychology doctoral students who have had a graduate level ethics course will have a higher report rate across all behaviors when compared to students who have not had a graduate level ethics course. Research Question 8

Are there differences in the perceptions of psychology doctoral students, who have had a doctoral level ethics course, with regard to whether or not the behaviors listed on the survey are unethical? It is hypothesized that psychology doctoral students who have had a graduate level ethics course will rate behaviors on the survey less ethical when compared to students who have not had a graduate level ethics course

\section{Definitions}

Counseling Psychology Doctoral Students: Counseling psychology doctoral students are enrolled in programs designed to train them to help people accommodate to change or make changes in their lifestyle. For example they provide vocational and career assessment and guidance or help someone come to terms with the death of a loved one. They help students adjust to college and people to stop smoking or overeating. They also consult with physicians on physical problems that have underlying psychological causes (APA, 2003a).

Clinical Psychology Doctoral Students: Clinical psychology doctoral students are enrolled in programs designed to train them to assess and treat mental, emotional, and behavioral disorders. These range from short-term crises, such as difficulties resulting 
from adolescent rebellion, to more severe, chronic conditions such as schizophrenia (APA, 2003a).

APA Accreditation: Accreditation is a voluntary, non-governmental process of self-study and external reviews intended to evaluate, enhance, and publicly recognize quality in institutions and in programs of higher education. Psychology's accrediting body, the Committee on Accreditation (CoA) publishes guidelines and procedures by which its accreditation process is carried out. The CoA also publishes a list of accredited programs each year in the December edition of the American Psychologist. Accreditation is intended to protect the interests of students, benefit the public, and improve the quality of teaching, learning, research, and professional practice (APA, 2003b). Through its domains and standards, the accrediting body is expected to encourage institutional freedom, ongoing improvement of educational institutions and training programs, sound educational experimentation, and constructive innovation (APA, 2003b).

Occurs in program (“Occurrence behaviors"): This refers to the portion of the student's perceptions survey in which the respondent ranks if the behavior on the survey has occurred within their program faculty by circling one of the following 1) Never 2) Rarely 3) Sometimes 4) Fairly often 5) Very often or N/A) Not applicable.

Is it Ethical (“Ethicality of behaviors"): This refers to the portion of the student's perceptions survey in which the respondent ranks the behavior on the survey with regard to it being ethical by circling one of the following 1) No; 2) Under rare circumstances; 3) Don’t know/not sure; 4) Under most circumstances; or 5) Yes. 


\section{CHAPTER II}

\section{METHOD}

\section{Participants}

Fifty clinical doctoral programs and 50 counseling psychology doctoral programs were chosen from a random sample of APA accredited schools listed in the American Psychological Association’s Graduate Study in Psychology (2004). Six surveys were sent to each doctoral program, totaling 600 surveys. In addition, all non-accredited clinical (13 programs) and counseling psychology doctoral programs (5) were chosen from the same source. Six surveys were sent to each non-accredited doctoral program, totaling 108 surveys. The total amount of surveys sent to APA accredited and nonaccredited programs were 708.

Procedure

This researcher had no direct contact with the participants in this study. Involvement in this study was solicited by writing to the training directors of each of the randomly selected counseling and clinical psychology programs. A separate letter was addressed to the students. A copy of these letters can be found in Appendix A on pages 119-120. The letter to the training directors requested that they distribute packets containing a demographic questionnaire, the students' perceptions survey, and a postage paid return envelope to students in their last semester prior to their internship. Copies of the instruments were attached to the letter sent to the training directors for their review. The letters noted that participation must be voluntary and students could decide to discontinue the survey at any time to correspond with the human subject regulations at West Virginia University. The letters also indicate that results from the survey will be 
kept as confidential as legally possible and that there is no way to identify a student or the program. Follow-up letters were sent to all of the training directors three weeks after the initial mailing of the survey packets. A copy of the follow-up letter can be found in Appendix A on page 121. Data collection ceased four months after the follow-up letters were sent. Data was collected by this researcher and entered into an SPSS program. Survey Instrument

Fifty-two survey questionnaire items were adapted from the survey used in a study of students' view of their undergraduate professors' ethical behavior (KeithSpiegel, Tabachnick, \& Allen, 1993). An additional 15 items were added to reflect the current 2002 Ethical Principles of Psychologists and Code of Conduct. The final survey instrument consisted of 67 questions. Students were asked to rate 67 faculty behaviors in terms of two categories. First, students rated if a particular behavior has occurred in their program. Students had the option of rating each behavior on the following 6-point scale: Occurs in program? 1) Never, 2) Rarely, 3) Sometimes, 4) Fairly Often, 5) Very Often, 6) N/A. The "Never" category and the "N/A" category were collapsed into the "Never" category for analyses. Second, students were asked to rate the 64 faculty behaviors in terms of whether or not the behavior was ethical. Students had the option of rating each behavior on the following 5-point scale: Is it ethical? 1) No 2) Under rare circumstances, 3) Don’t know/not sure, 4) Under most circumstances, 5) Yes. At the end of this instrument is an open-ended question asking the respondent to comment on any additional experiences they had related to the content of the survey. This instrument can be found in Appendix A on pages 122-125. 
Validity for the student perception survey (67 survey questions) has not been evaluated by a quantifiable method that resulted in a validity coefficient. However, several methods were used to establish the validity of this instrument.

Of particular concern was content validity. First, the review of this instrument by experts helped to establish that the questions used were accurate indicators of behavior that could be observed by the students taking the survey. The experts used to critically evaluate this instrument were professionals established in the field of psychology, both clinical and academic. Two of the experts have taught doctoral level courses in psychology ethics for over 20 years. One is a Diplomate in the American Board of Forensic Psychology. The instrument was also distributed to doctoral level clinical and counseling psychology students for additional review, comments and feedback.

This evaluation resulted in the removal and addition of questions in order to evaluate certain behaviors. The experts used to evaluate this instrument also grouped the 67 survey items into categories for the purpose of creating composite scores used for additional analysis. They were grouped according to general categories of non-sexual multiple relationships (21 questions), sexual multiple relationships (7 questions), cultural diversity (2 questions), research (3 questions), competence/impairment (21 questions), and unprofessional behavior (13 questions).

These categories are composed of the following survey questions: Non-sexual multiple relationships include questions $3,4,5,8,9,10,14,18,21,24,25,26,32,36$, 38, 39, 47, 52, 59, 51, and 60. Multiple relationships (sexual) include questions 2, 7, 15, 22, 31, 34, and 57. Unprofessional behavior includes questions 11, 23, 27, 28, 45, 53, 49, 55, 61, 62, 64, 65, and 67. Competence and impairment include questions 1, 6, 12, 16, 20, 
$29,30,33,35,37,40,41,42,46,48,50,53,54,56$, and 58 . Cultural diversity includes questions 13 and 17. Research includes questions 19, 63, and 66.

The majority of the questions on this survey have been used previously by other authors, which have also helped to establish the validity of this instrument (Pope, Tabachnick, \& Keith-Spiegel, 1987; Tabachnick, Keith-Spiegel, \& Pope, 1991; KeithSpiegel, Tabachnick \& Allen, 1993; Tubbs \& Pomerantz, 2001). These authors have focused many of their books and articles in the area of psychology ethics. Therefore, five different authors have reviewed most items in the past in addition to the current expert reviewers. This increased the likelihood that the questions measure what they are intended to measure.

These questions have also been used in other studies which found relationships between unethical behavior and dimensions such as the sex and age of the psychologist (Pope et al., 1987; Tabachnick et al., 1991). For example, in 1987 Pope and colleagues found that males were more likely than females to "Treat homosexuality per se as pathological" and "Directly soliciting a person to be a client" (p.998). Tabachnick and colleagues (1991) also revealed that with regard to age, psychology professors who were 50 years of age or younger are more likely to use profanity during their lectures than those older than 50 .

In order to determine the internal consistency of responses of the survey items for the 67 occurrence questions, as well as the 67 ethicality questions, Cronbach's coefficient alpha was applied. Reliability was also assessed by comparing two pairs of similar questions which were distributed throughout the survey. Items that are similar and elicit similar responses were checked for internal consistency. If the respondent was one item 
off on the likert scale on two of the three pairs of questions, that respondent's survey was omitted from the data set. Fourteen respondents were omitted from this data set for this purpose. The three sets of questions are listed below:

16. Teaching while under the influence of alcohol.

20. Teaching while under the influence of alcohol, cocaine, or some other illegal drug.

29. Insulting or ridiculing a student in the student's presence.

48. Demeaning a student publicly in class.

36. Setting up a course so that students are encouraged to share aspects of their very personal life in class.

39. Requiring students to disclose highly personal information in a group discussion class (e.g., the student who remains silent or "closed up" is graded down for that.)

\section{Demographics}

Students were also asked to provide demographic information as listed below.

- The respondent's field of study

- Whether or not the respondent's program is APA approved

- If the respondent's program requires a separate course in ethics and if they have taken it

- Gender

- If the respondent believes they have adequate knowledge of psychology ethics

- If the respondent has taken a course in ethics during their undergraduate or graduate degree

- Race/ethnicity

- The respondent's standing in terms of years spent in their program

- Age

- What degree will the respondent receive upon completion of their program's requirements

- Does the administration in the respondent's department tolerate unethical behavior

- Does the administration of the college in which the respondent's department is housed tolerate unethical behavior

- Estimates of the respondent's program's provision of opportunities to be educated about ethics

- Estimates of the respondent's opportunities to be educated about ethics prior to entering their doctoral program

- Estimates of the number of faculty involved in their doctoral program

- Estimates of how many of their male and female full/part-time professors have violated any psychology ethics

- What field is the respondent's masters and undergraduate degree in 
- Estimates of the number of students in the respondent's doctoral program

- Estimates of the respondent's years of clinical experience

A copy of the demographic questionnaire can be found in Appendix A on pages 126-127. Research Design and Analysis

A between-subjects approach was used in the research design. This indicates that the variation in responses comes from differences between subjects at a single point in time.

The analyses conducted for this study began with descriptive findings. Descriptive statistics include frequencies, means, and percentage rates that characterize demographic variables such as, but not limited to, the respondent's field of study, APA accreditation, gender, age, and ethnicity. Second, Cronbach’s coefficient alpha was applied to determine the internal consistency of responses to the survey items for the 67 occurrence questions and 67 ethicality questions (Peterson, 1993). A second reliability check included a comparison of three pairs of questions that were distributed throughout the survey, which by being similarly worded, were intended to produce similar responses.

Third, for research questions 1 and 2 means, standard deviations, frequencies, and percentages are reported for all the survey questions across counseling psychology and clinical psychology doctoral students. Reporting all of the responses often reveals potentially useful patterns regardless of whether or not there is significance.

Fourth, for research questions 3 through 8 a multivariate analysis of variance (MANOVA) was conducted and then followed-up with individual analyses of variance (ANOVAs). Since the MANOVA requires the same number of respondents in each cell, the degrees of freedom are reduced if respondents choose not to answer a question. The 
level of significance for the MANOVAs and ANOVAs (which have a larger N) was set at .05. A corresponding table with the means and standard deviations will be presented for each statistically significant ANOVA.

Steven's (1992, p.242), writing about the normality assumption, states that “Skewness has only a slight effect on level of significance, and sums of 50 or more observations approximate normality, and for moderately non-normal distributions, the approximation is good with as few as 10 observations.” Regarding homogeneity of variance, as long as the group sizes are approximately equal, $F$ is robust. Further, for every univariate ANOVA conducted a Levene homogeneity of variance test was conducted. When the Levene test was statistically significant, the F-value, assuming unequal variances, is used (Pan, 1999). In terms of homogeneity of covariance matrices assumption, Stevens (1992, p.251) states, “It is very unlikely that the equal covariance matrices assumptions would ever literally be satisfied in practice.”

Additional analyses were also conducted using composite scores for the following categories: Non-sexual multiple relationships, sexual multiple relationships, competence, cultural diversity, research, and unprofessional behavior. The additional analyses are listed as Questions 9, 10, and 11 in the results section. The same analysis using MANOVAs, followed by ANOVAs, are used with these composite scores on the same dependent variables used for Research Questions 3 through 8 (Type of program, accreditation, and ethics course). All ANOVAs in which there is a significant difference are presented in a table. A corresponding table with the means and standard deviations is provided for each significant difference. 
Finally, there were a number of students who responded to the open-ended question at the end of the survey. This question allowed for any additional experiences the student may have had related to the content of this survey. It also allowed the respondents to comment on any part of the survey that they felt needed clarification. This section was not intended as a qualitative study. However, an informal summary of the respondents' comments were included in the discussion section by grouping the comments into categories. The categories include general comments, personal experiences, clarifications, and suggestions. 


\section{CHAPTER III}

Results

The following demographic information about the doctoral students who participated in this survey is in Table 1 on page 43. The total number of doctoral students who participated in this study was 125 . By comparing the response rate for this investigation (17.7\%) to the response rates of similar research reviewed in Chapter 1 , the latter averaged a return rate of $30-40 \%$.

Sixty-seven (53.6\%) of this sample were counseling psychology students and 58 (46.4\%) were clinical psychology students. Of the 125 students, 25 (20\%) were male and 100 (80\%) were female. The majority of the sample used in this study ( $\mathrm{n}=94,75.2 \%)$ were Caucasian American. Hispanic/Latino-a Americans and African Americans followed with ( $n=10,8.0 \%)$ each, then Other ( $n=4,3.2 \%)$, Asian Americans $3(2.4 \%)$ and Pacific Islanders 1 (0.8\%). Most students were 26-33 years of age ( $n=82,65.6 \%)$, while 20 (16.0\%) were 18-25, 20 (16.0\%) were 34-41, and 3 (2.4\%) were 42 years of age or older.

The following data about the doctoral students’ educational experiences is in Table 2 on pages 44, 45, and 46. Most students ( $n=106,84.8 \%)$ were from APA approved programs, while 19 (15.2\%) were not in such programs (p.44). In most programs ( $\mathrm{n}=116,92.8 \%)$ an ethics course is required and in $9(7.2 \%)$ programs it is not required (p.44). The majority of students $(n=111,88.8 \%)$ had taken an ethics course and 14 (11.2\%) had not (p.44). Additionally, 121 (96.8\%) of the students reported adequate knowledge of psychology ethics and 4 (3.2\%) did not (p.44). Most students had undergraduate degrees in psychology ( $n=101,80.8 \%)$, and the other $24(19.2 \%)$ had 
degrees in a variety of other fields (p.44). Many of the doctoral students had a masters degrees in either psychology ( $n=62,49.6 \%)$, counseling $(n=24,19.2 \%)$ or counseling psychology ( $n=22,17.6 \%)(p .45)$. With regard to whether or not the doctoral students in this study have taken an ethics course as an undergraduate, 19 (15.2\%) had not taken ethics courses and 97 (77.6\%) had taken courses (p.45). There were 111 (88.8\%) doctoral students who had taken an ethics course at a graduate level and $12(9.6 \%)$ that had not (p.44). Of the 125 students that took part in this study, most ( $\mathrm{n}=68,54.4 \%)$ were either in the third or fourth year of their doctoral program (p.45). Students in the fifth year of their doctoral program followed with (n=27, 21.6\%) (p.45). Most students 107 (85.6\%) were in Ph.D. programs, 14 (11.2\%) in Psy.D. programs and 4 (3.2\%) were in Ed.D. programs (p.45).

There were 89 (71.2\%) students who did not believe the administration of their department tolerated unethical behavior, 27 (21.6\%) were not sure and 9 (7.2\%) thought the administration did tolerate unethical behavior (p.45). The majority of students, ( $n=75,60.0 \%$ ), did not believe that the administration of their college tolerated unethical behavior, ( $n=45,36.0 \%)$ were not sure, and ( $n=5,4.0 \%)$ thought the college administration did tolerate unethical behavior (p.46).

When asked about opportunities to be educated about ethics (1=extensive to $5=$ none), most students ( $n=78,62.4 \%)$ believed that they had extensive opportunities, $(n=42,33.6 \%)$ had some, $(n=4,3.2 \%)$ had little, and $(n=1,0.8 \%)$ had none (p.46). With regard to educational experiences in ethics as a doctoral student, most students ( $\mathrm{n}=27$, 21.6\%) stated that ethics material was integrated into their courses (p.46). This was followed by 24 (19.2\%) students who reported that they had an ethics course, ethics 
material was integrated into their courses, and that colloquia presentations were also focused on ethics (p.46). When asked about prior opportunities to be educated about ethics prior to entering their doctoral program, the majority of students ( $n=19,15.2 \%)$ also reported that ethics material had been integrated into their courses (p.46).

The following means and standard deviations of the doctoral students' faculty by full-time, part-time and gender are in Table 3 on page 47. More specifically, students estimated if they perceived their full-time/part-time faculty to have violated any psychology ethics. The mean number of full-time male and full-time female faculty who had violated psychology ethics is 1.30 and 0.60 , respectively. The mean number of parttime male and part-time female faculty who had violated psychology ethics is 0.24 and 0.24 respectively. The average number of students in each doctoral program (39.76), as well the average of their clinical experience in years (5.12) is also listed in Table 3.

\section{Research Questions}

\section{Research Question 1}

The first research questions asks, what are the perceptions of psychology doctoral students with regard to the report of possible unethical behavior by their program faculty. Table 4a pages 48-52 presents the frequency and percent of the survey questions by “occurs in program.” Table 4c on pages 58-65 presents the mean and standard deviation of each survey question by “occurs in program” and "is it ethical.” The reliability of the 67 occurrence behaviors yielded a Coefficient Alpha .91(internal consistency).

\section{Research Question 2}

The second research question asks, what are the perceptions of psychology doctoral students with regard to whether or not the specific behaviors listed in the survey 
are unethical. Table $4 \mathrm{~b}$ on page 53-57 presents the frequency and percent of all the survey questions by "is it ethical.” Table 4c on page 58 presents the mean and standard deviation of each survey question by "occurs in program" and "is it ethical." The reliability of the 67 ethicality behaviors yielded a Coefficient Alpha .91(internal consistency).

\section{Research Question 3}

The third research question asks, what are the differences in perceptions of counseling psychology doctoral students, versus the perceptions of clinical psychology doctoral students, with regard to the report of possible unethical behavior by their program faculty. The independent variable is Type of Doctoral Program (Counseling Psychology or Clinical Psychology). The dependent variables (Occurs in Program Questions) indicate how many students reported that the behavior has occurred in their program (Never, Rarely, Sometimes, Fairly often and Very often). A MANOVA (Wilks' Lambda) was conducted on the 67 "occurrence" behavior questions by program (Counseling Psychology vs. Clinical Psychology). The results were statistically significant, $F(66,40)=2.00, p<.01($ Eta $=.77$, power $=.99)$. Univariate ANOVAs in Table 5a on page 66 shows that there were significant differences in 7 of the 67 behavior questions by program. Table $5 \mathrm{~b}$ on page 67 presents the means and standard deviations by program. All of the behaviors occur more frequently in the clinical programs except for hugging, which occurs more frequently in counseling psychology programs,.

\section{Research Question 4}

The fourth research question asks, what are the differences in perceptions of counseling doctoral students, versus the perceptions of clinical psychology doctoral 
students, with regard to whether or not the behaviors listed on the survey are unethical. The independent variable is Type of Doctoral Program (Counseling Psychology or Clinical Psychology). The dependent variables (Is it Ethical Questions) indicate whether or not the student believes the behavior is ethical (No, Under rare circumstance, Don't know/not sure, Under most circumstances, and Yes). A MANOVA (Wilks’ Lambda) was conducted on the 67 "ethicality" ethics questions by program. The results were statistically significant, $F(66,31)=1.77, p<.05($ Eta=.79, power=.96). Univariate ANOVAs in Table 6a on page 68 show that 14 questions differed by program (Counseling Psychology vs. Clinical Psychology). Table 6b on pages 69-70 presents the means and standard deviations by program. All of the behaviors were rated as more ethical by students in the clinical program as compared to the counseling program. In other words, counseling psychology students perceive the behaviors listed in Table 6b to be less ethical than clinical students.

Research Question 5

The fifth research question asks, are there differences in the perceptions of psychology doctoral students who are enrolled in APA accredited doctoral programs, versus those enrolled in non-accredited doctoral programs, with regard to the report of possible unethical behavior by their program faculty. The independent variable is APA Accreditation (APA accredited vs. Non-accredited). The dependent variables (Occurs in Program Questions) indicate how many students reported that the behavior has occurred in their program (Never, Rarely, Sometimes, Fairly often and Very often). A MANOVA (Wilks’ Lambda) was conducted on the 67 “occurrence” behaviors by accreditation (APA accredited vs. Non-accredited). The results were not statistically significant, $F(66,40)=$ 
1.29, ns (Eta=.68, power=.91). Due to the results not being significant, results of the following ANOVAs must be interpreted with caution because the experiment-wise error increases. Univariate ANOVAs in Table 7a on page 71 show that two questions differed by accreditation. Table $7 \mathrm{~b}$ on page 72 presents the means and standard deviations by accreditation, where consistently letting class out early was rated as occurring more in non-accredited programs and assigning unpaid duties was rated as occurring more in accredited programs.

\section{Research Question 6}

The sixth research questions asks, are there differences in the perceptions of psychology doctoral students who are enrolled in APA accredited doctoral programs, versus those enrolled in non-accredited doctoral programs, with regard to whether or not the behaviors listed on the survey are unethical. The independent variable is APA Accreditation (APA accredited vs. Non-accredited). The dependent variables (Is it Ethical Questions) indicate whether or not the student believes the behavior is ethical (No, Under rare circumstance, Don’t know/not sure, Under most circumstances, and Yes). A MANOVA (Wilks' Lambda) was conducted on the 67 "ethicality” behaviors by accreditation. The MANOVA did not reveal statistically significant results, $F(66,33)=$ 0.75, ns (Eta=.62, power=.55). Due to the results not being significant, results of the following ANOVAs must be interpreted with caution because the experiment-wise error increases. Univariate ANOVAs (Table 8a on page 73) showed that six questions differed by accreditation. Table $8 \mathrm{~b}$ on page 74 presents the means and standard deviations by accreditation. While accepting a student's expensive gift, teaching classes when too distressed to be effective, dating a student, having students participate in research and 
announcing exam grades were rated more ethical by students in approved programs, plagiarizing material was rated as more ethical by those in non-accredited programs.

\section{Research Question 7}

The seventh research question asks, are there differences in the perceptions of psychology doctoral students, who have had a doctoral level ethics course, with regard to the report of possible unethical behavior by their program faculty. The independent variable is whether or not the student had a doctoral level ethics course. The dependent variables (Occurs in Program Questions) indicate how many students reported that the behavior has occurred in their program (Never, Rarely, Sometimes, Fairly often and Very often). A MANOVA (Wilks' Lambda) was conducted on the 67 “occurrence” behaviors by doctoral level ethics course (Taken vs. Not taken). The results were not statistically significant, $F(66,40)=1.56$, ns $($ Eta=.72, power=.96). Due to the results not being significant, results of the following ANOVAs must be interpreted with caution because the experiment-wise error increases. Univariate ANOVAs in Table 9a on page 75 show that five questions differed by whether the students had taken an ethics course. Table 9b on page 76 presents the means and standard deviations by course taken, where three of the behaviors were rated by students as occurring more when no ethics course was taken, and two behaviors were reported as occurring more frequently when students took such a doctoral-level ethics course.

\section{Research Question 8}

The eighth research question asks, are there differences in the perceptions of psychology doctoral students, who have had a doctoral level ethics course, with regard to whether or not the behaviors listed on the survey are unethical. The independent variable 
is whether or not the student has had a doctoral level ethics course. The dependent variables (Is it Ethical Questions) indicate whether or not the student believes the behavior is ethical (No, Under rare circumstance, Don't know/not sure, Under most circumstances, and Yes). A MANOVA (Wilks' Lambda) was conducted on the 67 “occurrence” behaviors by doctoral level ethics course (Taken vs. Not taken). The results were statistically significant, $F(66,31)=2.32, \mathrm{p}<.05(\mathrm{Eta}=.83$, power=.99). Univariate ANOVAs in Table 10a on page 77 show that eight questions differed by whether the students had taken an ethics course. Table 10b on page 78 presents the means and standard deviations by course taken, where all of behaviors were rated as less ethical by students who had taken a doctoral-level ethics course compared to those who had not, except for the behavior of promptly returning assignments, where those who took courses rated it as more ethical.

\section{Additional Analyses}

The additional analyses were conducted to determine if there were differences on the occurrence and ethicality of ethical behavior composite scores. The survey questions were grouped according to general categories by two experts. These experts are professionals in the field of psychology and have taught doctoral level courses in psychology ethics for over 20 years. The survey questions were grouped into the following categories: Non-sexual multiple relationships, sexual multiple relationships, competence, cultural diversity, research and unprofessional behavior.

\section{Question 9}

The ninth question asks, are there differences on occurrence and ethicality of ethical behavior composite scores (non-sexual multiple relationships, sexual multiple 
relationships, competence, cultural diversity, research, unprofessional behavior) by program (Counseling vs. Clinical). A MANOVA (Wilks' Lambda) was conducted on the 6 composite scores by program (Counseling vs. Clinical). The independent variable is Type of Doctoral Program (Counseling Psychology and Clinical Psychology). The dependent variables, which focus on the "Occurrence of Behaviors," are the 6 composite scores. The results were statistically significant, $F(6,100)=2.44, p<.05$ (Eta=.13, power=.80). However, no results from the univariate ANOVAs were statistically significant.

A MANOVA (Wilks' Lambda) was conducted on the 6 composite scores by program (Counseling vs. Clinical). The independent variable is Type of Doctoral Program (Counseling Psychology and Clinical Psychology). The dependent variables are the 6 composite scores, which focus on the "Ethicality of Behaviors." The results were not statistically significant, $F(6,92)=1.73$, ns $(E t a=.10$, power=.62). Due to the results not being significant, results of the following ANOVAs must be interpreted with caution because the experiment-wise error increases. Two univariate ANOVAs were found to be statistically significant (Table 11a on page 79). Table 11b on page 80 shows that clinical students rated the composite scores on competence/impairment and unprofessional behavior more ethical than counseling students.

\section{Question 10}

The tenth question asks, are there are differences on occurrence and ethicality of behavior composite scores (non-sexual multiple relationships, sexual multiple relationships, competence, cultural diversity, research, unprofessional behavior) by accreditation status (Accredited vs. Non-accredited). A MANOVA (Wilks' Lambda) was 
conducted on the 6 composite scores by accreditation status (Accredited vs. NonAccredited). The independent variable is accreditation status (Accredited vs. NonAccredited). The dependent variables, which focus on the "Occurrence of Behaviors," are the 6 composite scores. The results were not statistically significant, $F(6,100)=$ 0.60 , ns (Eta $=.04$, power $=.23)$, nor were any of the univariate results statistically significant.

A MANOVA (Wilks' Lambda) was also conducted on the 6 composite scores by accreditation status (Accredited vs. Non-Accredited). The independent variable is accreditation status (Accredited vs. Non-Accredited). The dependent variables, which focus on the "Ethicality of Behaviors", are the 6 composite scores. The results were not statistically significant, $F(6,92)=0.78, n s($ Eta= .5 , power=.30). Due to the MANOVA not being significant, results of the following ANOVA must be interpreted with caution because the experiment-wise error increases. One univariate result was found to be statistically significant (Table 12a on page 81 ). Table 12b on page 82 shows that students in APA accredited programs rate the behaviors in the category of non-sexual multiple relationships more ethical than those in non-accredited programs.

\section{Question 11}

The eleventh question asks, are there are differences on occurrence and ethicality of behavior composite scores (non-sexual multiple relationships, sexual multiple relationships, competence, cultural diversity, research, unprofessional behavior) by ethics course (Completed vs. Not completed). A MANOVA (Wilks' Lambda) was conducted on the 6 composite scores by ethics course (Completed vs. Not completed). The independent variable is ethics course (Completed vs. Not completed). The dependent 
variables, which focus on the "Occurrence of Behaviors," are the 6 composite scores. The results were not statistically significant, $F(6,100)=1.27$, ns $($ Eta= $=.07$, power=.48), nor were any of the univariate ANOVAs statistically significant.

A MANOVA (Wilks' Lambda) was conducted on the 6 composite scores by ethics course (Completed vs. Not completed). The independent variable is ethics course (Completed vs. Not completed). The dependent variables, which focus on the "Ethicality of Behaviors", are the 6 composite scores. The results were not statistically significant, $F$ $(6,92)=3.97, n s(\mathrm{Eta}=.21$, power $=.96)$. Due to the MANOVA not being significant, results of the following ANOVAs must be interpreted with caution because the experiment-wise error increases. Three univariate ANOVAs were found to be statistically significant (Table 13a on page 83). Table 13b on page 84 shows that those who had not taken a course rated the behaviors in the categories of non-sexual multiple relationships, sexual multiple relationships, competence/impairment more ethical than those who had taken courses. 
Table 1

Frequency and Percent of Doctoral Students’ Demographic Information

Variable

Frequency Percent

Doctoral Program

Counseling Psychology

Clinical Psychology

67

58

53.6

46.4

Gender

Male

25

20.0

Female

100

80.0

Race

African American

10

8.0

Native American

2

Asian American

Caucasian American

3

Hispanic/Latino-a American

94

10

$1 \quad 0.8$

Pacific Islander

$4 \quad 3.2$

Other

1

0.8

Age

18-25

20

16.0

26-33

82

65.6

34-41

20

16.0

42-49

1

50 or above

$2 \quad 1.6$ 
Table 2

Frequency and Percent of Doctoral Students’ Educational Experiences

Variable

Frequency Percent

APA Accredited Program

Yes

No

Ethics Course Required

Yes

No

Ethics Course Taken

Yes

No

$\underline{\text { Knowledge of Ethics }}$

Yes

No

$\underline{\text { Undergraduate Degrees }}$

Psychology

Sociology

Liberal Arts

Women's Studies

English

Communications

Music

Biology

Elementary Education

Human Development

Marriage \& Family Studies

Dietetics

Art

Journalism

Missing
116

9

92.8

7.2

111

121

4

96.8

106

84.8

15.2

14

88.8

11.2

3.2

101

80.8

2

1.6

$2 \quad 1.6$

10.8

$1 \quad 0.8$

$2 \quad 1.6$

$3 \quad 2.4$

$4 \quad 3.2$

$1 \quad 0.8$

$1 \quad 0.8$

$1 \quad 0.8$

$1 \quad 0.8$

$2 \quad 1.6$

$2 \quad 1.6$
10.8 
Table 2 continued

Variable

Frequency Percent

Masters Degrees

Psychology

Counselor Education

Counseling

Education Psychology

Anthropology

Counseling Psychology

Art Therapy

Missing

$\begin{array}{ll}62 & 49.6 \\ 2 & 1.6 \\ 24 & 19.2 \\ 3 & 2.4 \\ 1 & 0.8 \\ 22 & 17.6 \\ 1 & 0.8 \\ 9 & 7.2\end{array}$

Ethics Course as an Undergraduate

Yes

19

15.2

No

97

77.6

Missing

9

7.2

$\underline{\text { Ethics Course as a Graduate }}$

Yes

111

88.8

No

12

9.6

Missing

2

1.6

$\underline{\text { Students' Year on their Doctoral Program }}$

1

2

3

4

5

6

7

Type of Degree Being Sought

Ph.D.

Ed.D.

Psy.D.

$\underline{\text { Administration Tolerate Unethical Behavior }}$

Yes

No

Not sure
9

3

17

31

37

27

4

6

2.4

13.6

24.8

29.6

21.6

3.2

4.8

107

85.6

4

3.2

14

11.2

14.2

7.2

$89 \quad 71.2$

$27 \quad 21.6$ 
Table 2 continued

Variable

Frequency

Percent

$\underline{\text { Administration of College Tolerating Unethical Behavior }}$

Yes

5

4.0

No

75

60.0

Not sure

45

36.0

Opportunities to be Educated about Ethics

Extensive 19

15.2

Somewhat extensive

47.2

Some

Little

4

3.2

None

1

0.8

Educational Experiences in Ethics as a Doctoral Student

Ethics course

Clinical supervision

Ethics material integrated into courses

Ethics course and clinical supervision

Ethics course, integrated into courses, and colloquia

Ethics course and colloquia

Clinical supervision and colloquia

3.2

Colloquia

3.2

Colloquia and ethics material integrated into class

4

6.4

Missing

Educational Experiences in Ethics Prior to Entering

\section{a Doctoral Program}

Independent Research

Ethics Material integrated into undergraduate courses

Independent research and ethics integrated into courses

Ethics course and independent research

Undergraduate ethics course

Graduate ethics course

Undergraduate and graduate ethics course

Ethics material integrated into class

None

Workshops

Ethics class and supervision

Colloquia

Work Experiences

Missing
$8 \quad 6.4$

$2 \quad 1.6$

$2 \quad 1.6$

32.4

$4 \quad 3.2$

$11 \quad 8.8$

$4 \quad 3.2$

$19 \quad 15.2$

$\begin{array}{ll}9 & 7.2\end{array}$

$3 \quad 2.4$

$1 \quad 0.8$

$\begin{array}{ll}1 & 3.2\end{array}$

10.8

$54 \quad 43.2$


Table 3

Estimated Number of Faculty by Full-Time, Part-Time, Gender Violations of Ethics, Number of Students in Program, and Years of Clinical Experience

\begin{tabular}{|c|c|c|}
\hline Demographics & Mean & Standard Deviation \\
\hline Estimated number of full-time faculty & 9.97 & 7.03 \\
\hline Estimated number of part-time faculty & 4.71 & 7.09 \\
\hline $\begin{array}{l}\text { Estimated number of full-time male faculty } \\
\text { who have violated psychology ethics }\end{array}$ & 1.30 & 2.39 \\
\hline $\begin{array}{l}\text { Estimated number of full-time female faculty } \\
\text { who have violated psychology ethics }\end{array}$ & 0.60 & 1.30 \\
\hline $\begin{array}{l}\text { Estimated number of part-time male faculty } \\
\text { who have violated psychology ethics }\end{array}$ & 0.24 & 0.66 \\
\hline $\begin{array}{l}\text { Estimated number of part-time female faculty } \\
\text { who have violated psychology ethics }\end{array}$ & 0.24 & 0.70 \\
\hline Estimated number of students in program & 39.76 & 31.40 \\
\hline Estimated number of years of clinical experience & 5.12 & 3.59 \\
\hline
\end{tabular}


Table 4a

Frequency and Percent of "Occurs in program" Ethics Questions by Program

\begin{tabular}{|c|c|c|c|c|c|c|c|c|c|c|}
\hline \multirow[b]{2}{*}{ Qu. } & \multicolumn{5}{|c|}{ Counseling } & \multicolumn{5}{|c|}{ Clinical } \\
\hline & Never & Rarely & $\begin{array}{l}\text { Some- } \\
\text { times }\end{array}$ & $\begin{array}{l}\text { Fairly } \\
\text { Often }\end{array}$ & Always & Never & Rarely & $\begin{array}{c}\text { Some- } \\
\text { times }\end{array}$ & $\begin{array}{l}\text { Fairly } \\
\text { Often }\end{array}$ & Always \\
\hline 1 & $\begin{array}{c}41 \\
61.2 \%\end{array}$ & $\begin{array}{c}19 \\
28.4 \%\end{array}$ & $\begin{array}{c}6 \\
9.0 \%\end{array}$ & $\begin{array}{c}1 \\
1.5 \%\end{array}$ & $\begin{array}{c}0 \\
0.0 \%\end{array}$ & $\begin{array}{c}36 \\
62.1 \%\end{array}$ & $\begin{array}{c}17 \\
29.3 \%\end{array}$ & $\begin{array}{c}5 \\
8.6 \%\end{array}$ & $\begin{array}{c}0 \\
0.0 \%\end{array}$ & $\begin{array}{c}0 \\
0.0 \%\end{array}$ \\
\hline 2 & $\begin{array}{c}41 \\
61.2 \%\end{array}$ & $\begin{array}{c}14 \\
20.9 \%\end{array}$ & $\begin{array}{c}12 \\
17.9 \%\end{array}$ & $\begin{array}{c}0 \\
0.0 \%\end{array}$ & $\begin{array}{c}0 \\
0.0 \%\end{array}$ & $\begin{array}{c}31 \\
53.4 \%\end{array}$ & $\begin{array}{c}17 \\
29.3 \%\end{array}$ & $\begin{array}{c}10 \\
17.2 \%\end{array}$ & $\begin{array}{c}0 \\
0.0 \%\end{array}$ & $\begin{array}{c}0 \\
0.0 \%\end{array}$ \\
\hline 3 & $\begin{array}{c}23 \\
34.3 \%\end{array}$ & $\begin{array}{c}23 \\
34.3 \%\end{array}$ & $\begin{array}{c}17 \\
25.4 \%\end{array}$ & $\begin{array}{c}4 \\
6.0 \%\end{array}$ & $\begin{array}{c}0 \\
0.0 \%\end{array}$ & $\begin{array}{c}19 \\
32.8 \%\end{array}$ & $\begin{array}{c}21 \\
36.2 \%\end{array}$ & $\begin{array}{c}11 \\
19.0 \%\end{array}$ & $\begin{array}{c}6 \\
10.3 \%\end{array}$ & $\begin{array}{c}1 \\
1.7 \%\end{array}$ \\
\hline 4 & $\begin{array}{c}7 \\
10.4 \%\end{array}$ & $\begin{array}{c}22 \\
32.8 \%\end{array}$ & $\begin{array}{c}23 \\
34.3 \%\end{array}$ & $\begin{array}{c}14 \\
20.9 \%\end{array}$ & $\begin{array}{c}1 \\
1.5 \%\end{array}$ & $\begin{array}{c}7 \\
12.3 \%\end{array}$ & $\begin{array}{c}26 \\
45.6 \%\end{array}$ & $\begin{array}{c}20 \\
35.1 \%\end{array}$ & $\begin{array}{c}3 \\
5.3 \%\end{array}$ & $\begin{array}{c}1 \\
1.8 \%\end{array}$ \\
\hline 5 & $\begin{array}{c}56 \\
83.6 \%\end{array}$ & $\begin{array}{c}6 \\
9.0 \%\end{array}$ & $\begin{array}{c}5 \\
7.5 \%\end{array}$ & $\begin{array}{c}0 \\
0.0 \%\end{array}$ & $\begin{array}{c}0 \\
0.0 \%\end{array}$ & $\begin{array}{c}43 \\
74.1 \%\end{array}$ & $\begin{array}{c}9 \\
15.5 \%\end{array}$ & $\begin{array}{c}5 \\
8.6 \%\end{array}$ & $\begin{array}{c}1 \\
1.7 \%\end{array}$ & $\begin{array}{c}0 \\
0.0 \%\end{array}$ \\
\hline 6 & $\begin{array}{c}15 \\
22.4 \%\end{array}$ & $\begin{array}{c}40 \\
59.7 \%\end{array}$ & $\begin{array}{c}9 \\
13.4 \%\end{array}$ & $\begin{array}{c}3 \\
4.5 \%\end{array}$ & $\begin{array}{c}0 \\
0.0 \%\end{array}$ & $\begin{array}{c}16 \\
28.1 \%\end{array}$ & $\begin{array}{c}27 \\
47.4 \%\end{array}$ & $\begin{array}{c}11 \\
19.3 \%\end{array}$ & $\begin{array}{c}2 \\
3.5 \%\end{array}$ & $\begin{array}{c}1 \\
1.8 \%\end{array}$ \\
\hline 7 & $\begin{array}{c}49 \\
73.1 \%\end{array}$ & $\begin{array}{c}12 \\
17.9 \%\end{array}$ & $\begin{array}{c}6 \\
9.0 \%\end{array}$ & $\begin{array}{c}0 \\
0.0 \%\end{array}$ & $\begin{array}{c}0 \\
0.0 \%\end{array}$ & $\begin{array}{c}34 \\
58.6 \%\end{array}$ & $\begin{array}{c}17 \\
29.3 \%\end{array}$ & $\begin{array}{c}7 \\
12.1 \%\end{array}$ & $\begin{array}{c}0 \\
0.0 \%\end{array}$ & $\begin{array}{c}0 \\
0.0 \%\end{array}$ \\
\hline 8 & $\begin{array}{c}53 \\
79.1 \%\end{array}$ & $\begin{array}{c}12 \\
17.9 \%\end{array}$ & $\begin{array}{c}2 \\
3.0 \%\end{array}$ & $\begin{array}{c}0 \\
0.0 \%\end{array}$ & $\begin{array}{c}0 \\
0.0 \%\end{array}$ & $\begin{array}{c}39 \\
67.2 \%\end{array}$ & $\begin{array}{c}15 \\
25.9 \%\end{array}$ & $\begin{array}{c}4 \\
6.9 \%\end{array}$ & $\begin{array}{c}0 \\
0.0 \%\end{array}$ & $\begin{array}{c}0 \\
0.0 \%\end{array}$ \\
\hline 9 & $\begin{array}{c}16 \\
23.9 \%\end{array}$ & $\begin{array}{c}16 \\
23.9 \%\end{array}$ & $\begin{array}{c}30 \\
44.8 \%\end{array}$ & $\begin{array}{c}4 \\
6.0 \%\end{array}$ & $\begin{array}{c}1 \\
1.5 \%\end{array}$ & $\begin{array}{c}12 \\
20.7 \%\end{array}$ & $\begin{array}{c}11 \\
19.0 \%\end{array}$ & $\begin{array}{c}24 \\
41.4 \%\end{array}$ & $\begin{array}{c}8 \\
13.8 \%\end{array}$ & $\begin{array}{c}3 \\
5.2 \%\end{array}$ \\
\hline 10 & $\begin{array}{c}45 \\
67.2 \%\end{array}$ & $\begin{array}{c}16 \\
23.9 \%\end{array}$ & $\begin{array}{c}5 \\
7.5 \%\end{array}$ & $\begin{array}{c}1 \\
1.5 \%\end{array}$ & $\begin{array}{c}0 \\
0.0 \%\end{array}$ & $\begin{array}{c}37 \\
63.8 \%\end{array}$ & $\begin{array}{c}10 \\
17.2 \%\end{array}$ & $\begin{array}{c}6 \\
10.3 \%\end{array}$ & $\begin{array}{c}5 \\
8.6 \%\end{array}$ & $\begin{array}{c}0 \\
0.0 \%\end{array}$ \\
\hline 11 & $\begin{array}{c}29 \\
45.3 \%\end{array}$ & $\begin{array}{c}13 \\
20.3 \%\end{array}$ & $\begin{array}{c}18 \\
28.1 \%\end{array}$ & $\begin{array}{c}3 \\
4.7 \%\end{array}$ & $\begin{array}{c}1 \\
1.6 \%\end{array}$ & $\begin{array}{c}23 \\
40.4 \%\end{array}$ & $\begin{array}{c}12 \\
21.1 \%\end{array}$ & $\begin{array}{c}18 \\
31.6 \%\end{array}$ & $\begin{array}{c}2 \\
3.5 \%\end{array}$ & $\begin{array}{c}2 \\
3.5 \%\end{array}$ \\
\hline 12 & $\begin{array}{c}14 \\
20.9 \%\end{array}$ & $\begin{array}{c}37 \\
55.2 \%\end{array}$ & $\begin{array}{c}11 \\
16.4 \%\end{array}$ & $\begin{array}{c}5 \\
7.5 \%\end{array}$ & $\begin{array}{c}0 \\
0.0 \%\end{array}$ & $\begin{array}{c}11 \\
19.0 \%\end{array}$ & $\begin{array}{c}28 \\
48.3 \%\end{array}$ & $\begin{array}{c}16 \\
27.6 \%\end{array}$ & $\begin{array}{c}2 \\
3.4 \%\end{array}$ & $\begin{array}{c}1 \\
1.7 \%\end{array}$ \\
\hline 13 & $\begin{array}{c}65 \\
97.0 \%\end{array}$ & $\begin{array}{c}2 \\
3.0 \%\end{array}$ & $\begin{array}{c}0 \\
0.0 \%\end{array}$ & $\begin{array}{c}0 \\
0.0 \%\end{array}$ & $\begin{array}{c}0 \\
0.0 \%\end{array}$ & $\begin{array}{c}56 \\
96.6 \%\end{array}$ & $\begin{array}{c}2 \\
3.4 \%\end{array}$ & $\begin{array}{c}0 \\
0.0 \%\end{array}$ & $\begin{array}{c}0 \\
0.0 \%\end{array}$ & $\begin{array}{c}0 \\
0.0 \%\end{array}$ \\
\hline
\end{tabular}


Students’ Perceptions, 49

\begin{tabular}{|c|c|c|c|c|c|c|c|c|c|c|}
\hline \multirow[b]{2}{*}{ Qu. } & \multicolumn{5}{|c|}{ Counseling } & \multicolumn{5}{|c|}{ Clinical } \\
\hline & Never & Rarely & $\begin{array}{l}\text { Some- } \\
\text { times }\end{array}$ & Fairly Often & Always & Never & Rarely & $\begin{array}{l}\text { Some- } \\
\text { times }\end{array}$ & $\begin{array}{l}\text { Fairly } \\
\text { Often }\end{array}$ & Always \\
\hline \multirow[t]{2}{*}{14} & 9 & 9 & 37 & 6 & 6 & 12 & 11 & 22 & 8 & 5 \\
\hline & $13.4 \%$ & $13.4 \%$ & $55.2 \%$ & $9.0 \%$ & $9.0 \%$ & $20.7 \%$ & $19.0 \%$ & $37.9 \%$ & $13.8 \%$ & $8.6 \%$ \\
\hline \multirow[t]{2}{*}{15} & 48 & 15 & 4 & 0 & 0 & 47 & 9 & 2 & 0 & 0 \\
\hline & $71.6 \%$ & $22.4 \%$ & $6.0 \%$ & $0.0 \%$ & $0.0 \%$ & $81.0 \%$ & $15.5 \%$ & $3.4 \%$ & $0.0 \%$ & $0.0 \%$ \\
\hline \multirow[t]{2}{*}{16} & 66 & 1 & 0 & 0 & 0 & 58 & 0 & 0 & 0 & 0 \\
\hline & $98.5 \%$ & $1.5 \%$ & $0.0 \%$ & $0.0 \%$ & $0.0 \%$ & $100.0 \%$ & $0.0 \%$ & $0.0 \%$ & $0.0 \%$ & $0.0 \%$ \\
\hline \multirow[t]{2}{*}{17} & 67 & 0 & 0 & 0 & 0 & 55 & 2 & 1 & 0 & 0 \\
\hline & $100.0 \%$ & $0.0 \%$ & $0.0 \%$ & $0.0 \%$ & $0.0 \%$ & $94.8 \%$ & $3.4 \%$ & $1.7 \%$ & $0.0 \%$ & $0.0 \%$ \\
\hline \multirow[t]{2}{*}{18} & 42 & 13 & 9 & 1 & 2 & 32 & 14 & 11 & 0 & 0 \\
\hline & $62.7 \%$ & $19.4 \%$ & $13.4 \%$ & $1.5 \%$ & $3.0 \%$ & $56.1 \%$ & $24.6 \%$ & $19.3 \%$ & $0.0 \%$ & $0.0 \%$ \\
\hline \multirow[t]{2}{*}{19} & 60 & 2 & 4 & 1 & 0 & 46 & 6 & 4 & 1 & 1 \\
\hline & $89.6 \%$ & $3.0 \%$ & $6.0 \%$ & $1.5 \%$ & $0.0 \%$ & $79.3 \%$ & $10.3 \%$ & $6.9 \%$ & $1.7 \%$ & $1.7 \%$ \\
\hline \multirow[t]{2}{*}{20} & 63 & 3 & 1 & 0 & 0 & 58 & 0 & 0 & 0 & 0 \\
\hline & $94.0 \%$ & $4.5 \%$ & $1.5 \%$ & $0.0 \%$ & $0.0 \%$ & $100.0 \%$ & $0.0 \%$ & $0.0 \%$ & $0.0 \%$ & $0.0 \%$ \\
\hline \multirow[t]{2}{*}{21} & 23 & 22 & 14 & 6 & 1 & 19 & 18 & 19 & 1 & 0 \\
\hline & $34.8 \%$ & $33.3 \%$ & $21.2 \%$ & $9.1 \%$ & $1.5 \%$ & $33.3 \%$ & $31.6 \%$ & $33.3 \%$ & $1.8 \%$ & $0.0 \%$ \\
\hline \multirow[t]{2}{*}{22} & 55 & 8 & 3 & 1 & 0 & 50 & 7 & 0 & 1 & 0 \\
\hline & $82.1 \%$ & $11.9 \%$ & $4.5 \%$ & $1.5 \%$ & $0.0 \%$ & $86.2 \%$ & $12.1 \%$ & $0.0 \%$ & $1.7 \%$ & $0.0 \%$ \\
\hline \multirow[t]{2}{*}{23} & 41 & 17 & 6 & 2 & 1 & 37 & 9 & 8 & 3 & 1 \\
\hline & $61.2 \%$ & $25.4 \%$ & $9.0 \%$ & $3.0 \%$ & $1.5 \%$ & $63.8 \%$ & $15.5 \%$ & $13.8 \%$ & $5.2 \%$ & $1.7 \%$ \\
\hline \multirow[t]{2}{*}{24} & 35 & 20 & 10 & 2 & 0 & 28 & 12 & 12 & 4 & 2 \\
\hline & $52.2 \%$ & $29.9 \%$ & $14.9 \%$ & $3.0 \%$ & $0.0 \%$ & $48.3 \%$ & $20.7 \%$ & $20.7 \%$ & $6.9 \%$ & $3.4 \%$ \\
\hline \multirow[t]{2}{*}{25} & 65 & 1 & 1 & 0 & 0 & 55 & 2 & 1 & 0 & 0 \\
\hline & $97.0 \%$ & $1.5 \%$ & $1.5 \%$ & $0.0 \%$ & $0.0 \%$ & $94.8 \%$ & $3.4 \%$ & $1.7 \%$ & $0.0 \%$ & $0.0 \%$ \\
\hline \multirow[t]{2}{*}{26} & 56 & 8 & 3 & 0 & 0 & 47 & 10 & 0 & 1 & 0 \\
\hline & $83.6 \%$ & $11.9 \%$ & $4.5 \%$ & $0.0 \%$ & $0.0 \%$ & $81.0 \%$ & $17.2 \%$ & $0.0 \%$ & $1.7 \%$ & $0.0 \%$ \\
\hline \multirow[t]{2}{*}{27} & 35 & 20 & 11 & 1 & 0 & 12 & 20 & 17 & 9 & 0 \\
\hline & $52.2 \%$ & $29.9 \%$ & $16.4 \%$ & $1.5 \%$ & $0.0 \%$ & $20.7 \%$ & $34.5 \%$ & $29.3 \%$ & $15.5 \%$ & $0.0 \%$ \\
\hline
\end{tabular}


Students’ Perceptions, 50

\begin{tabular}{|c|c|c|c|c|c|c|c|c|c|c|}
\hline \multirow[b]{2}{*}{ Qu. } & \multicolumn{5}{|c|}{ Counseling } & \multicolumn{5}{|c|}{ Clinical } \\
\hline & Never & Rarely & $\begin{array}{l}\text { Some- } \\
\text { times }\end{array}$ & $\begin{array}{l}\text { Fairly } \\
\text { Often }\end{array}$ & Always & Never & Rarely & $\begin{array}{l}\text { Some- } \\
\text { times }\end{array}$ & $\begin{array}{l}\text { Fairly } \\
\text { Often }\end{array}$ & Always \\
\hline \multirow[t]{2}{*}{28} & 64 & 1 & 2 & 0 & 0 & 46 & 8 & 3 & 1 & 0 \\
\hline & $95.5 \%$ & $1.5 \%$ & $3.0 \%$ & $0.0 \%$ & $0.0 \%$ & $79.3 \%$ & $13.8 \%$ & $5.2 \%$ & $1.7 \%$ & $0.0 \%$ \\
\hline \multirow[t]{2}{*}{29} & 37 & 23 & 7 & 0 & 0 & 21 & 23 & 14 & 0 & 0 \\
\hline & $55.2 \%$ & $34.3 \%$ & $10.4 \%$ & $0.0 \%$ & $0.0 \%$ & $36.2 \%$ & $39.7 \%$ & $24.1 \%$ & $0.0 \%$ & $0.0 \%$ \\
\hline \multirow[t]{2}{*}{30} & 32 & 19 & 13 & 3 & 0 & 17 & 24 & 12 & 4 & 1 \\
\hline & $47.8 \%$ & $28.4 \%$ & $19.4 \%$ & $4.5 \%$ & $0.0 \%$ & $29.3 \%$ & $41.4 \%$ & $20.7 \%$ & $6.9 \%$ & $1.7 \%$ \\
\hline \multirow[t]{2}{*}{31} & 50 & 11 & 6 & 0 & 0 & 42 & 12 & 4 & 0 & 0 \\
\hline & $74.6 \%$ & $16.4 \%$ & $9.0 \%$ & $0.0 \%$ & $0.0 \%$ & $72.4 \%$ & $20.7 \%$ & $6.9 \%$ & $0.0 \%$ & $0.0 \%$ \\
\hline \multirow[t]{2}{*}{32} & 15 & 12 & 25 & 7 & 8 & 13 & 21 & 16 & 7 & 1 \\
\hline & $22.4 \%$ & $17.9 \%$ & $37.3 \%$ & $10.4 \%$ & $11.9 \%$ & $22.4 \%$ & $36.2 \%$ & $27.6 \%$ & $12.1 \%$ & $1.7 \%$ \\
\hline \multirow[t]{2}{*}{33} & 38 & 16 & 10 & 2 & 0 & 29 & 12 & 15 & 1 & 1 \\
\hline & $57.6 \%$ & $24.2 \%$ & $15.2 \%$ & $3.0 \%$ & $0.0 \%$ & $50.0 \%$ & $20.7 \%$ & $25.9 \%$ & $1.7 \%$ & $1.7 \%$ \\
\hline \multirow[t]{2}{*}{34} & 38 & 14 & 11 & 1 & 2 & 25 & 20 & 11 & 1 & 1 \\
\hline & $57.6 \%$ & $21.2 \%$ & $16.7 \%$ & $1.5 \%$ & $3.0 \%$ & $43.1 \%$ & $34.5 \%$ & $19.0 \%$ & $1.7 \%$ & $1.7 \%$ \\
\hline \multirow[t]{2}{*}{35} & 31 & 11 & 14 & 9 & 2 & 16 & 23 & 14 & 4 & 1 \\
\hline & $46.3 \%$ & $16.4 \%$ & $20.9 \%$ & $13.4 \%$ & $3.0 \%$ & $27.6 \%$ & $39.7 \%$ & $24.1 \%$ & $6.9 \%$ & $1.7 \%$ \\
\hline \multirow[t]{2}{*}{36} & 21 & 26 & 16 & 3 & 1 & 21 & 22 & 10 & 5 & 0 \\
\hline & $31.3 \%$ & $38.8 \%$ & $23.9 \%$ & $4.5 \%$ & $1.5 \%$ & $36.2 \%$ & $37.9 \%$ & $17.2 \%$ & $8.6 \%$ & $0.0 \%$ \\
\hline \multirow[t]{2}{*}{37} & 66 & 1 & 0 & 0 & 0 & 56 & 2 & 0 & 0 & 0 \\
\hline & $98.5 \%$ & $1.5 \%$ & $0.0 \%$ & $0.0 \%$ & $0.0 \%$ & $96.6 \%$ & $3.4 \%$ & $0.0 \%$ & $0.0 \%$ & $0.0 \%$ \\
\hline \multirow[t]{2}{*}{38} & 64 & 2 & 1 & 0 & 0 & 55 & 3 & 0 & 0 & 0 \\
\hline & $95.5 \%$ & $3.0 \%$ & $1.5 \%$ & $0.0 \%$ & $0.0 \%$ & $94.8 \%$ & $5.2 \%$ & $0.0 \%$ & $0.0 \%$ & $0.0 \%$ \\
\hline \multirow[t]{2}{*}{39} & 46 & 10 & 9 & 1 & 1 & 45 & 9 & 3 & 1 & 0 \\
\hline & $68.7 \%$ & $14.9 \%$ & $13.4 \%$ & $1.5 \%$ & $1.5 \%$ & $77.6 \%$ & $15.5 \%$ & $5.2 \%$ & $1.7 \%$ & $0.0 \%$ \\
\hline \multirow[t]{2}{*}{40} & 12 & 20 & 27 & 6 & 1 & 11 & 12 & 28 & 5 & 1 \\
\hline & $18.2 \%$ & $30.3 \%$ & $40.9 \%$ & $9.1 \%$ & $1.5 \%$ & $19.3 \%$ & $21.1 \%$ & $49.1 \%$ & $8.8 \%$ & $1.8 \%$ \\
\hline \multirow[t]{2}{*}{41} & 29 & 21 & 16 & 1 & 0 & 19 & 20 & 15 & 3 & 1 \\
\hline & $43.3 \%$ & $31.3 \%$ & 23.9\% & $1.5 \%$ & $0.0 \%$ & $32.8 \%$ & $34.5 \%$ & $25.9 \%$ & $5.2 \%$ & $1.7 \%$ \\
\hline
\end{tabular}


Students’ Perceptions, 51

\begin{tabular}{|c|c|c|c|c|c|c|c|c|c|c|}
\hline \multirow[b]{2}{*}{ Qu. } & \multicolumn{5}{|c|}{ Counseling } & \multicolumn{5}{|c|}{ Clinical } \\
\hline & Never & Rarely & $\begin{array}{l}\text { Some- } \\
\text { times }\end{array}$ & $\begin{array}{l}\text { Fairly } \\
\text { Often }\end{array}$ & Always & Never & Rarely & $\begin{array}{l}\text { Some- } \\
\text { times }\end{array}$ & $\begin{array}{l}\text { Fairly } \\
\text { Often }\end{array}$ & Always \\
\hline \multirow{2}{*}{42} & 20 & 26 & 16 & 4 & 0 & 21 & 16 & 19 & 1 & 1 \\
\hline & $30.3 \%$ & $39.4 \%$ & $24.2 \%$ & $6.1 \%$ & $0.0 \%$ & $36.2 \%$ & $27.6 \%$ & $32.8 \%$ & $1.7 \%$ & $1.7 \%$ \\
\hline \multirow[t]{2}{*}{43} & 23 & 25 & 18 & 1 & 0 & 25 & 19 & 12 & 2 & 0 \\
\hline & $34.3 \%$ & $37.3 \%$ & $26.9 \%$ & $1.5 \%$ & $0.0 \%$ & $43.1 \%$ & $32.8 \%$ & $20.7 \%$ & $3.4 \%$ & $0.0 \%$ \\
\hline \multirow[t]{2}{*}{44} & 13 & 18 & 29 & 5 & 1 & 2 & 20 & 22 & 12 & 2 \\
\hline & $19.7 \%$ & $27.3 \%$ & $43.9 \%$ & $7.6 \%$ & $1.5 \%$ & $3.4 \%$ & $34.5 \%$ & $37.9 \%$ & $20.7 \%$ & $3.4 \%$ \\
\hline \multirow[t]{2}{*}{45} & 2 & 3 & 9 & 25 & 28 & 2 & 0 & 11 & 29 & 15 \\
\hline & $3.0 \%$ & $4.5 \%$ & $13.4 \%$ & $37.3 \%$ & $41.8 \%$ & $3.5 \%$ & $0.0 \%$ & $19.3 \%$ & $50.9 \%$ & $26.3 \%$ \\
\hline \multirow[t]{2}{*}{46} & 39 & 20 & 8 & 0 & 0 & 35 & 13 & 9 & 1 & 0 \\
\hline & $58.2 \%$ & $29.9 \%$ & $11.9 \%$ & $0.0 \%$ & $0.0 \%$ & $60.3 \%$ & $22.4 \%$ & $15.5 \%$ & $1.7 \%$ & $0.0 \%$ \\
\hline \multirow[t]{2}{*}{47} & 58 & 5 & 3 & 1 & 0 & 45 & 8 & 4 & 1 & 0 \\
\hline & $86.6 \%$ & $7.5 \%$ & $4.5 \%$ & $1.5 \%$ & $0.0 \%$ & $77.6 \%$ & $13.8 \%$ & $6.9 \%$ & $1.7 \%$ & $0.0 \%$ \\
\hline \multirow[t]{2}{*}{48} & 45 & 19 & 2 & 1 & 0 & 30 & 23 & 5 & 0 & 0 \\
\hline & $67.2 \%$ & $28.4 \%$ & $3.0 \%$ & $1.5 \%$ & $0.0 \%$ & $51.7 \%$ & $39.7 \%$ & $8.6 \%$ & $0.0 \%$ & $0.0 \%$ \\
\hline \multirow[t]{2}{*}{49} & 52 & 6 & 7 & 1 & 0 & 52 & 4 & 2 & 0 & 0 \\
\hline & $78.8 \%$ & $9.1 \%$ & $10.6 \%$ & $1.5 \%$ & $0.0 \%$ & $89.7 \%$ & $6.9 \%$ & $3.4 \%$ & $0.0 \%$ & $0.0 \%$ \\
\hline \multirow[t]{2}{*}{50} & 48 & 14 & 2 & 1 & 1 & 36 & 14 & 7 & 1 & 0 \\
\hline & $72.7 \%$ & $21.2 \%$ & $3.0 \%$ & $1.5 \%$ & $1.5 \%$ & $62.1 \%$ & $24.1 \%$ & $12.1 \%$ & $1.7 \%$ & $0.0 \%$ \\
\hline \multirow[t]{2}{*}{51} & 36 & 18 & 10 & 1 & 1 & 30 & 16 & 10 & 2 & 0 \\
\hline & $54.5 \%$ & $27.3 \%$ & $15.2 \%$ & $1.5 \%$ & $1.5 \%$ & $51.7 \%$ & $27.6 \%$ & $17.2 \%$ & $3.4 \%$ & $0.0 \%$ \\
\hline \multirow[t]{2}{*}{52} & 53 & 14 & 0 & 0 & 0 & 47 & 7 & 3 & 1 & 0 \\
\hline & $79.1 \%$ & $20.9 \%$ & $0.0 \%$ & $0.0 \%$ & $0.0 \%$ & $81.0 \%$ & $12.1 \%$ & $5.2 \%$ & $1.7 \%$ & $0.0 \%$ \\
\hline \multirow[t]{2}{*}{53} & 29 & 20 & 12 & 3 & 3 & 20 & 19 & 12 & 6 & 1 \\
\hline & $43.3 \%$ & $29.9 \%$ & $17.9 \%$ & $4.5 \%$ & $4.5 \%$ & $34.5 \%$ & $32.8 \%$ & $20.7 \%$ & $10.3 \%$ & $1.7 \%$ \\
\hline \multirow[t]{2}{*}{54} & 27 & 23 & 12 & 4 & 1 & 14 & 21 & 17 & 5 & 1 \\
\hline & $40.3 \%$ & $34.3 \%$ & $17.9 \%$ & $6.0 \%$ & $1.5 \%$ & $24.1 \%$ & $36.2 \%$ & $29.3 \%$ & $8.6 \%$ & $1.7 \%$ \\
\hline
\end{tabular}


Students’ Perceptions, 52

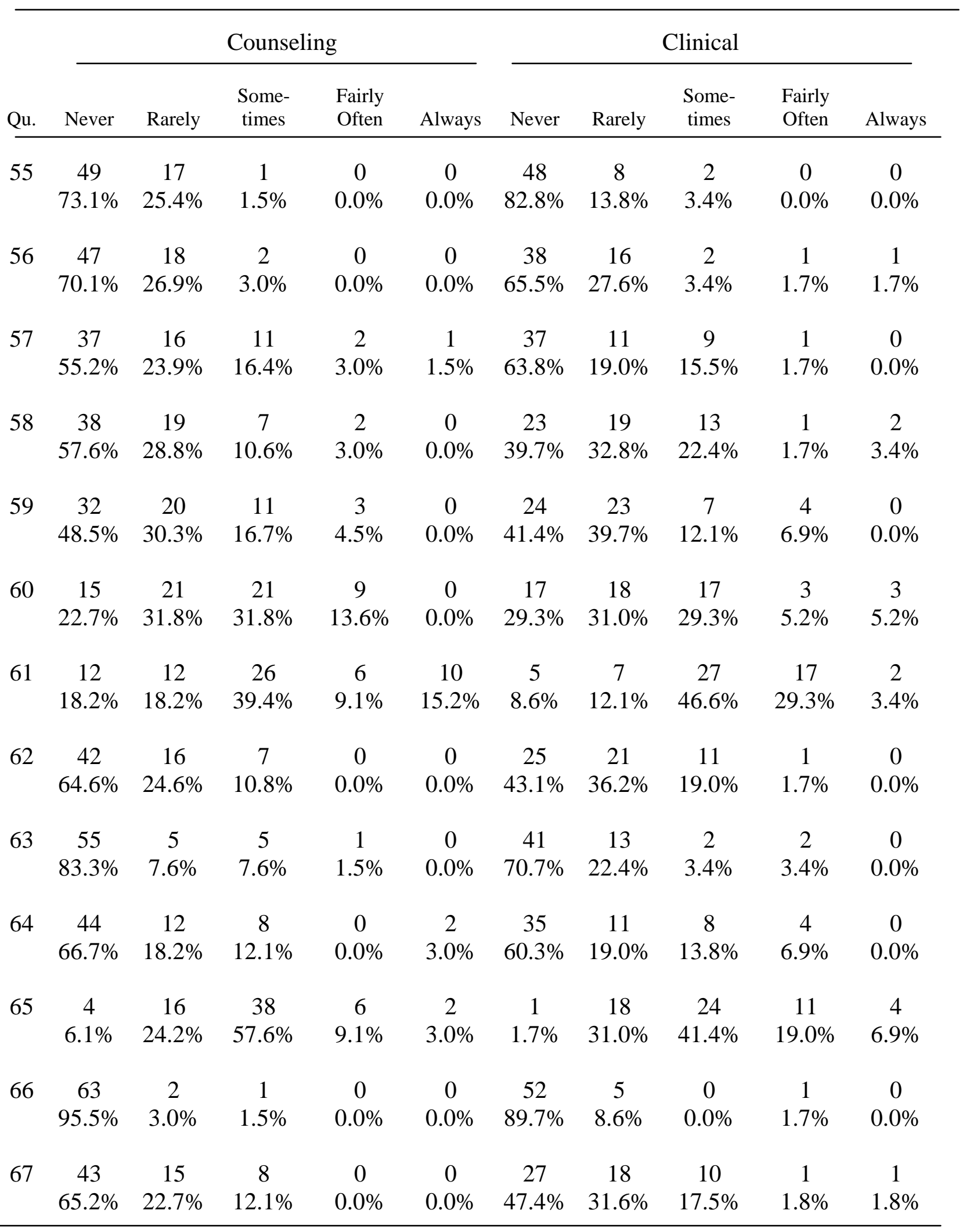


Students’ Perceptions, 53

Table 4b

Frequency and Percent of "Is it ethical” Ethics Questions by Program

\begin{tabular}{|c|c|c|c|c|c|c|c|c|c|c|}
\hline \multirow[b]{2}{*}{ Qu. } & \multicolumn{5}{|c|}{ Counseling } & \multicolumn{5}{|c|}{ Clinical } \\
\hline & No & Rarely & $\begin{array}{l}\text { Don’t } \\
\text { Know }\end{array}$ & $\begin{array}{c}\text { Most } \\
\text { Circumstances }\end{array}$ & Yes & No & Rarely & $\begin{array}{l}\text { Don’t } \\
\text { Know }\end{array}$ & $\begin{array}{c}\text { Most } \\
\text { Circumstances }\end{array}$ & Yes \\
\hline \multirow[t]{2}{*}{1} & 56 & 8 & 0 & 0 & 1 & 51 & 3 & 1 & 0 & 2 \\
\hline & $86.2 \%$ & $12.3 \%$ & $0.0 \%$ & $0.0 \%$ & $1.5 \%$ & $89.5 \%$ & $5.3 \%$ & $1.8 \%$ & $0.0 \%$ & $3.5 \%$ \\
\hline \multirow[t]{2}{*}{2} & 47 & 18 & 1 & 0 & 0 & 39 & 13 & 6 & 0 & 0 \\
\hline & $71.2 \%$ & $27.3 \%$ & $1.5 \%$ & $0.0 \%$ & $0.0 \%$ & $67.2 \%$ & $22.4 \%$ & $10.3 \%$ & $0.0 \%$ & $0.0 \%$ \\
\hline \multirow[t]{2}{*}{3} & 6 & 22 & 15 & 22 & 1 & 5 & 11 & 16 & 23 & 2 \\
\hline & $9.1 \%$ & $33.3 \%$ & $22.7 \%$ & $33.3 \%$ & $1.5 \%$ & $8.8 \%$ & $19.3 \%$ & $28.1 \%$ & $40.4 \%$ & $3.5 \%$ \\
\hline \multirow[t]{2}{*}{4} & 6 & 22 & 7 & 23 & 9 & 0 & 23 & 8 & 24 & 2 \\
\hline & $9.0 \%$ & $32.8 \%$ & $10.4 \%$ & $34.3 \%$ & $13.4 \%$ & $0.0 \%$ & $40.4 \%$ & $14.0 \%$ & $42.1 \%$ & $3.5 \%$ \\
\hline \multirow[t]{2}{*}{5} & 36 & 21 & 6 & 1 & 1 & 24 & 22 & 8 & 2 & 1 \\
\hline & $55.4 \%$ & $32.3 \%$ & $9.2 \%$ & $1.5 \%$ & $1.5 \%$ & $42.1 \%$ & $38.6 \%$ & $14.0 \%$ & $3.5 \%$ & $1.8 \%$ \\
\hline \multirow[t]{2}{*}{6} & 27 & 21 & 16 & 1 & 1 & 9 & 20 & 19 & 5 & 2 \\
\hline & $40.9 \%$ & $31.8 \%$ & $24.2 \%$ & $1.5 \%$ & $1.5 \%$ & $16.4 \%$ & $36.4 \%$ & $34.5 \%$ & $9.1 \%$ & $3.6 \%$ \\
\hline \multirow[t]{2}{*}{7} & 57 & 7 & 0 & 0 & 1 & 46 & 9 & 2 & 1 & 0 \\
\hline & $87.7 \%$ & $10.8 \%$ & $0.0 \%$ & $0.0 \%$ & $1.5 \%$ & $79.3 \%$ & $15.5 \%$ & $3.4 \%$ & $1.7 \%$ & $0.0 \%$ \\
\hline \multirow[t]{2}{*}{8} & 27 & 30 & 7 & 1 & 0 & 20 & 27 & 5 & 3 & 1 \\
\hline & $41.5 \%$ & $46.2 \%$ & $10.8 \%$ & $1.5 \%$ & $0.0 \%$ & $35.7 \%$ & $48.2 \%$ & $8.9 \%$ & $5.4 \%$ & $1.8 \%$ \\
\hline \multirow[t]{2}{*}{9} & 13 & 21 & 13 & 17 & 3 & 2 & 15 & 14 & 20 & 6 \\
\hline & $19.4 \%$ & $31.3 \%$ & $19.4 \%$ & $25.4 \%$ & $4.5 \%$ & $3.5 \%$ & $26.3 \%$ & $24.6 \%$ & $35.1 \%$ & $10.5 \%$ \\
\hline \multirow[t]{2}{*}{10} & 20 & 20 & 14 & 10 & 1 & 8 & 21 & 15 & 11 & 1 \\
\hline & $30.8 \%$ & $30.8 \%$ & $21.5 \%$ & $15.4 \%$ & $1.5 \%$ & $14.3 \%$ & $37.5 \%$ & $26.8 \%$ & $19.6 \%$ & $1.8 \%$ \\
\hline \multirow[t]{2}{*}{11} & 21 & 6 & 16 & 9 & 14 & 13 & 10 & 13 & 5 & 15 \\
\hline & $31.8 \%$ & $9.1 \%$ & $24.2 \%$ & $13.6 \%$ & $21.2 \%$ & $23.2 \%$ & $17.9 \%$ & $23.2 \%$ & $8.9 \%$ & $26.8 \%$ \\
\hline \multirow[t]{2}{*}{12} & 32 & 26 & 7 & 1 & 0 & 20 & 27 & 8 & 2 & 1 \\
\hline & $48.5 \%$ & $39.4 \%$ & $10.6 \%$ & $1.5 \%$ & $0.0 \%$ & $34.5 \%$ & $46.6 \%$ & $13.8 \%$ & $3.4 \%$ & $1.7 \%$ \\
\hline \multirow[t]{2}{*}{13} & 60 & 5 & 1 & 0 & 0 & 49 & 2 & 4 & 2 & 0 \\
\hline & $90.9 \%$ & $7.6 \%$ & $1.5 \%$ & $0.0 \%$ & $0.0 \%$ & $86.0 \%$ & $3.5 \%$ & $7.0 \%$ & $3.5 \%$ & $0.0 \%$ \\
\hline
\end{tabular}


Students’ Perceptions, 54

\begin{tabular}{|c|c|c|c|c|c|c|c|c|c|c|}
\hline \multirow[b]{2}{*}{ Qu. } & \multicolumn{4}{|c|}{ Counseling } & \multicolumn{5}{|c|}{ Clinical } & \multirow[b]{2}{*}{ Yes } \\
\hline & No & Rarely & $\begin{array}{l}\text { Don’t } \\
\text { Know }\end{array}$ & Most Circumstances & Yes & No & Rarely & $\begin{array}{l}\text { Don’t } \\
\text { Know }\end{array}$ & $\begin{array}{c}\text { Most } \\
\text { Circumstances }\end{array}$ & \\
\hline \multirow[t]{2}{*}{14} & 6 & 9 & 6 & 25 & 20 & 2 & 8 & 6 & 25 & 17 \\
\hline & $9.1 \%$ & $13.6 \%$ & $9.1 \%$ & $37.9 \%$ & $30.3 \%$ & $3.4 \%$ & $13.8 \%$ & $10.3 \%$ & $43.1 \%$ & $29.3 \%$ \\
\hline \multirow[t]{2}{*}{15} & 65 & 1 & 0 & 0 & 0 & 58 & 0 & 0 & 0 & 0 \\
\hline & $98.5 \%$ & $1.5 \%$ & $0.0 \%$ & $0.0 \%$ & $0.0 \%$ & $100.0 \%$ & $0.0 \%$ & $0.0 \%$ & $0.0 \%$ & $0.0 \%$ \\
\hline \multirow[t]{2}{*}{16} & 65 & 0 & 0 & 0 & 0 & 56 & 0 & 2 & 0 & 0 \\
\hline & $100.0 \%$ & $0.0 \%$ & $0.0 \%$ & $0.0 \%$ & $0.0 \%$ & $96.6 \%$ & $0.0 \%$ & $3.4 \%$ & $0.0 \%$ & $0.0 \%$ \\
\hline \multirow[t]{2}{*}{17} & 64 & 2 & 0 & 0 & 0 & 56 & 2 & 0 & 0 & 0 \\
\hline & $97.0 \%$ & $3.0 \%$ & $0.0 \%$ & $0.0 \%$ & $0.0 \%$ & $96.6 \%$ & $3.4 \%$ & $0.0 \%$ & $0.0 \%$ & $0.0 \%$ \\
\hline \multirow[t]{2}{*}{18} & 35 & 12 & 7 & 9 & 1 & 26 & 12 & 12 & 7 & 1 \\
\hline & $54.7 \%$ & $18.8 \%$ & $10.9 \%$ & $14.1 \%$ & $1.6 \%$ & $44.8 \%$ & $20.7 \%$ & $20.7 \%$ & $12.1 \%$ & $1.7 \%$ \\
\hline \multirow[t]{2}{*}{19} & 54 & 7 & 4 & 1 & 0 & 42 & 6 & 8 & 1 & 0 \\
\hline & $81.8 \%$ & $10.6 \%$ & $6.1 \%$ & $1.5 \%$ & $0.0 \%$ & $73.7 \%$ & $10.5 \%$ & $14.0 \%$ & $1.8 \%$ & $0.0 \%$ \\
\hline \multirow[t]{2}{*}{20} & 66 & 0 & 0 & 0 & 0 & 56 & 0 & 2 & 0 & 0 \\
\hline & $100.0 \%$ & $0.0 \%$ & $0.0 \%$ & $0.0 \%$ & $0.0 \%$ & $96.6 \%$ & $0.0 \%$ & $3.4 \%$ & $0.0 \%$ & $0.0 \%$ \\
\hline \multirow[t]{2}{*}{21} & 58 & 6 & 2 & 0 & 0 & 50 & 4 & 2 & 1 & 0 \\
\hline & $87.9 \%$ & $9.1 \%$ & $3.0 \%$ & $0.0 \%$ & $0.0 \%$ & $87.7 \%$ & $7.0 \%$ & $3.5 \%$ & $1.8 \%$ & $0.0 \%$ \\
\hline \multirow[t]{2}{*}{22} & 53 & 9 & 3 & 0 & 0 & 51 & 6 & 1 & 0 & 0 \\
\hline & $81.5 \%$ & $13.8 \%$ & $4.6 \%$ & $0.0 \%$ & $0.0 \%$ & $87.9 \%$ & $10.3 \%$ & $1.7 \%$ & $0.0 \%$ & $0.0 \%$ \\
\hline \multirow[t]{2}{*}{23} & 21 & 18 & 16 & 8 & 1 & 14 & 17 & 20 & 4 & 2 \\
\hline & $32.8 \%$ & $28.1 \%$ & $25.0 \%$ & $12.5 \%$ & $1.6 \%$ & $24.6 \%$ & $29.8 \%$ & $35.1 \%$ & $7.0 \%$ & $3.5 \%$ \\
\hline \multirow[t]{2}{*}{24} & 46 & 14 & 5 & 0 & 0 & 27 & 19 & 8 & 3 & 0 \\
\hline & $70.8 \%$ & $21.5 \%$ & $7.7 \%$ & $0.0 \%$ & $0.0 \%$ & $47.4 \%$ & $33.3 \%$ & $14.0 \%$ & $5.3 \%$ & $0.0 \%$ \\
\hline \multirow[t]{2}{*}{25} & 45 & 12 & 6 & 0 & 1 & 34 & 8 & 13 & 0 & 2 \\
\hline & $70.3 \%$ & $18.8 \%$ & $9.4 \%$ & $0.0 \%$ & $1.6 \%$ & $59.6 \%$ & $14.0 \%$ & $22.8 \%$ & $0.0 \%$ & $3.5 \%$ \\
\hline \multirow[t]{2}{*}{26} & 33 & 14 & 13 & 3 & 1 & 26 & 12 & 15 & 4 & 0 \\
\hline & $51.6 \%$ & $21.9 \%$ & $20.3 \%$ & $4.7 \%$ & $1.6 \%$ & $45.6 \%$ & $21.1 \%$ & $26.3 \%$ & $7.0 \%$ & $0.0 \%$ \\
\hline \multirow[t]{2}{*}{27} & 44 & 10 & 9 & 1 & 2 & 26 & 17 & 10 & 5 & 0 \\
\hline & $66.7 \%$ & $15.2 \%$ & $13.6 \%$ & $1.5 \%$ & $3.0 \%$ & $44.8 \%$ & $29.3 \%$ & $17.2 \%$ & $8.6 \%$ & $0.0 \%$ \\
\hline
\end{tabular}


Students’ Perceptions, 55

\begin{tabular}{|c|c|c|c|c|c|c|c|c|c|c|}
\hline \multirow[b]{2}{*}{ Qu. } & \multicolumn{5}{|c|}{ Counseling } & \multicolumn{5}{|c|}{ Clinical } \\
\hline & No & Rarely & $\begin{array}{l}\text { Don't } \\
\text { Know }\end{array}$ & $\begin{array}{c}\text { Most } \\
\text { Circumstances }\end{array}$ & Yes & No & Rarely & $\begin{array}{l}\text { Don’t } \\
\text { Know }\end{array}$ & $\begin{array}{c}\text { Most } \\
\text { Circumstances }\end{array}$ & Yes \\
\hline \multirow[t]{2}{*}{28} & 41 & 5 & 16 & 1 & 1 & 16 & 7 & 23 & 5 & 6 \\
\hline & $64.1 \%$ & $7.8 \%$ & $25.0 \%$ & $1.6 \%$ & $1.6 \%$ & $28.1 \%$ & $12.3 \%$ & $40.4 \%$ & $8.8 \%$ & $10.5 \%$ \\
\hline \multirow[t]{2}{*}{29} & 56 & 5 & 5 & 0 & 0 & 47 & 4 & 7 & 0 & 0 \\
\hline & $84.8 \%$ & $7.6 \%$ & $7.6 \%$ & $0.0 \%$ & $0.0 \%$ & $81.0 \%$ & $6.9 \%$ & $12.1 \%$ & $0.0 \%$ & $0.0 \%$ \\
\hline \multirow[t]{2}{*}{30} & 57 & 7 & 1 & 1 & 0 & 45 & 12 & 1 & 0 & 0 \\
\hline & $86.4 \%$ & $10.6 \%$ & $1.5 \%$ & $1.5 \%$ & $0.0 \%$ & $77.6 \%$ & $20.7 \%$ & $1.7 \%$ & $0.0 \%$ & $0.0 \%$ \\
\hline \multirow[t]{2}{*}{31} & 37 & 19 & 5 & 4 & 0 & 32 & 14 & 7 & 4 & 1 \\
\hline & $56.9 \%$ & $29.2 \%$ & $7.7 \%$ & $6.2 \%$ & $0.0 \%$ & $55.2 \%$ & $24.1 \%$ & $12.1 \%$ & $6.9 \%$ & $1.7 \%$ \\
\hline \multirow[t]{2}{*}{32} & 18 & 16 & 17 & 12 & 4 & 9 & 17 & 17 & 13 & 2 \\
\hline & $26.9 \%$ & $23.9 \%$ & $25.4 \%$ & $17.9 \%$ & $6.0 \%$ & $15.5 \%$ & $29.3 \%$ & $29.3 \%$ & $22.4 \%$ & $3.4 \%$ \\
\hline \multirow[t]{2}{*}{33} & 44 & 10 & 8 & 3 & 0 & 31 & 14 & 10 & 2 & 0 \\
\hline & $67.7 \%$ & $15.4 \%$ & $12.3 \%$ & $4.6 \%$ & $0.0 \%$ & $54.4 \%$ & $24.6 \%$ & $17.5 \%$ & $3.5 \%$ & $0.0 \%$ \\
\hline \multirow[t]{2}{*}{34} & 53 & 7 & 4 & 0 & 1 & 43 & 6 & 9 & 0 & 0 \\
\hline & $81.5 \%$ & $10.8 \%$ & $6.2 \%$ & $0.0 \%$ & $1.5 \%$ & $74.1 \%$ & $10.3 \%$ & $15.5 \%$ & $0.0 \%$ & $0.0 \%$ \\
\hline \multirow[t]{2}{*}{35} & 55 & 8 & 2 & 0 & 0 & 35 & 14 & 7 & 1 & 0 \\
\hline & $84.6 \%$ & $12.3 \%$ & $3.1 \%$ & $0.0 \%$ & $0.0 \%$ & $61.4 \%$ & $24.6 \%$ & $12.3 \%$ & $1.8 \%$ & $0.0 \%$ \\
\hline \multirow[t]{2}{*}{36} & 36 & 16 & 9 & 4 & 2 & 34 & 16 & 5 & 3 & 0 \\
\hline & $53.7 \%$ & $23.9 \%$ & $13.4 \%$ & $6.0 \%$ & $3.0 \%$ & $58.6 \%$ & $27.6 \%$ & $8.6 \%$ & $5.2 \%$ & $0.0 \%$ \\
\hline \multirow[t]{2}{*}{37} & 60 & 1 & 3 & 1 & 0 & 50 & 4 & 4 & 0 & 0 \\
\hline & $92.3 \%$ & $1.5 \%$ & $4.6 \%$ & $1.5 \%$ & $0.0 \%$ & $86.2 \%$ & $6.9 \%$ & $6.9 \%$ & $0.0 \%$ & $0.0 \%$ \\
\hline \multirow[t]{2}{*}{38} & 63 & 1 & 0 & 1 & 0 & 55 & 2 & 1 & 0 & 0 \\
\hline & $96.9 \%$ & $1.5 \%$ & $0.0 \%$ & $1.5 \%$ & $0.0 \%$ & $94.8 \%$ & $3.4 \%$ & $1.7 \%$ & $0.0 \%$ & $0.0 \%$ \\
\hline \multirow[t]{2}{*}{39} & 57 & 7 & 3 & 0 & 0 & 52 & 6 & 0 & 0 & 0 \\
\hline & $85.1 \%$ & $10.4 \%$ & $4.5 \%$ & $0.0 \%$ & $0.0 \%$ & $89.7 \%$ & $10.3 \%$ & $0.0 \%$ & $0.0 \%$ & $0.0 \%$ \\
\hline \multirow[t]{2}{*}{40} & 36 & 19 & 9 & 1 & 0 & 21 & 12 & 18 & 4 & 2 \\
\hline & $55.4 \%$ & $29.2 \%$ & $13.8 \%$ & $1.5 \%$ & $0.0 \%$ & $36.8 \%$ & $21.1 \%$ & $31.6 \%$ & $7.0 \%$ & $3.5 \%$ \\
\hline \multirow[t]{2}{*}{41} & 34 & 20 & 6 & 6 & 0 & 24 & 19 & 10 & 3 & 1 \\
\hline & $51.5 \%$ & $30.3 \%$ & $9.1 \%$ & $9.1 \%$ & $0.0 \%$ & $42.1 \%$ & $33.3 \%$ & $17.5 \%$ & $5.3 \%$ & $1.8 \%$ \\
\hline
\end{tabular}


Students' Perceptions, 56

\begin{tabular}{|c|c|c|c|c|c|c|c|c|c|c|}
\hline \multirow[b]{2}{*}{ Qu. } & \multicolumn{5}{|c|}{ Counseling } & \multicolumn{5}{|c|}{ Clinical } \\
\hline & No & Rarely & $\begin{array}{l}\text { Don’t } \\
\text { Know }\end{array}$ & $\begin{array}{c}\text { Most } \\
\text { Circumstances }\end{array}$ & Yes & No & Rarely & $\begin{array}{l}\text { Don’t } \\
\text { Know }\end{array}$ & $\begin{array}{c}\text { Most } \\
\text { Circumstances }\end{array}$ & Yes \\
\hline \multirow[t]{2}{*}{42} & 12 & 18 & 29 & 5 & 1 & 10 & 9 & 28 & 6 & 4 \\
\hline & $18.5 \%$ & $27.7 \%$ & $44.6 \%$ & $7.7 \%$ & $1.5 \%$ & $17.5 \%$ & $15.8 \%$ & $49.1 \%$ & $10.5 \%$ & $7.0 \%$ \\
\hline \multirow[t]{2}{*}{43} & 11 & 22 & 19 & 9 & 4 & 17 & 15 & 17 & 4 & 4 \\
\hline & $16.9 \%$ & $33.8 \%$ & $29.2 \%$ & $13.8 \%$ & $6.2 \%$ & $29.8 \%$ & $26.3 \%$ & $29.8 \%$ & $7.0 \%$ & $7.0 \%$ \\
\hline \multirow[t]{2}{*}{44} & 11 & 10 & 26 & 14 & 6 & 7 & 5 & 29 & 10 & 7 \\
\hline & $16.4 \%$ & $14.9 \%$ & $38.8 \%$ & $20.9 \%$ & $9.0 \%$ & $12.1 \%$ & $8.6 \%$ & $50.0 \%$ & $17.2 \%$ & $12.1 \%$ \\
\hline \multirow[t]{2}{*}{45} & 5 & 2 & 5 & 5 & 49 & 3 & 1 & 4 & 1 & 48 \\
\hline & $7.6 \%$ & $3.0 \%$ & $7.6 \%$ & $7.6 \%$ & $74.2 \%$ & $5.3 \%$ & $1.8 \%$ & $7.0 \%$ & $1.8 \%$ & $84.2 \%$ \\
\hline \multirow[t]{2}{*}{46} & 58 & 5 & 1 & 1 & 0 & 49 & 9 & 0 & 0 & 0 \\
\hline & $89.2 \%$ & $7.7 \%$ & $1.5 \%$ & $1.5 \%$ & $0.0 \%$ & $84.5 \%$ & $15.5 \%$ & $0.0 \%$ & $0.0 \%$ & $0.0 \%$ \\
\hline \multirow[t]{2}{*}{47} & 49 & 9 & 6 & 1 & 0 & 35 & 11 & 10 & 1 & 0 \\
\hline & $75.4 \%$ & $13.8 \%$ & $9.2 \%$ & $1.5 \%$ & $0.0 \%$ & $61.4 \%$ & $19.3 \%$ & $17.5 \%$ & $1.8 \%$ & $0.0 \%$ \\
\hline \multirow[t]{2}{*}{48} & 61 & 2 & 1 & 0 & 1 & 52 & 4 & 2 & 0 & 0 \\
\hline & $93.8 \%$ & $3.1 \%$ & $1.5 \%$ & $0.0 \%$ & $1.5 \%$ & $89.7 \%$ & $6.9 \%$ & $3.4 \%$ & $0.0 \%$ & $0.0 \%$ \\
\hline \multirow[t]{2}{*}{49} & 45 & 4 & 10 & 3 & 2 & 31 & 16 & 8 & 2 & 0 \\
\hline & $70.3 \%$ & $6.3 \%$ & $15.6 \%$ & $4.7 \%$ & $3.1 \%$ & $54.4 \%$ & $28.1 \%$ & $14.0 \%$ & $3.5 \%$ & $0.0 \%$ \\
\hline \multirow[t]{2}{*}{50} & 53 & 4 & 5 & 0 & 1 & 40 & 11 & 2 & 1 & 2 \\
\hline & $84.1 \%$ & $6.3 \%$ & $7.9 \%$ & $0.0 \%$ & $1.6 \%$ & $71.4 \%$ & $19.6 \%$ & $3.6 \%$ & $1.8 \%$ & $3.6 \%$ \\
\hline \multirow[t]{2}{*}{51} & 42 & 13 & 5 & 2 & 2 & 35 & 14 & 5 & 4 & 0 \\
\hline & $65.6 \%$ & $20.3 \%$ & $7.8 \%$ & $3.1 \%$ & $3.1 \%$ & $60.3 \%$ & $24.1 \%$ & $8.6 \%$ & $6.9 \%$ & $0.0 \%$ \\
\hline \multirow[t]{2}{*}{52} & 52 & 7 & 4 & 0 & 1 & 47 & 5 & 5 & 0 & 0 \\
\hline & $81.3 \%$ & $10.9 \%$ & $6.3 \%$ & $0.0 \%$ & $1.6 \%$ & $82.5 \%$ & $8.8 \%$ & $8.8 \%$ & $0.0 \%$ & $0.0 \%$ \\
\hline \multirow[t]{2}{*}{53} & 41 & 10 & 8 & 1 & 6 & 34 & 11 & 9 & 2 & 1 \\
\hline & $62.1 \%$ & $15.2 \%$ & $12.1 \%$ & $1.5 \%$ & $9.1 \%$ & $59.6 \%$ & $19.3 \%$ & $15.8 \%$ & $3.5 \%$ & $1.8 \%$ \\
\hline \multirow[t]{2}{*}{54} & 37 & 11 & 12 & 5 & 1 & 20 & 22 & 13 & 3 & 0 \\
\hline & $56.1 \%$ & $16.7 \%$ & $18.2 \%$ & $7.6 \%$ & $1.5 \%$ & $34.5 \%$ & $37.9 \%$ & $22.4 \%$ & $5.2 \%$ & $0.0 \%$ \\
\hline
\end{tabular}


Students' Perceptions, 57

\begin{tabular}{|c|c|c|c|c|c|c|c|c|c|c|}
\hline \multirow[b]{2}{*}{ Qu. } & \multicolumn{5}{|c|}{ Counseling } & \multicolumn{5}{|c|}{ Clinical } \\
\hline & No & Rarely & $\begin{array}{l}\text { Don’t } \\
\text { Know }\end{array}$ & $\begin{array}{c}\text { Most } \\
\text { Circumstances }\end{array}$ & Yes & No & Rarely & $\begin{array}{l}\text { Don’t } \\
\text { Know }\end{array}$ & $\begin{array}{c}\text { Most } \\
\text { Circumstances }\end{array}$ & Yes \\
\hline \multirow[t]{2}{*}{55} & 28 & 19 & 13 & 3 & 3 & 24 & 21 & 7 & 5 & 0 \\
\hline & $42.4 \%$ & $28.8 \%$ & $19.7 \%$ & $4.5 \%$ & $4.5 \%$ & $42.1 \%$ & $36.8 \%$ & $12.3 \%$ & $8.8 \%$ & $0.0 \%$ \\
\hline \multirow[t]{2}{*}{56} & 30 & 16 & 14 & 5 & 1 & 27 & 15 & 12 & 2 & 1 \\
\hline & $45.5 \%$ & $24.2 \%$ & $21.2 \%$ & $7.6 \%$ & $1.5 \%$ & $47.4 \%$ & $26.3 \%$ & $21.1 \%$ & $3.5 \%$ & $1.8 \%$ \\
\hline \multirow[t]{2}{*}{57} & 60 & 2 & 1 & 2 & 1 & 56 & 0 & 2 & 0 & 0 \\
\hline & $90.9 \%$ & $3.0 \%$ & $1.5 \%$ & $3.0 \%$ & $1.5 \%$ & $96.6 \%$ & $0.0 \%$ & $3.4 \%$ & $0.0 \%$ & $0.0 \%$ \\
\hline \multirow[t]{2}{*}{58} & 38 & 15 & 9 & 0 & 1 & 27 & 23 & 6 & 1 & 1 \\
\hline & $60.3 \%$ & $23.8 \%$ & $14.3 \%$ & $0.0 \%$ & $1.6 \%$ & $46.6 \%$ & $39.7 \%$ & $10.3 \%$ & $1.7 \%$ & $1.7 \%$ \\
\hline \multirow[t]{2}{*}{59} & 43 & 15 & 4 & 2 & 1 & 33 & 17 & 4 & 3 & 1 \\
\hline & $66.2 \%$ & $23.1 \%$ & $6.2 \%$ & $3.1 \%$ & $1.5 \%$ & $56.9 \%$ & $29.3 \%$ & $6.9 \%$ & $5.2 \%$ & $1.7 \%$ \\
\hline \multirow[t]{2}{*}{60} & 20 & 16 & 13 & 11 & 6 & 10 & 19 & 14 & 12 & 3 \\
\hline & $30.3 \%$ & $24.2 \%$ & $19.7 \%$ & $16.7 \%$ & $9.1 \%$ & $17.2 \%$ & $32.8 \%$ & $24.1 \%$ & $20.7 \%$ & $5.2 \%$ \\
\hline \multirow[t]{2}{*}{61} & 20 & 10 & 18 & 12 & 6 & 6 & 9 & 20 & 12 & 11 \\
\hline & $30.3 \%$ & $15.2 \%$ & $27.3 \%$ & $18.2 \%$ & $9.1 \%$ & $10.3 \%$ & $15.5 \%$ & $34.5 \%$ & $20.7 \%$ & $19.0 \%$ \\
\hline \multirow[t]{2}{*}{62} & 49 & 7 & 5 & 2 & 0 & 34 & 14 & 8 & 2 & 0 \\
\hline & $77.8 \%$ & $11.1 \%$ & $7.9 \%$ & $3.2 \%$ & $0.0 \%$ & $58.6 \%$ & $24.1 \%$ & $13.8 \%$ & $3.4 \%$ & $0.0 \%$ \\
\hline \multirow[t]{2}{*}{63} & 62 & 1 & 1 & 0 & 0 & 57 & 1 & 0 & 0 & 0 \\
\hline & $96.9 \%$ & $1.6 \%$ & $1.6 \%$ & $0.0 \%$ & $0.0 \%$ & $98.3 \%$ & $1.7 \%$ & $0.0 \%$ & $0.0 \%$ & $0.0 \%$ \\
\hline \multirow[t]{2}{*}{64} & 50 & 6 & 4 & 3 & 0 & 37 & 12 & 6 & 1 & 1 \\
\hline & $79.4 \%$ & $9.5 \%$ & $6.3 \%$ & $4.8 \%$ & $0.0 \%$ & $64.9 \%$ & $21.1 \%$ & $10.5 \%$ & $1.8 \%$ & $1.8 \%$ \\
\hline \multirow[t]{2}{*}{65} & 7 & 10 & 8 & 25 & 16 & 4 & 7 & 14 & 19 & 14 \\
\hline & $10.6 \%$ & $15.2 \%$ & $12.1 \%$ & $37.9 \%$ & $24.2 \%$ & $6.9 \%$ & $12.1 \%$ & $24.1 \%$ & $32.8 \%$ & $24.1 \%$ \\
\hline \multirow[t]{2}{*}{66} & 62 & 1 & 0 & 0 & 0 & 57 & 1 & 0 & 0 & 0 \\
\hline & $98.4 \%$ & $1.6 \%$ & $0.0 \%$ & $0.0 \%$ & $0.0 \%$ & $98.3 \%$ & $1.7 \%$ & $0.0 \%$ & $0.0 \%$ & $0.0 \%$ \\
\hline \multirow[t]{2}{*}{67} & 18 & 8 & 18 & 11 & 8 & 9 & 6 & 15 & 13 & 14 \\
\hline & $28.6 \%$ & $12.7 \%$ & $28.6 \%$ & $17.5 \%$ & $12.7 \%$ & $15.8 \%$ & $10.5 \%$ & $26.3 \%$ & $22.8 \%$ & $24.6 \%$ \\
\hline
\end{tabular}


Table 4c

Means and Standard Deviations of each Ethics Question by Counseling and Clinical Program

Counseling Clinical

\begin{tabular}{lcccccc}
\multicolumn{1}{c}{ Question } & $\mathrm{N}$ & $\mathrm{M}$ & $\mathrm{SD}$ & $\mathrm{N}$ & $\mathrm{M}$ & $\mathrm{SD}$ \\
\hline Ignoring strong evidence of student's cheating (Occurs) & 67 & 1.51 & 0.73 & 58 & 1.47 & 0.66 \\
Ignoring strong evidence of student's cheating & 65 & 1.18 & 0.58 & 57 & 1.23 & 0.80 \\
Dating a student (Occurs) & 67 & 1.57 & 0.78 & 58 & 1.64 & 0.77 \\
Dating a student & 66 & 1.30 & 0.50 & 58 & 1.43 & 0.68 \\
Asking small favors (such as a ride home from & & & & & & \\
students) from students (Occurs) & 67 & 2.03 & 0.92 & 58 & 2.12 & 1.04 \\
Asking small favors (such as a ride home from & & & & & & \\
students) from students & 66 & 2.85 & 1.04 & 57 & 3.11 & 1.05 \\
Hugging a student (Occurs) & 67 & 2.70 & 0.97 & 57 & 2.39 & 0.84 \\
Hugging a student & 67 & 3.10 & 1.26 & 57 & 3.09 & 0.99 \\
Accepting a student's expensive gift (Occurs) & 67 & 1.24 & 0.58 & 58 & 1.38 & 0.72 \\
Accepting a student's expensive gift & 65 & 1.62 & 0.84 & 57 & 1.84 & 0.92 \\
Teaching classes when too distressed to be effective & & & & & & \\
(Occurs) & 67 & 2.00 & 0.74 & 57 & 2.04 & 0.89 \\
Teaching classes when too distressed to be effective & 66 & 1.91 & 0.92 & 55 & 2.47 & 1.00 \\
Becoming sexually involved with a student (Occurs) & 67 & 1.36 & 0.64 & 58 & 1.53 & 0.71 \\
Becoming sexually involved with a student & 65 & 1.17 & 0.58 & 58 & 1.28 & 0.62 \\
Lending money to a student (Occurs) & 67 & 1.24 & 0.50 & 58 & 1.40 & 0.62 \\
Lending money to a student & 65 & 1.72 & 0.72 & 56 & 1.89 & 0.91 \\
Accepting a student's invitation to a party (Occurs) & 67 & 2.37 & 0.97 & 58 & 2.64 & 1.12
\end{tabular}

Note. "Occurs" question range from $1=$ never occurs to $5=$ very often. "Ethicality" questions range from $1=$ no, not ethical to $5=$ Yes, is ethical. 


\begin{tabular}{|c|c|c|c|c|c|c|}
\hline Table 4c (Con’t) & $\mathrm{N}$ & M & SD & $\mathrm{N}$ & M & SD \\
\hline Accepting a student's invitation to a party & 67 & 2.64 & 1.19 & 57 & 3.23 & 1.07 \\
\hline $\begin{array}{l}\text { Selling goods (such as a car or books to a student) to a } \\
\text { student (Occurs) }\end{array}$ & 67 & 1.43 & 0.70 & 58 & 1.64 & 0.99 \\
\hline $\begin{array}{l}\text { Selling goods (such as a car or books to a student) to a } \\
\text { student }\end{array}$ & 65 & 2.26 & 1.11 & 56 & 2.57 & 1.02 \\
\hline Being sexually attracted to a student (Occurs) & 64 & 1.97 & 1.04 & 57 & 2.09 & 1.09 \\
\hline Being sexually attracted to a student & 66 & 2.83 & 1.54 & 56 & 2.98 & 1.52 \\
\hline $\begin{array}{l}\text { Teaching material that they don't know much about } \\
\text { (Occurs) }\end{array}$ & 67 & 2.10 & 0.82 & 58 & 2.21 & 0.85 \\
\hline Teaching material that they don't know much about & 66 & 1.65 & 0.73 & 58 & 1.91 & 0.88 \\
\hline $\begin{array}{l}\text { Teaching that homosexuality is a mental sickness } \\
\text { (Occurs) }\end{array}$ & 67 & 1.03 & 0.17 & 58 & 1.03 & 0.18 \\
\hline Teaching that homosexuality is a mental sickness & 66 & 1.11 & 0.36 & 57 & 1.28 & 0.75 \\
\hline $\begin{array}{l}\text { Accepting a student's inexpensive gift (e.g., worth less } \\
\text { than \$5) (Occurs) }\end{array}$ & 67 & 2.87 & 1.06 & 58 & 2.71 & 1.20 \\
\hline $\begin{array}{l}\text { Accepting a student's inexpensive gift (e.g., worth less } \\
\text { than \$5) }\end{array}$ & 66 & 3.67 & 1.29 & 58 & 3.81 & 1.12 \\
\hline $\begin{array}{l}\text { Making deliberate or repeated sexual comments, } \\
\text { gestures, or physical contact toward a student that are } \\
\text { unwanted by the student (Occurs) }\end{array}$ & 67 & 1.34 & 0.59 & 58 & 1.22 & 0.50 \\
\hline $\begin{array}{l}\text { Making deliberate or repeated sexual comments, } \\
\text { gestures, or physical contact toward a student that are } \\
\text { unwanted by the student }\end{array}$ & 66 & 1.02 & 0.12 & 58 & 1.00 & 0.00 \\
\hline Teaching while under the influence of alcohol (Occurs) & 67 & 1.03 & 0.24 & 58 & 1.00 & 0.00 \\
\hline Teaching while under the influence of alcohol & 65 & 1.00 & 0.00 & 58 & 1.07 & 0.37 \\
\hline $\begin{array}{l}\text { Teaching that certain races are intellectually inferior } \\
\text { (Occurs) }\end{array}$ & 67 & 1.00 & 0.00 & 58 & 1.07 & 0.32 \\
\hline Teaching that certain races are intellectually inferior & 66 & 1.03 & 0.17 & 58 & 1.03 & 0.18 \\
\hline $\begin{array}{l}\text { Encouraging students to volunteer to participate in their } \\
\text { research projects as "subjects" (Occurs) }\end{array}$ & 67 & 1.63 & 0.98 & 57 & 1.63 & 0.79 \\
\hline
\end{tabular}

Note. "Occurs" question range from $1=$ never occurs to $5=$ very often. "Ethicality" questions range from $1=$ no, not ethical to $5=$ Yes, is ethical. 
Encouraging students to volunteer to participate in their research projects as "subjects"

$\begin{array}{llllll}64 & 1.89 & 1.17 & 58 & 2.05 & 1.15\end{array}$

Having students be research participants as part of a course requirement (with no alternative way of satisfying the class requirement) (Occurs)

Having students be research participants as part of a course requirement (with no alternative way of satisfying the class requirement)

$\begin{array}{llllll}66 & 1.27 & 0.65 & 57 & 1.44 & 0.80\end{array}$

Teaching while under the influence of alcohol, cocaine, or some other illegal drug (Occurs)

$\begin{array}{llllll}67 & 1.07 & 0.32 & 58 & 1.00 & 0.01\end{array}$

Teaching while under the influence of alcohol, cocaine, or some other illegal drug

$\begin{array}{llllll}66 & 1.00 & 0.01 & 58 & 1.07 & 0.37\end{array}$

Allowing how much a student is liked to influence what grade the student gets (Occurs)

$\begin{array}{llllll}66 & 2.09 & 1.03 & 57 & 2.04 & 0.87\end{array}$

Allowing how much a student is liked to influence what grade the student gets

$\begin{array}{llllll}66 & 1.15 & 0.44 & 57 & 1.19 & 0.58\end{array}$

Telling a student "I'm sexually attracted to you"

(Occurs)

$\begin{array}{llllll}67 & 1.25 & 0.61 & 58 & 1.17 & 0.50\end{array}$

Telling a student "I'm sexually attracted to you"

$\begin{array}{llllll}65 & 1.23 & 0.52 & 58 & 1.14 & 0.40\end{array}$

Using university time, funds, or resources to create a scholarly textbook then requiring it for their classes (Occurs)

$\begin{array}{llllll}67 & 1.58 & 0.89 & 58 & 1.66 & 1.02\end{array}$

Using university time, funds, or resources to create a scholarly textbook then requiring it for their classes

$\begin{array}{llllll}64 & 2.22 & 1.09 & 57 & 2.35 & 1.04\end{array}$ Assigning unpaid students to carry out work for the professors that has little educational value for the students (Occurs)

Assigning unpaid students to carry out work for the professors that has little educational value for the students

Privately tutoring students in the department for a fee (Occurs)

$\begin{array}{llllll}67 & 1.04 & 0.27 & 58 & 1.07 & 0.32\end{array}$

\begin{tabular}{llllllll} 
Privately tutoring students in the department for a fee & 64 & 1.44 & 0.79 & 57 & 1.74 & 1.04 \\
\hline
\end{tabular}

Note. "Occurs” question range from $1=$ never occurs to $5=$ very often. "Ethicality” questions range from $1=$ no, not ethical to $5=$ Yes, is ethical. 
Taking advantage of a student's offer such as getting wholesale prices at a parent's store (Occurs)

$\begin{array}{llllll}67 & 1.21 & 0.51 & 58 & 1.22 & 0.53\end{array}$

Taking advantage of a student's offer such as getting wholesale prices at a parent's store

$\begin{array}{llllll}64 & 1.83 & 1.02 & 57 & 1.95 & 1.01\end{array}$

Criticizing all theoretical approaches except those the professor personally prefers (Occurs)

$\begin{array}{llllll}67 & 1.67 & 0.81 & 58 & 2.40 & 0.99\end{array}$

Criticizing all theoretical approaches except those the professor personally prefers

$\begin{array}{llllll}66 & 1.59 & 0.99 & 58 & 1.90 & 0.99\end{array}$

Using cocaine or other illegal drugs in their personal (nonteaching) life (Occurs)

$\begin{array}{llllll}67 & 1.07 & 0.36 & 58 & 1.29 & 0.65\end{array}$

Using cocaine or other illegal drugs in their personal (nonteaching) life

$\begin{array}{llllll}64 & 1.69 & 1.01 & 57 & 2.61 & 1.28\end{array}$

Insulting or ridiculing a student in the student's

presence (Occurs)

$\begin{array}{llllll}67 & 1.55 & 0.68 & 58 & 1.88 & 0.77\end{array}$

Insulting or ridiculing a student in the student's

presence

$\begin{array}{llllll}66 & 1.23 & 0.58 & 58 & 1.31 & 0.68\end{array}$

Ignoring unethical behavior committed by their colleagues (Occurs)

$\begin{array}{llllll}67 & 1.81 & 0.91 & 58 & 2.1 & 0.97\end{array}$

Ignoring unethical behavior committed by their colleagues

$\begin{array}{llllll}66 & 1.18 & 0.52 & 58 & 1.24 & 0.47\end{array}$

Becoming sexually involved with a student after the class is over and the grades have been assigned (Occurs)

$\begin{array}{llllll}67 & 1.34 & 0.64 & 58 & 1.34 & 0.61\end{array}$

Becoming sexually involved with a student after the class is over and the grades have been assigned

$\begin{array}{llllll}65 & 1.63 & 0.88 & 58 & 1.76 & 1.03\end{array}$

Picking their favorite students to do projects with them (Occurs)

$\begin{array}{llllll}67 & 2.72 & 1.27 & 58 & 2.34 & 1.02\end{array}$

Picking their favorite students to do projects with them

$\begin{array}{llllll}67 & 2.52 & 1.24 & 58 & 2.69 & 1.10\end{array}$

Agreeing to write a recommendation letter for a student, but not getting it in until 2 weeks past the deadline (Occurs)

Agreeing to write a recommendation letter for a student, but not getting it in until 2 weeks past the deadline

$\begin{array}{llllll}65 & 1.54 & 0.89 & 57 & 1.70 & 0.89\end{array}$

Note. "Occurs” question range from $1=$ never occurs to $5=$ very often. "Ethicality” questions range from $1=$ no, not ethical to $5=$ Yes, is ethical. 
Flirting with students (Occurs)

$\begin{array}{llllll}66 & 1.71 & 1.00 & 58 & 1.84 & 0.91\end{array}$

Flirting with students

$\begin{array}{llllll}65 & 1.29 & 0.72 & 58 & 1.41 & 0.75\end{array}$

Giving every student a high grade regardless of the quality of their work (Occurs)

$\begin{array}{llllll}67 & 2.10 & 1.22 & 58 & 2.16 & 0.97\end{array}$

Giving every student a high grade regardless of the quality of their work

$\begin{array}{llllll}65 & 1.18 & 0.46 & 57 & 1.54 & 0.78\end{array}$

Setting up a course so that students are encouraged to share aspects of their very personal life in class

(Occurs)

$\begin{array}{llllll}67 & 2.06 & 0.94 & 58 & 1.98 & 0.95\end{array}$

Setting up a course so that students are encouraged to share aspects of their very personal life in class

$\begin{array}{llllll}67 & 1.81 & 1.08 & 58 & 1.60 & 0.86\end{array}$

Announcing exam grades of each student, by name, in front of the class (Occurs)

$\begin{array}{llllll}67 & 1.01 & 0.12 & 58 & 1.03 & 0.18\end{array}$

Announcing exam grades of each student, by name, in front of the class

$\begin{array}{llllll}65 & 1.15 & 0.57 & 58 & 1.21 & 0.55\end{array}$

Accepting current students as psychotherapy clients in a professor's private practice (Occurs)

$\begin{array}{llllll}67 & 1.07 & 0.40 & 58 & 1.05 & 0.22\end{array}$

Accepting current students as psychotherapy clients in a professor's private practice

$\begin{array}{llllll}65 & 1.06 & 0.39 & 58 & 1.07 & 0.32\end{array}$

Requiring students to disclose highly personal information in a group discussion class (e.g., the student who remains silent or "closed up" is graded down for that) (Occurs)

$\begin{array}{llllll}67 & 1.52 & 0.89 & 58 & 1.31 & 0.65\end{array}$

Requiring students to disclose highly personal information in a group discussion class (e.g., the student who remains silent or "closed up" is graded down for that)

$\begin{array}{llllll}67 & 1.19 & 0.50 & 58 & 1.10 & 0.31\end{array}$

Failing to periodically update class content (Occurs)

$\begin{array}{llllll}66 & 2.45 & 0.95 & 57 & 2.53 & 0.97\end{array}$

Failing to periodically update class content

$\begin{array}{llllll}65 & 1.62 & 0.78 & 57 & 2.19 & 1.13\end{array}$

Changing the criteria for successful completion of a class in the middle of the semester (e.g., adding an extra term paper or saying that something was going to count more and changing it to count less) (Occurs)

$\begin{array}{llllll}67 & 1.84 & 0.85 & 58 & 2.09 & 0.98\end{array}$

Note. "Occurs” question range from $1=$ never occurs to $5=$ very often. "Ethicality" questions range from $1=$ no, not ethical to $5=$ Yes, is ethical. 
Changing the criteria for successful completion of a class in the middle of the semester (e.g., adding an extra term paper or saying that something was going to count more and changing it to count less)

Inability to control class (e.g., too-talkative students who dominate class time are not curtailed) (Occurs)

$\begin{array}{llllll}66 & 2.06 & 0.89 & 58 & 2.05 & 0.96\end{array}$ Inability to control class (e.g., too-talkative students who dominate class time are not curtailed)

$\begin{array}{llllll}65 & 2.46 & 0.94 & 57 & 2.74 & 1.09\end{array}$ Consistently letting class out 30, or more, minutes early (Occurs)

$\begin{array}{llllll}67 & 1.96 & 0.82 & 58 & 1.84 & 0.88\end{array}$

Consistently letting class out 30, or more, minutes early $\quad \begin{array}{llllll}65 & 2.58 & 1.12 & 57 & 2.35 & 1.19\end{array}$

Writing comments on tests or assignments that are illegible (Occurs)

$\begin{array}{llllll}66 & 2.44 & 0.95 & 58 & 2.86 & 0.91\end{array}$

Writing comments on tests or assignments that are illegible

$\begin{array}{llllll}67 & 2.91 & 1.18 & 58 & 3.09 & 1.11\end{array}$

Returns assignments promptly (Occurs)

$\begin{array}{llllll}67 & 4.10 & 1.00 & 57 & 3.96 & 0.89\end{array}$

Returns assignments promptly

$\begin{array}{llllll}66 & 4.38 & 1.23 & 57 & 4.58 & 1.07\end{array}$

Letting an unqualified individual supervise your work in school or practicum (Occurs)

$\begin{array}{llllll}67 & 1.54 & 0.70 & 58 & 1.59 & 0.82\end{array}$

Letting an unqualified individual supervise your work in school or practicum

$\begin{array}{llllll}65 & 1.15 & 0.51 & 58 & 1.16 & 0.37\end{array}$

Giving testimonials in class (e.g., telling students to refer people to their private office or purchase their book) (Occurs)

Giving testimonials in class (e.g., telling students to refer people to their private office or purchase their book)

$\begin{array}{llllll}65 & 1.37 & 0.72 & 57 & 1.60 & 0.84\end{array}$

Demeaning a student publicly in class (Occurs)

$\begin{array}{llllll}67 & 1.39 & 0.63 & 58 & 1.57 & 0.65\end{array}$

Demeaning a student publicly in class

$\begin{array}{llllll}65 & 1.12 & 0.57 & 58 & 1.14 & 0.44\end{array}$

Inviting selected students to participate in a study group closed to other students (Occurs)

$\begin{array}{llllll}66 & 1.35 & 0.73 & 58 & 1.14 & 0.44\end{array}$

Inviting selected students to participate in a study group closed to other students

$\begin{array}{llllll}64 & 1.64 & 1.10 & 57 & 1.67 & 0.85\end{array}$

Note. "Occurs" question range from $1=$ never occurs to $5=$ very often. "Ethicality" questions range from $1=$ no, not ethical to $5=$ Yes, is ethical. 
$\begin{array}{llllll}\mathrm{N} & \mathrm{M} & \mathrm{SD} & \mathrm{N} & \mathrm{M} & \mathrm{SD}\end{array}$

Viewing students as being unfit for the program based

on very little evidence (Occurs)

$\begin{array}{llllll}66 & 1.38 & 0.76 & 58 & 1.53 & 0.78\end{array}$

Viewing students as being unfit for the program based on very little evidence

$\begin{array}{llllll}63 & 1.29 & 0.75 & 56 & 1.46 & 0.93\end{array}$

Using students as informants to report on the

functioning of their class members (Occurs)

$\begin{array}{llllll}66 & 1.68 & 0.90 & 58 & 1.72 & 0.87\end{array}$

Using students as informants to report on the

functioning of their class members

$\begin{array}{llllll}64 & 1.58 & 0.99 & 58 & 1.62 & 0.91\end{array}$

Encouraging students to select field placement sites (e.g., practicum/internship) for the instructor's personal benefit (Occurs)

$\begin{array}{llllll}67 & 1.21 & 0.41 & 58 & 1.28 & 0.64\end{array}$

Encouraging students to select field placement sites

(e.g., practicum/internship) for the instructor's personal benefit

$\begin{array}{llllll}64 & 1.30 & 0.73 & 57 & 1.26 & 0.61\end{array}$

Consistently being unavailable during office hours

(Occurs)

$\begin{array}{llllll}67 & 1.97 & 1.10 & 58 & 2.12 & 1.06\end{array}$

Consistently being unavailable during office hours

$\begin{array}{llllll}66 & 1.80 & 1.27 & 57 & 1.68 & 0.99\end{array}$

Consistently returning e-mails and/or phone calls to students more than a week late or not at all (Occurs)

$\begin{array}{llllll}67 & 1.94 & 0.98 & 58 & 2.28 & 0.99\end{array}$

Consistently returning e-mails and/or phone calls to students more than a week late or not at all

$\begin{array}{llllll}66 & 1.82 & 1.08 & 58 & 1.98 & 0.89\end{array}$

Frequently missing class for weather related problems when class members who have much worse driving conditions are able to attend (Occurs)

$\begin{array}{llllll}67 & 1.28 & 0.49 & 58 & 1.21 & 0.49\end{array}$

Frequently missing class for weather related problems when class members who have much worse driving conditions are able to attend

$\begin{array}{llllll}66 & 2.00 & 1.11 & 57 & 1.88 & 0.95\end{array}$

Not notifying class members in advance of their class cancellation when not in emergency situation and prior notice could have been given (Occurs)

Not notifying class members in advance of their class cancellation when not in emergency situation and prior notice could have been given

Given preference to students based on their physical appearance and/or gender (Occurs) 
$\begin{array}{llllll}\mathrm{N} & \mathrm{M} & \mathrm{SD} & \mathrm{N} & \mathrm{M} & \mathrm{SD}\end{array}$

Given preference to students based on their physical appearance and/or gender

$\begin{array}{llllll}66 & 1.21 & 0.76 & 58 & 1.07 & 0.37\end{array}$

Giving a student advice in areas in which the professor is not really qualified to offer advice (Occurs)

$\begin{array}{llllll}66 & 1.59 & 0.80 & 58 & 1.97 & 1.01\end{array}$

Giving a student advice in areas in which the professor is not really qualified to offer advice

$\begin{array}{llllll}63 & 1.59 & 0.85 & 58 & 1.72 & 0.85\end{array}$

Talking to student (in private) about another student's personal problems (Occurs)

$\begin{array}{llllll}66 & 1.77 & 0.89 & 58 & 1.84 & 0.89\end{array}$

Talking to student (in private) about another student's personal problems

$\begin{array}{llllll}65 & 1.51 & 0.87 & 58 & 1.66 & 0.95\end{array}$

Talking to students (in private) about their own personal problems (Occurs)

$\begin{array}{llllll}66 & 2.36 & 0.99 & 58 & 2.26 & 1.10\end{array}$

Talking to students (in private) about their own personal problems

$\begin{array}{llllll}66 & 2.5 & 1.33 & 58 & 2.64 & 1.15\end{array}$

Being more friendly to some students than to others

(Occurs)

$\begin{array}{llllll}66 & 2.85 & 1.27 & 58 & 3.07 & 0.95\end{array}$

Being more friendly to some students than to others

$\begin{array}{llllll}66 & 2.61 & 1.33 & 58 & 3.22 & 1.23\end{array}$

Telling "off-color" jokes in class (Occurs)

Telling "off-color" jokes in class

$\begin{array}{llllll}65 & 1.46 & 0.69 & 58 & 1.79 & 0.81\end{array}$

$\begin{array}{llllll}63 & 1.37 & 0.77 & 58 & 1.62 & 0.86\end{array}$

Taking publishing credit for work they were not involved with (Occurs)

$\begin{array}{llllll}66 & 1.27 & 0.67 & 58 & 1.40 & 0.72\end{array}$

Taking publishing credit for work they were not involved with

$\begin{array}{llllll}64 & 1.05 & 0.28 & 58 & 1.02 & 0.13\end{array}$

Demeaning a student in a faculty meeting or discussion

$\begin{array}{llllll}66 & 1.55 & 0.93 & 58 & 1.67 & 0.96\end{array}$

Demeaning a student in a faculty meeting or discussion

$\begin{array}{llllll}63 & 1.37 & 0.81 & 57 & 1.54 & 0.89\end{array}$

Occasionally 5 minutes late to class (Occurs)

$\begin{array}{llllll}66 & 2.79 & 0.81 & 58 & 2.98 & 0.93\end{array}$

Occasionally 5 minutes late to class

$\begin{array}{llllll}66 & 3.5 & 1.30 & 58 & 3.55 & 1.19\end{array}$

Plagiarizes material (Occurs)

$\begin{array}{llllll}66 & 1.06 & 0.30 & 58 & 1.14 & 0.48\end{array}$

Plagiarizes material

$\begin{array}{llllll}63 & 1.02 & 0.13 & 58 & 1.02 & 0.13\end{array}$

Occasionally unkempt in class (Occurs)

$\begin{array}{llllll}66 & 1.47 & 0.71 & 57 & 1.79 & 0.92\end{array}$

Occasionally unkempt in class

$\begin{array}{llllll}63 & 2.73 & 1.38 & 57 & 3.30 & 1.38\end{array}$

Note. "Occurs" question range from $1=$ never occurs to $5=$ very often. "Ethicality" questions range from $1=$ no, not ethical to $5=$ Yes, is ethical. 
Table 5a

Significant ANOVA's on Ethics Questions (Occurs in program) by Program (counseling vs. clinical)

\begin{tabular}{|c|c|c|c|c|}
\hline Dependent Variable & $\mathrm{F}$ & Sig. & Eta & Power \\
\hline Hugging a student & 4.10 & 0.05 & 0.04 & 0.52 \\
\hline $\begin{array}{l}\text { Criticizing all theoretical approaches except } \\
\text { those the professor personally prefers }\end{array}$ & 19.41 & 0.01 & 0.16 & 0.99 \\
\hline $\begin{array}{l}\text { Using cocaine or other illegal drugs in their } \\
\text { personal (non-teaching) life }\end{array}$ & 6.82 & 0.01 & 0.06 & 0.74 \\
\hline $\begin{array}{l}\text { Insulting or ridiculing a student in the } \\
\text { student's presence }\end{array}$ & 5.03 & 0.03 & 0.05 & 0.60 \\
\hline $\begin{array}{l}\text { Consistently returning e-mails and/or phone } \\
\text { calls to students more than a week late or } \\
\text { not at all }\end{array}$ & 5.44 & 0.02 & 0.05 & 0.64 \\
\hline $\begin{array}{l}\text { Giving a student advice in areas in which } \\
\text { the professor is not really qualified to offer } \\
\text { advice }\end{array}$ & 5.52 & 0.02 & 0.05 & 0.64 \\
\hline Telling "off-color" jokes in class & 4.22 & 0.04 & 0.04 & 0.53 \\
\hline
\end{tabular}

Note. $\mathrm{df}=1,105$.

Note. An ANOVA was calculated for each of the 67 dependent variables. Although all of the Ns reported in Table 5b indicate either 124 or 125 as the total number of participants for the two groups, the denominator degrees of freedom for these analyses of variance are less than would be expected because of the preliminary MANOVA calculation involving some participants who did not answer a small number of the questions. 
Table 5b

Means and Standard Deviations on Ethics Questions (Occurs) with Significant ANOVAs by Program

\begin{tabular}{|c|c|c|c|c|}
\hline Question & Program & $\mathrm{n}$ & M & SD \\
\hline \multirow[t]{2}{*}{ Hugging a student } & Counseling & 67 & 2.70 & 0.97 \\
\hline & Clinical & 57 & 2.39 & 0.84 \\
\hline \multirow{2}{*}{$\begin{array}{l}\text { Criticizing all theoretical approaches except those the } \\
\text { professor personally prefers }\end{array}$} & Counseling & 67 & 1.67 & 0.81 \\
\hline & Clinical & 58 & 2.40 & 0.99 \\
\hline \multirow{2}{*}{$\begin{array}{l}\text { Using cocaine or other illegal drugs in their personal } \\
\text { (nonteaching) life }\end{array}$} & Counseling & 67 & 1.07 & 0.36 \\
\hline & Clinical & 58 & 1.29 & 0.65 \\
\hline \multirow[t]{2}{*}{ Insulting or ridiculing a student in the student's presence } & Counseling & 67 & 1.55 & 0.68 \\
\hline & Clinical & 58 & 1.88 & 0.77 \\
\hline \multirow{2}{*}{$\begin{array}{l}\text { Consistently returning e-mails and/or phone calls to } \\
\text { students more than a week late or not at all }\end{array}$} & Counseling & 67 & 1.94 & 0.98 \\
\hline & Clinical & 58 & 2.28 & 0.99 \\
\hline \multirow{2}{*}{$\begin{array}{l}\text { Giving a student advice in areas in which the professor is } \\
\text { not really qualified to offer advice }\end{array}$} & Counseling & 66 & 1.59 & 0.80 \\
\hline & Clinical & 58 & 1.97 & 1.01 \\
\hline \multirow[t]{2}{*}{ Telling "off-color" jokes in class } & Counseling & 65 & 1.46 & 0.69 \\
\hline & Clinical & 58 & 1.79 & 0.81 \\
\hline
\end{tabular}


Table 6a

Significant ANOVA's on Ethics Questions (Is it ethical) by Program (counseling vs. clinical)

\begin{tabular}{l} 
Dependent Variable \\
\hline $\begin{array}{l}\text { Teaching classes when too distressed } \\
\text { to be effective }\end{array}$ \\
Accepting a student's invitation to a \\
party
\end{tabular}

Assigning unpaid students to carry out work for the professors that has little educational value for the students

Privately tutoring students in the department for a fee

Criticizing all theoretical approaches except those the professor personally prefers

Using cocaine or other illegal drugs in their personal (non-teaching) life

Agreeing to write a recommendation letter for a student, but not getting it in until 2 weeks past the deadline

Flirting with students

Giving every student a high grade regardless of the quality of their work

Failing to periodically update class content

Giving testimonials in class (e.g., telling students to refer people to their private office or purchase their book)

Being more friendly to some students than to others

Telling "off-color" jokes in class

5.25

5.76

12.14

6.99

25.52

4.61

4.11

8.91

5.92

3.92

7.39
0.05

0.04

0.51

0.01

0.11

0.93

0.05

0.04

0.50

0.01

0.21

1.00

0.03

0.05

0.57

0.05

0.04

0.52

0.01

0.09

0.84

0.02

0.06

0.67

0.05

0.04

0.50

0.01

0.07

0.77

Occasionally unkempt in class

\begin{tabular}{llll}
5.25 & 0.02 & 0.05 & 0.62 \\
5.76 & 0.02 & 0.06 & 0.66 \\
\hline
\end{tabular}

Note. $\mathrm{df}=1,96$

Note. An ANOVA was calculated for each of the 67 dependent variables. Although all of the Ns reported in Table $6 \mathrm{~b}$ indicate either 120,121, 122 or 124 as the total number of participants for the two groups, the denominator degrees of freedom for these analyses of variance are less than would be expected because of the preliminary MANOVA calculation involving some participants who did not answer a small number of the questions. 
Table 6b

Means and Standard Deviations on Ethics Questions (Ethicality) with Significant ANOVAs by Program

\begin{tabular}{|c|c|c|c|c|}
\hline Question & Program & $\mathrm{n}$ & M & SD \\
\hline \multirow{2}{*}{$\begin{array}{l}\text { Teaching classes when too distressed to be } \\
\text { effective }\end{array}$} & Counseling & 66 & 1.91 & 0.92 \\
\hline & Clinical & 55 & 2.47 & 1.00 \\
\hline \multirow[t]{2}{*}{ Accepting a student's invitation to a party } & Counseling & 67 & 2.64 & 1.19 \\
\hline & Clinical & 57 & 3.23 & 1.07 \\
\hline \multirow{2}{*}{$\begin{array}{l}\text { Assigning unpaid students to carry out work for } \\
\text { the professors that has little educational value for } \\
\text { the students }\end{array}$} & Counseling & 65 & 1.37 & 0.63 \\
\hline & Clinical & 57 & 1.77 & 0.89 \\
\hline \multirow[t]{2}{*}{$\begin{array}{l}\text { Privately tutoring students in the department for a } \\
\text { fee }\end{array}$} & Counseling & 64 & 1.44 & 0.79 \\
\hline & Clinical & 57 & 1.74 & 1.04 \\
\hline \multirow[t]{2}{*}{$\begin{array}{l}\text { Criticizing all theoretical approaches except those } \\
\text { the professor personally prefers }\end{array}$} & Counseling & 66 & 1.59 & 0.99 \\
\hline & Clinical & 58 & 1.90 & 0.99 \\
\hline \multirow[t]{2}{*}{$\begin{array}{l}\text { Using cocaine or other illegal drugs in their } \\
\text { personal (nonteaching) life }\end{array}$} & Counseling & 64 & 1.69 & 1.01 \\
\hline & Clinical & 57 & 2.61 & 1.28 \\
\hline \multirow{2}{*}{$\begin{array}{l}\text { Agreeing to write a recommendation letter for a } \\
\text { student, but not getting it in until } 2 \text { weeks past the } \\
\text { deadline }\end{array}$} & Counseling & 65 & 1.54 & 0.89 \\
\hline & Clinical & 57 & 1.70 & 0.89 \\
\hline \multirow[t]{2}{*}{ Flirting with students } & Counseling & 65 & 1.29 & 0.72 \\
\hline & Clinical & 58 & 1.41 & 0.75 \\
\hline \multirow[t]{2}{*}{$\begin{array}{l}\text { Giving every student a high grade regardless of } \\
\text { the quality of their work }\end{array}$} & Counseling & 65 & 1.18 & 0.46 \\
\hline & Clinical & 57 & 1.54 & 0.78 \\
\hline Failing to periodically update class content & $\begin{array}{c}\text { Counseling } \\
\text { Clinical }\end{array}$ & $\begin{array}{l}65 \\
57\end{array}$ & $\begin{array}{l}1.62 \\
2.19\end{array}$ & $\begin{array}{l}0.78 \\
1.13\end{array}$ \\
\hline
\end{tabular}


Table 6b (con’t)

Giving testimonials in class (e.g., telling students to refer people to their private office or purchase their book)

$\begin{array}{llll}\text { Counseling } \quad 65 & 1.37 & 0.72\end{array}$

Clinical $\quad 57 \quad 1.60 \quad 0.84$

Being more friendly to some students than to others

$\begin{array}{llll}\text { Counseling } & 66 & 2.61 & 1.33\end{array}$

$\begin{array}{llll}\text { Clinical } \quad 58 & 3.22 & 1.23\end{array}$

Telling "off-color" jokes in class

$\begin{array}{llll}\text { Counseling } \quad 63 & 1.37 & 0.77\end{array}$

$\begin{array}{llll}\text { Clinical } \quad 58 & 1.62 & 0.86\end{array}$

Occasionally unkempt in class

$\begin{array}{llll}\text { Counseling } \quad 63 \quad 2.73 & 1.38\end{array}$

Clinical $\quad 57 \quad 3.30 \quad 1.38$ 
Table 7a

Significant ANOVA's on Ethics Questions (Occurs in program) by APA Accreditation (Yes vs. No)

\begin{tabular}{lcccc}
\hline Dependent Variable & F & Sig. & Eta & Power \\
\hline $\begin{array}{l}\text { Assigning unpaid students to carry out } \\
\begin{array}{l}\text { work for the professors that has little } \\
\text { educational value for the students }\end{array}\end{array}$ & 5.40 & 0.02 & 0.05 & 0.63 \\
$\begin{array}{l}\text { Consistently letting class out 30, or } \\
\text { more, minutes early }\end{array}$ & 7.50 & 0.01 & 0.07 & 0.78 \\
\hline
\end{tabular}

Note. $\mathrm{df}=1,105$.

Note. An ANOVA was calculated for each of the 67 dependent variables. Although all of the Ns reported in Table 7b indicate either 122 or 125 as the total number of participants for the two groups, the denominator degrees of freedom for these analyses of variance are less than would be expected because of the preliminary MANOVA calculation involving some participants who did not answer a small number of the questions. 
Table 7b

Means and Standard Deviations on Ethics Questions (Occurs in program) with Significant ANOVAs by APA Accreditation Status (Yes vs. No)

\begin{tabular}{lccccc}
\hline \multicolumn{1}{c}{ Question } & Accredited & N & M & SD \\
\hline Assigning unpaid students to carry out work for the & Yes & 104 & 1.92 & 1.02 \\
professors that has little educational value for the students & No & 18 & 1.26 & 0.65 \\
& & & & \\
Consistently letting class out 30, or more, minutes early & Yes & 106 & 1.84 & 0.83 \\
& No & 19 & 2.26 & 0.87 \\
\hline
\end{tabular}


Table 8a

Significant ANOVA's on Ethics Questions (Is it ethical) by APA Accreditation (Yes vs. No)

\begin{tabular}{lcccc}
\hline Dependent Variable & F & Sig. & Eta & Power \\
\hline Accepting a student's expensive gift & 4.84 & 0.03 & 0.05 & 0.59 \\
$\begin{array}{l}\text { Teaching classes when too distressed } \\
\text { to be effective }\end{array}$ & 4.73 & 0.03 & 0.05 & 0.58 \\
& & & & \\
Dating a student & 5.34 & .026 & 0.02 & 0.31 \\
$\begin{array}{l}\text { Having students participate in research } \\
\text { Announcing exam grades }\end{array}$ & 7.65 & .007 & 0.02 & 0.28 \\
& 12.82 & .001 & 0.02 & 0.28 \\
Plagiarizes material & & & & \\
\hline
\end{tabular}

Note. $\mathrm{df}=1,96$.

Note. An ANOVA was calculated for each of the 67 dependent variables. Although all of the Ns reported in Table 8b indicate either 121 or 122 as the total number of participants for the two groups, the denominator degrees of freedom for these analyses of variance are less than would be expected because of the preliminary MANOVA calculation involving some participants who did not answer a small number of the questions. 
Table 8b

Means and Standard Deviations on Ethics Questions (Is it ethical) with Significant ANOVAs by APA Accreditation Status (Yes vs. No)

\begin{tabular}{llrrr}
\hline \multicolumn{1}{c}{ Question } & Accredited & $\mathrm{N}$ & $\mathrm{M}$ & $\mathrm{SD}$ \\
\hline Accepting a student's expensive gift & Yes & 104 & 1.80 & 0.92 \\
& No & 18 & 1.28 & 0.46 \\
Teaching classes when too distressed to be effective & Yes & 103 & 2.22 & 0.97 \\
& No & 18 & 1.83 & 1.10 \\
& & & & \\
Dating a student & Yes & 103 & 1.40 & 0.61 \\
& No & 18 & 1.16 & 0.38 \\
Having students participate in research & & & & \\
& Yes & 103 & 1.39 & 0.77 \\
Announcing exam grades & No & 18 & 1.11 & 0.32 \\
& & & & \\
& Yes & 103 & 1.21 & 0.60 \\
Plagiarizes material & No & 18 & 1.00 & 0.01 \\
& & & & \\
& Yes & 104 & 1.01 & 0.10 \\
& No & 17 & 1.06 & 0.24 \\
\hline
\end{tabular}


Table 9a

Significant ANOVA's on Ethics Questions (Occurs in program) by Ethics Courses Taken (Yes vs. No)

\begin{tabular}{|c|c|c|c|c|}
\hline Question & $\mathrm{F}$ & Sig. & Eta & Power \\
\hline Hugging a student & 9.18 & 0.01 & 0.08 & 0.85 \\
\hline Using cocaine & 14.22 & 0.01 & 0.01 & 0.20 \\
\hline Frequently missed class & 5.84 & 0.04 & 0.01 & 0.80 \\
\hline $\begin{array}{l}\text { Inability to control class (e.g., too-talkative students who } \\
\text { dominate class time are not curtailed) }\end{array}$ & 6.46 & 0.01 & 0.06 & 0.71 \\
\hline $\begin{array}{l}\text { Giving testimonials in class (e.g., telling students to refer } \\
\text { people to their private office or purchase their book) }\end{array}$ & 3.99 & 0.05 & 0.04 & 0.51 \\
\hline
\end{tabular}

Note. $\mathrm{df}=1,105$.

Note. An ANOVA was calculated for each of the 67 dependent variables. Although all of the Ns reported in Table 9b indicate either 124 or 125 as the total number of participants for the two groups, the denominator degrees of freedom for these analyses of variance are less than would be expected because of the preliminary MANOVA calculation involving some participants who did not answer a small number of the questions. 
Table 9b

Means and Standard Deviations on Ethics Questions (Occurs in program) with Significant ANOVAs by Ethics Courses Taken (Yes vs. No)

\begin{tabular}{llrrr}
\hline \multicolumn{1}{c}{ Behavior } & Classes & $\mathrm{n}$ & $\mathrm{M}$ & SD \\
\hline Hugging a student & Yes & 110 & 2.49 & 0.93 \\
& No & 14 & 3.07 & 0.73 \\
& & & & \\
Using cocaine or other illegal drugs in their personal life & Yes & 111 & 1.20 & 0.55 \\
& No & 14 & 1.00 & 0.01 \\
& & & & \\
Frequently missed class & Yes & 111 & 1.27 & 0.50 \\
& No & 14 & 1.07 & 0.27 \\
& & & & \\
Inability to control class (e.g., too-talkative students who & Yes & 110 & 1.97 & 0.88 \\
dominate class time are not curtailed) & No & 14 & 2.71 & 0.99 \\
& & & & \\
Giving testimonials in class (e.g., telling students to refer & & & & \\
people to their private office or purchase their book) & Yes & 111 & 1.23 & 0.58 \\
& No & 14 & 1.57 & 0.94
\end{tabular}


Table 10a

Significant ANOVA's on Ethics Questions (Is it ethical) by Ethics Courses Taken (Yes vs. No)

\section{Behavior}

Having students be research participants as part of a course requirement (with no alternative way of satisfying the class requirement)

Flirting with students

Giving every student a high grade regardless of the quality of their work

Returns assignments promptly

Giving testimonials in class (e.g., telling students to refer people to their private office or purchase their book)

Demeaning a student publicly in class

Consistently returning e-mails and/or phone calls to students more than a week late or not at all

Not notifying class members in advance of their class cancellation when not in emergency situation and prior notice could have been given

\section{F Sig. Eta Power}

$\begin{array}{llll}4.30 & 0.04 & 0.04 & 0.54\end{array}$

$\begin{array}{llll}6.46 & 0.01 & 0.06 & 0.71\end{array}$

$\begin{array}{llll}6.01 & 0.02 & 0.06 & 0.68\end{array}$

$\begin{array}{llll}10.21 & 0.01 & 0.10 & 0.89\end{array}$

$\begin{array}{llll}21.90 & 0.01 & 0.19 & 1.00\end{array}$

$\begin{array}{llll}6.13 & 0.02 & 0.06 & 0.69\end{array}$

$\begin{array}{llll}4.74 & 0.03 & 0.05 & 0.58\end{array}$

Note. $\mathrm{df}=1,96$.

Note. An ANOVA was calculated for each of the 67 dependent variables. Although all of the Ns reported in Table 10b indicate either 122, 123 or 124 as the total number of participants for the two groups, the denominator degrees of freedom for these analyses of variance are less than would be expected because of the preliminary MANOVA calculation involving some participants who did not answer a small number of the questions. 
Table 10b

Means and Standard Deviations on Ethics Questions (Is it ethical) with Significant ANOVAs by Ethics Courses Taken (Yes vs. No)

\begin{tabular}{|c|c|c|c|c|}
\hline Behavior & & $\mathrm{n}$ & M & SD \\
\hline $\begin{array}{l}\text { Having students be research participants as part of a course } \\
\text { requirement (with no alternative way of satisfying the class } \\
\text { requirement) }\end{array}$ & $\begin{array}{l}\text { Yes } \\
\text { No }\end{array}$ & $\begin{array}{c}110 \\
13\end{array}$ & $\begin{array}{l}1.31 \\
1.69\end{array}$ & $\begin{array}{l}0.70 \\
0.86\end{array}$ \\
\hline Flirting with students & $\begin{array}{l}\text { Yes } \\
\text { No }\end{array}$ & $\begin{array}{c}109 \\
14\end{array}$ & $\begin{array}{l}1.31 \\
1.64\end{array}$ & $\begin{array}{l}0.70 \\
0.93\end{array}$ \\
\hline $\begin{array}{l}\text { Giving every student a high grade regardless of the quality of } \\
\text { their work }\end{array}$ & $\begin{array}{l}\text { Yes } \\
\text { No }\end{array}$ & $\begin{array}{c}108 \\
14\end{array}$ & $\begin{array}{l}1.30 \\
1.79\end{array}$ & $\begin{array}{l}0.63 \\
0.70\end{array}$ \\
\hline Returns assignments promptly & $\begin{array}{l}\text { Yes } \\
\text { No }\end{array}$ & $\begin{array}{c}109 \\
14\end{array}$ & $\begin{array}{l}4.56 \\
3.79\end{array}$ & $\begin{array}{l}1.10 \\
1.37\end{array}$ \\
\hline
\end{tabular}

Giving testimonials in class (e.g., telling students to refer people $\quad$ Yes $109 \quad \begin{array}{lll}1.38 & 0.70\end{array}$ to their private office or purchase their book)

Demeaning a student publicly in class

Yes $\quad \begin{array}{lll}109 & 1.06 & 0.31\end{array}$

No $14 \quad 1.64 \quad 1.15$

Consistently returning e-mails and/or phone calls to students more than a week late or not at all

Yes $110 \quad 1.80 \quad 0.95$

No $\quad 14 \quad 2.64 \quad 1.08$

Not notifying class members in advance of their class

Yes $109 \quad 1.851 .01$

cancellation when not in a emergency situation and prior notice

No $\quad 14 \quad 2.36 \quad 1.08$

could have been given 
Table 11a

Significant ANOVAs on Matched Categories (Is it ethical) by program (Clinical vs. Counseling).

\begin{tabular}{lcccc}
\hline Variable & F & Sig. & Eta & Power \\
\hline $\begin{array}{l}\text { Competence/ } \\
\text { impairment }\end{array}$ & 7.56 & 0.01 & 0.07 & 0.78 \\
$\begin{array}{l}\text { Unprofessional } \\
\text { Behavior }\end{array}$ & 7.09 & 0.01 & 0.07 & 0.75 \\
\hline
\end{tabular}

Note. $\mathrm{df}=1,97$. 
Table 11b

Means and Standard Deviations on Competence/impairment and Unprofessional Behavior Composite Scores (Is it ethical) with Significant ANOVAs by Program

\begin{tabular}{llccc}
\hline Variable & Field & M & SD & $\mathrm{n}$ \\
\hline Competence/ & Counseling & 1.49 & 0.28 & 54 \\
impairment & Clinical & 1.68 & 0.39 & 45 \\
& & & & \\
Unprofessional & Counseling & 2.22 & 0.45 & 54 \\
Behavior & Clinical & 2.50 & 0.62 & 45 \\
\hline
\end{tabular}


Table 12a

Significant ANOVAs on Matched Categories (Is it ethical) by APA Accreditation Status (Yes vs. No).

\begin{tabular}{lcccc}
\hline Variable & F & Sig. & Eta & Power \\
\hline $\begin{array}{l}\text { Multile } \\
\begin{array}{l}\text { Relationships- } \\
\text { non-sexual }\end{array}\end{array}$ & 1.48 & 0.04 & 0.04 & 0.53 \\
\hline
\end{tabular}

Note. $\mathrm{df}=1,97$. 
Table 12b

Means and Standard Deviations on Composite Scores with Significant ANOVAs by APA Accreditation Status (Yes vs. No)

\begin{tabular}{llccc}
\hline Variable & $\begin{array}{l}\text { APA } \\
\text { Accreditation }\end{array}$ & M & SD & N \\
\hline $\begin{array}{l}\text { Multiple } \\
\text { Relationships } \\
\text {-non-sexual }\end{array}$ & Yes & 2.00 & 0.41 & 84 \\
\hline
\end{tabular}


Table 13a

Significant ANOVAs on Matched Categories (Is it ethical) by Ethics Courses Taken (Yes vs. No).

\begin{tabular}{lcccc}
\hline Variable & F & Sig. & Eta & Power \\
\hline $\begin{array}{l}\text { Multiple } \\
\begin{array}{l}\text { Relationships- } \\
\text { non-sexual }\end{array}\end{array}$ & 4.65 & 0.03 & 0.05 & 0.57 \\
$\begin{array}{l}\text { Multiple } \\
\begin{array}{l}\text { Relationships- } \\
\text { sexual }\end{array}\end{array}$ & 15.25 & 0.01 & 0.14 & 0.97 \\
& & & & \\
$\begin{array}{l}\text { Competence/ } \\
\text { impairment }\end{array}$ & 5.01 & 0.03 & 0.05 & 0.60 \\
\hline
\end{tabular}

Note. $\mathrm{df}=1,97$. 
Table 13b

Means and Standard Deviations on Composite Scores with Significant ANOVAs by Ethic Courses Taken (Yes vs. No)

\begin{tabular}{lllll}
\hline Variable & $\begin{array}{l}\text { Took an ethics } \\
\text { course }\end{array}$ & $\mathrm{M}$ & $\mathrm{SD}$ & $\mathrm{N}$ \\
\hline Multiple & Yes & 1.94 & 0.41 & 89 \\
$\begin{array}{l}\text { Relationships } \\
\text { non-sexual }\end{array}$ & No & 2.23 & 0.46 & 10 \\
Multiple & Yes & & & \\
Relationships & No & 1.22 & 0.27 & 89 \\
-sexual & & 1.59 & 0.39 & 10 \\
Competence/ & Yes & & & \\
impairment & No & 1.55 & 0.33 & 89 \\
& & 1.80 & 0.39 & 10 \\
\hline
\end{tabular}


Table 14a

Means and Standard Deviations of the top 10 Ethics Behaviors (Occurs in program) ranked by Counseling Psychology Students

\begin{tabular}{llll}
\hline Question & N & M & SD \\
\hline Returns assignments promptly & 67 & 4.10 & 1.00 \\
Accepting a students' inexpensive gift (e.g., worth less than \$5) & 67 & 2.87 & 1.06 \\
Being more friendly to some students than to others & 66 & 2.85 & 3.07 \\
Occasionally 5 minutes late to class & 66 & 2.79 & 0.81 \\
Picking their favorite students to do projects with them & 67 & 2.72 & 1.27 \\
Hugging a student & 67 & 2.70 & 0.97 \\
Accepting a student's invitation to a party & 67 & 2.37 & 0.97 \\
Talking to students (in private) about their own personal problems & 66 & 2.36 & 0.99 \\
Failing to periodically update class content & 66 & 2.45 & 0.95 \\
Writing comments on tests or assignments that are illegible & 66 & 2.44 & 0.95 \\
\hline
\end{tabular}

Note. "Occurs” questions range from $1=$ never occurs to $5=$ very often. 
Table 14b

Means and Standard Deviations of the top 10 Ethics Behaviors (Is it ethical) ranked by Counseling Psychology Students

Question

$\mathrm{N} \quad \mathrm{M} \quad \mathrm{SD}$

Teaching while under the influence of alcohol

$65 \quad 1.00 \quad 0.01$

Teaching while under the influence of alcohol, cocaine, or some other illegal drug

$66 \quad 1.00 \quad 0.01$

Making deliberate or repeated sexual comments, gestures, or physical contact toward a student that are unwanted by the student

Plagiarizes material

$63 \quad 1.02 \quad 0.13$

Teaching that certain races are intellectually inferior

$66 \quad 1.03 \quad 0.17$

Taking publishing credit for work they were not involved with

$64 \quad 1.05 \quad 0.28$

Accepting current students as psychotherapy clients in a professor's private practice

$65 \quad 1.06 \quad 0.39$

Teaching that homosexuality is a mental sickness

$66 \quad 1.11 \quad 0.36$

Allowing how much a student is liked to influence what grade the student gets

$66 \quad 1.15 \quad 0.44$

Announcing exam grades of each student, by name, in front of 65 $1.15 \quad 0.57$ the class

Note. "Ethicality" questions range from 1=no, not ethical to 5=yes, is ethical. 
Table 15a

Means and Standard Deviations of the top 10 Ethics Behaviors (Occurs in program) ranked by Clinical Psychology Students

\begin{tabular}{|c|c|c|c|}
\hline Question & $\mathrm{N}$ & M & SD \\
\hline Returns assignments promptly & 57 & 3.96 & 0.89 \\
\hline Being more friendly to some students than to others & 58 & 3.07 & 0.95 \\
\hline Occasionally 5 minutes late to class & 58 & 2.98 & 0.93 \\
\hline Writing comments on tests or assignments that are illegible & 58 & 2.86 & 0.91 \\
\hline Accepting a student's inexpensive gift (e.g., worth less than \$5) & 58 & 2.71 & 1.20 \\
\hline Accepting a student's invitation to a party & 58 & 2.64 & 1.12 \\
\hline Failing to periodically update class content & 57 & 2.53 & 0.97 \\
\hline $\begin{array}{l}\text { Criticizing all theoretical approaches except those the professor } \\
\text { personally prefers }\end{array}$ & 58 & 2.40 & 0.99 \\
\hline $\begin{array}{l}\text { Consistently returning e-mail and/or phone calls to students } \\
\text { more than a week late or not at all }\end{array}$ & 58 & 2.28 & 0.99 \\
\hline Talking to students (in private) about their own personal problem & 58 & 2.26 & 1.10 \\
\hline
\end{tabular}


Table 15b

Means and Standard Deviations of the top 10 Ethics Behaviors (Is it ethical) ranked by Clinical Psychology Students

Question

$\mathrm{N} \quad \mathrm{M} \quad \mathrm{SD}$

Making deliberate or repeated sexual comments, gestures, or physical contact toward a student that are unwanted by

$58 \quad 1.00 \quad 0.01$ the student

Taking publishing credit for work they were not involved with

$58 \quad 1.02 \quad 0.13$

Plagiarizes material

$58 \quad 1.02 \quad 0.13$

Accepting current students as psychotherapy clients in a

$58 \quad 1.07 \quad 0.32$

professor's private practice

Teaching while under the influence of alcohol, cocaine, or some other illegal drug

$58 \quad 1.07 \quad 0.37$

Teaching while under the influence of alcohol

$\begin{array}{lll}58 & 1.07 & 0.37\end{array}$

Given preference to students based on their physical appearance and/or gender

$\begin{array}{lll}58 & 1.07 & 0.37\end{array}$

Requiring students to disclose highly personal information in a

$58 \quad 1.10 \quad 0.31$

group discussion class (e.g., the student who remains silent or "closed up" is graded down for that)

Demeaning a student publicly in class

$58 \quad 1.14 \quad 0.44$

Letting an unqualified individual supervise your work in $58 \quad 1.16 \quad 0.37$ school or practicum

Note. "Ethicality" questions range from 1=no, not ethical to 5=yes, is ethical. 


\section{CHAPTER IV}

\section{Discussion and Limitations of the Study}

\section{Discussion and Implications of Research Findings}

In order to structure the discussion section, relevant findings are presented under each of the eight research questions. The remaining questions (\#9-11) which were presented in the additional analyses section of this document were not significant and not primary to the study. They are, therefore, not being discussed. Reasons for nonsignificance are similar to those discussed for previous non-significant results. Research Question \#1

Although no hypotheses were made for research question number one it was expected that doctoral students, with regard to the 67 behaviors listed on the survey, would find that most of the behaviors "never" or "rarely" occur. Results listed in Table 4a on page 48 reiterate this point. Most of the doctoral students in this study (90\% or more) responded "never” to whether or not they perceive the members of their department faculty engaged in: Announcing exam grades of each student, by name, in front of the class (97.6\%); teaching while under the influence of alcohol, cocaine, or some other illegal drug (96.8\%); teaching that homosexuality is a mental sickness (96.8\%); privately tutoring students in the department for a fee (96.0\%); accepting current students as psychotherapy clients in a professor’s private practice (95.2\%); and plagiarizing material (92.7\%).

Although many of the questions that are considered clearly unethical were rarely endorsed as occurring in either clinical or counseling psychology programs, nevertheless, there are areas that need improvement. This is particularly true of items relating to sexual 
or dating contact with students which were endorsed by approximately one third of the students. When these two categories were compared with the results of the Tabachnick, Keith-Spiegel and Pope's (1991) study of the beliefs and behaviors of psychologists as educators, response frequencies were considerably lower. There are a number of factors that may account for the differences.

First, the Tabachnick et al., 1991 study reported the responses of faculty members not students. These perceptions by the nature of their origin can be expected to be different. Faculty, reporting on their own behavior, may be more accurate (Stone, Turkkan, Bachrach, Jobe, Kurtzman \& Lain, 2000). Presently, their ethical shortcomings are compared to students who may have heard about the behavior second or third hand. Second, the faculty studied were different in the Tabachnick et al., 1991 study as compared to this study. For example, of Tabachnick and colleague’s (1991) sample of 482 APA members, whose primary work setting is in an institution of higher education, $46.5 \%$ of their primary teaching setting was in a PhD granting department, $21.4 \%$ in a department granting an MA, 21.4\% in a 4-year college, 6.6\% was in a medical school, $3.3 \%$ in a 2-year college; and $0.8 \%$ other. Since less than half of the faculty who completed the survey items taught at the doctoral level, they may not be comparable to the faculty in the current study.

Another difference between their study and the current study was that the respondents of the Tabachnick et al., 1991 study were educators whose primary specialties in psychology were as follows: Clinical (23.6\%), experimental (17.7\%), social (16.3\%), developmental/aging (14.0\%), counseling (8.6\%), industrial/organization/ human factors (5.6\%), educational (3.3\%), physiological and related (2.9\%), personality 
(2.3\%), school (1.7\%), other (4.0\%), and no answer (0.6). Since less than $1 / 3$ of the faculty were clinical or counseling faculty, comparing results is difficult.

History is also a factor that needs to be considered when considering the differences found between the current study and the Tabachnick et al., 1991 study. For example, with the continuing expansion and emphasis on psychology ethics, it is likely that psychology professors today are more aware of what constitutes unethical behavior and more aware of the negative consequences of serious ethical violations.

\section{Research Question \#2}

Although no hypotheses were made for research question two is was expected that doctoral students, with regard to the 67 behaviors listed in the survey, would find that most of the behaviors are not ethical or are ethical "under rare circumstances." The majority of doctoral students (90\% or more) responded "no" to whether or not the following behaviors, which were also included in the Tabachnick et al., 1991 study are ethical: Making deliberate or repeated sexual comments, gestures or physical contact toward a student that are unwanted by the student (99.2\%); teaching while under the influence of alcohol, cocaine, or some other illegal drug (98.4); teaching under the influence of alcohol (98.4\%) and; teaching that certain races are intellectually inferior (96.8\%). When compared to Tabachnick, Keith-Spiegel and Pope’s (1991) student of the beliefs and behaviors of psychologist as educators, response frequencies were consistently lower on the same questions. There are a number of factors that may account for these differences.

First, the Tabachnick et al., 1991 study the reports are from faculty about their behavior, not from students about the behavior of their faculty. Second, the faculty 
members studied in the Tabachnick et al., 1991 study were different in that the educators' work settings and specialties in psychology were different from the current study. Third, since fewer students were at doctoral level in the Tabachnick et al., 1991 study they may not have the same level of knowledge regarding the ethical appropriateness of the behaviors listed on the survey when compared to the doctoral students in the current study. Fourth, historical differences may also be impacting the differences between the views of educators in 1991 when compared to the respondents of the current study in 2004. Currently, both students and faculty are more sensitive to a variety of issues including dual relationships, competence and differences among individuals from various ethnic and racial backgrounds.

The majority (90\% or more) of doctoral students also responded "no" to whether or not the following behaviors are ethical: Plagiarizing material (98.3\%); taking publishing credit for work they were not involved with (97.5\%); accepting current students as psychotherapy clients in a professor’s private practice (95.9\%); giving preference to students based on their physical appearance and/or gender (93.5\%) and; demeaning a student publicly in class (91.9\%). Tabachnick and colleagues (1991) did not use these specific questions in their survey so comparison data was not available.

Future research should include more questions on unethical behavior as well as clearly stated ethical behavior. The survey used for this study was adapted from KeithSpiegel and colleague's (1993) study of students' view of their undergraduate professors' ethical behavior. Although this survey has been used in several similar studies, many of the questions listed on the survey ask about behaviors that are unprofessional but not unethical. More specifically, questions that are unprofessional should be reduced with an 
increase in questions about cultural diversity and research. Categories of behaviors that are sufficiently covered in the survey are multiple relationships (sexual and non-sexual) and competence/impairment.

In light of the responses in Table $4 \mathrm{~b}$ on pages 53-57, this researcher suggests that faculty spend more time teaching their students the difference between ethical, unethical, and unprofessional behavior. On the majority of survey questions that were unprofessional in nature, participants frequently responded with “don’t know/not sure.” Instructors could present students with various behaviors and scenarios to identify during their ethics training to help students better distinguish the difference between these types of behavior.

\section{Research Question \#3}

A possible explanation for the lack of significance on research question three is that there are not enough questions on the survey that relate to cultural issues. There are only two questions that relate to cultural diversity on the survey, so students may have had other experiences to which they did not have the opportunity to respond. It may also be that there are no differences between the programs on this issue. Future research should include a variety of questions that touch upon multicultural issues.

The question with the biggest disparity between mean scores on the occurrence scale was “criticizing all theoretical approaches except those the professor personally prefers” (Counseling=1.67 vs. Clinical $=2.40$ ). This may indicate, as Bechtoldt and colleagues (2000) have stated, that the two programs identify with the orientation they are typically associated (Counseling $=$ Client-centered and humanistic vs. Clinical $=$ behavioral and psychoanalytic). Bechtoldt and colleagues (2000) also reported that both 
programs embrace an eclectic/integrative orientation and cognitive orientation, $29 \%$ and 26\%, respectively. Therefore, another possibility may be that both clinical and counseling programs have become more similar with regard to their theoretical orientation. It is impossible to come to a definitive conclusion without knowing the theoretical orientation to which the students in the current study were referring to.

Future research should include the survey questions on which the counseling psychology and clinical psychology students had significant differences. Further, counseling psychology students responded that "hugging a student” occurs more frequently in their program than in clinical programs. This leads to the question, in what type of environment are doctoral students training. Future research could include an additional question in the demographic section that states, how would you categorize the atmosphere of your doctoral program. Responses could include safe, supportive, collegial, competitive or unsafe. Additionally, another question could inquire into the theoretical orientations of the faculty. This will help to clarify if these programs are more similar or dissimilar in this respect.

\section{Research Question \#4}

Although there was no evidence to support the hypothesis for research question number four, statistically significant differences between clinical psychology students and counseling psychology doctoral students were revealed. It is difficult to understand why clinical students would rate the 14 behaviors in Table $6 \mathrm{~b}$ as more ethical then counseling students. It may be that counseling students were too conservative when rating the ethicality of unethical behaviors. Perhaps the moral development and characteristics of clinical students is different from counseling students. Another 
explanation may be that clinical faculty are less conservative and more liberal in their interpretation and instruction regarding the "ethicality" of certain behaviors. Further research regarding the differences between clinical and counseling programs is needed. Specifically, differences that need to be investigated are the characteristics of psychology educators, their students, and their types of instruction.

\section{Research Question \#5}

The primary hypothesis with regard to APA accreditation, on research question number five, was that students who are enrolled in APA accredited doctoral programs would have a higher report rate across all behaviors on the survey when compared to students in non-accredited doctoral programs. The reasoning behind the hypothesis was that students in accredited psychology programs may be receiving better training, and therefore would be better able to identify unethical behavior in their program.

Results reveal two significant differences (Tables 7a and 7b on pages 71-72). For the question "Assigning unpaid students to carry out work for the professors that has little educational value for the students," respondents from APA accredited programs state that it occurs more frequently in their programs when compared to non-accredited programs. For the question "consistently letting class out 30, or more, minutes early," respondents from non-accredited programs state that it occurs more frequently in their programs.

Mean responses for both questions on the "occurs scale" (1=never, $2=$ rarely, $3=$ sometimes, $4=$ fairly often and $5=$ very often) reveal that these behaviors are perceived to occur "never" or "rarely." These results indicate that despite the two significant differences, students in both APA accredited and non-accredited psychology programs 
perceive that their professors are more similar than dissimilar with regard to the 67 behaviors listed on the survey. There is too little available evidence to speculate on the differences on these two items.

Future quantitative research on this difference between accredited and nonaccredited programs with respect to the frequency of unethical or inappropriate professional behavior may be difficult with only 5 counseling psychology and 13 clinical psychology doctoral programs being non-accredited. Perhaps more qualitative analyses can contribute to the research in this area.

Research Question \#6

The primary hypothesis with regard to APA accreditation, on research question number six, was that students who are enrolled in APA accredited doctoral programs would rate the behaviors on the survey less ethical when compared to students in nonaccredited doctoral programs. With the exception of "plagiarizes material," the converse of this hypothesis was proven to be true (Tables $8 \mathrm{a}$ and $8 \mathrm{~b}$ on pages 73-74). Students enrolled in APA accredited programs rate the following behaviors as more ethical than their non-accredited counterparts: Accepting a student’s expensive gift, teaching classes when too distressed to be effective, dating a student, having students participate in research and announcing exam grades. Plagiarizing material was rated as slightly more ethical in non-accredited programs. Despite these differences it should be noted that doctoral students' from both APA accredited and non-accredited programs rate the ethicality of the survey behaviors very low. Therefore, even though there are differences, they have little significance since they are being rated appropriately and accurately with regard to their "ethicality." 
The mean scores for the survey behaviors listed in Table 8b did not exceed "no" on the “ethicality scale” (1=no, 2=under rare circumstances, 3=don’t know/not sure, 4= under most circumstances and 5=yes) with the exception of "teaching classes when too distressed to be effective”. This indicates that students, regardless of their program’s APA accreditation status, have adequate knowledge when deciding the ethicality of the behaviors listed on the survey.

This may be in part, due to results that the vast majority of respondents had or will complete an ethics course. Ninety-two point eight percent of respondents’ programs in the current study required one, and $88.8 \%$ had already completed an ethics course. Thus, the majority of doctoral students are receiving some type of ethics training, with the majority taking a separate course in ethics. Only 4 (3.2\%) of this sample state that they did not have knowledge of ethics, while 121 (96.8\%) state they do. Respondents also reported that, with regard to educational experiences in ethics, material is integrated into class discussions, clinical supervision, and colloquia.

For future research a better question with regard to APA accreditation would be, what is the status of your program's accreditation. Responses could include nonaccredited, recently lost accreditation, working toward accreditation, and accredited. By having this question in the demographic section, it will allow for a more accurate view of the status of psychology doctoral programs and how that status may or may not be impacting ethics training.

\section{Research Question \#7}

The primary hypothesis, for research question number seven, was that students who have taken a separate course in ethics in their doctoral program would have a higher 
report rate across all behaviors when compared to students who have not. Except for "hugging a student," which the mean response on the "occurrence scale" (1=never, $2=$ rarely, 3 =sometimes, $4=$ fairly often and 5=very often) was "sometimes," the mean responses on the other behaviors listed in Table 9b did not exceed "rarely." Although there are statistically significant differences between those who have had a separate course in ethics and those who have not, the mean response rate of the behaviors continue to follow a trend that indicate the 67 behaviors on the survey "never" or "rarely" occur. In fact, there is little reason to speculate on the differences that do exist since students who have completed a separate course in ethics, and those who have not, both perceive unethical behaviors to "never" or "rarely" occur in their program.

\section{Research Question \#8}

The primary hypothesis, for research question number eight, was that students who have taken a separate course in ethics in their doctoral program, would rate the behaviors on the survey less ethical when compared to students who have not had a separate course in ethics. Univariate ANOVAs reveal eight statistically significant differences (Tables 10a and 10b on pages 77-78). Respondents who have not taken a separate course in ethics rated the following behaviors as more ethical: Having students be research participants as part of a course requirement (with no alternative way of satisfying the class requirement); flirting with students; giving every student a high grade regardless of the quality of their work; giving testimonials in class (e.g., telling students to refer people to their private office or purchase their book); demeaning a student publicly in class; consistently returning e-mails and/or phone calls to students more than 
a week late or not at all; and not notifying class members in advance of their class cancellation when not in a emergency situation and prior notice could have been given. Mean responses on the "ethically scale” (1=no, 2=under rare circumstances, 3=don't know/not sure, 4= under most circumstances and 5=yes) reveal that the survey behaviors were rated accurately, and continue to follow a trend that indicate the majority of the 67 behaviors on the survey are not ethical or are ethical "under rare circumstances.”

Themes were found among the respondents' ranked responses of which survey behaviors occur most frequently, and which were perceived to be the most unethical (Tables 14a-15b on pages 85-88). Clinical and counseling psychology students acknowledge that of the 10 highest ranked survey behaviors eight occur in both programs. The behavior ranked as occurring most frequently in both programs (returns assignments promptly) indicates ethical and appropriate behavior with regard to returning assignments by faculty in this sample. Other behaviors ranked by both counseling and clinical psychology students are categorized as unprofessional and did not exceed "rarely" on the likert scale. The four survey behaviors not ranked by both programs (picking their favorite students to do projects with them; hugging a student; criticizing all theoretical approaches except those the professor personally prefers; and consistently returning e-mail and/or phone calls to students more than a week late or not at all) are also categorized as unprofessional and did not exceed "rarely occurring” on the likert scale. This may be an indication that unprofessional behavior is often ambiguous and difficult to categorize as unethical behavior. Even though unprofessional behavior rarely 
occurs in either program, further research could be used to evaluate the perception of unprofessional behavior by both faculty and students.

Counseling and clinical psychology students also ranked six of the same 10 survey behaviors as being the most unethical. Students perceive that unethical research practices, the use of alcohol or drugs while teaching and sexual boundary crossing are unethical. Behaviors that are categorized as unprofessional were not ranked by either counseling or clinical psychology students indicating that they may have an awareness of the differences between the two and selected those that were clearly unethical.

Research questions three and four did not reveal statistically significant differences between counseling and clinical students on questions pertaining to cultural diversity. However, counseling psychology students ranked the only two unethical survey behaviors pertaining to cultural diversity while clinical students did not. This may indicate that counseling psychology programs focus more on issues relating to cultural diversity, and the training they receive is reflected in the perceptions of their students. It is not to say that clinical students do not get this training, but that it is of more importance in counseling psychology programs as it was mentioned in Chapter 1.

\section{Anecdotal Findings}

Many respondents made comments on the open-ended question at the end of the survey. This question allowed the respondent to convey any additional experiences they may have had related to the content of the survey. It also allowed them to comment on any part of the survey they felt needed clarification. The comments were arranged into the following categories: general comments, personal experiences, clarifications, and suggestions. 


\section{General Comments}

There were both positive and negative comments made about the survey. Some responses were general such as "Good survey, I think you touched on a lot of points that are often ignored or overlooked by most programs” and “Interesting study, I’m glad I had the opportunity to take part in it.” Another respondent stated, "Your survey really made me think critically about the behavior of my faculty." The respondents' comments were very much appreciated and this researcher was glad to hear that some of them were challenged to think critically about the behavior of their own faculty. In fact, one respondent sums up a common trend that is revealed in this study by saying "I have realized just how ethical my faculty were! I feel lucky.”

Although the majority of comments on the survey were positive, some were more critical. One respondent simply states “Difficult survey” while another stated, "Some of the questions are hard to answer because of the different scales.” The “Occurs in program scale” and the "Is it ethical scale” could have been separated into two different sections so the respondent could concentrate on one scale at a time. However, this would have increased the length of the survey, and altering the survey this way would have deviated from how the original was presented. Additional respondent critical comments are considered in the following sections as well.

Personal Experiences

Although the majority of comments are made about the survey itself, there are several respondents who share personal experiences. One respondent stated, “Sexual harassment of female students is par for the course” while another recounts: 
I was sexually involved with a professor here during my first year in the program, while I was in his class! I'm pretty sure at least some of the other profs (the Chair of the Dept-his good friend) knew about it. Another grad student had her advisor tell her very intimate details of his sex life while another solicited a grad student to do manual labor at her home and paid him minimally.

Of all the personal experiences offered, most of them involve encounters between the faculty and their students. One respondent though recalls an incident between two students: "There was a sexual harassment complaint by one student about another in my program-it was reported to a supervisor/faculty member but they failed to make a report to the program administration - I thought this was unethical.” This respondent makes a good point by pointing out that unethical behavior is also likely to come from ones' peers as well as from faculty. Although the purpose of this study was not developed to evaluate the existence of unethical behavior among doctoral students, this issue is addressed in the Limitations and Future Research section later in this paper. Other experiences that were shared were not always unethical, but unprofessional as one respondent explained:

During my first year of my doctoral program I had the experience of a professor having a tantrum in class - yelling and screaming at students re: our failure to perform at the level she desired. I addressed the issue with my professor and we were able to come to amicable terms. However, I still believe it was unfortunate that she expressed her frustration in that manner.

Another respondent discusses the issue of using students as informants and stated: 
As a doctoral student I have seen unethical behavior occur primarily as doctoral students serve as “informants” for faculty regarding other doctoral students. I also have seen doctoral students conspire with each other and with faculty in order to scapegoat or target selected students for reasons that are subjective and prejudiced.

Whereas most of the previous personal experiences do not discuss how or if they were resolved, one respondent discusses how their department appropriately addressed a problem that one of their faculty members was having:

There was a professor who developed a substance abuse problem. The faculty intervened, and the professor left his duties at the university. It was a tough situation, but faculty were very supportive and acted in ethical, appropriate ways to meet needs of students and try to intervene with their colleague.

Finally, one respondent stated:

There seems to be the understanding that tenured faculty can do no wrong. I think we've all encountered some questionable behavior on behalf of faculty. However, I don't know how informed we are as students about what to do about it.

\section{Clarifications}

Several respondents made clarifications regarding which of their professors they were thinking about while filling out the survey. One respondent stated, "I only referred to current faculty members in our program although faculty members in which I have had more contact have left the program within the last five years.” Although it was this researcher's intention to gather information on past and current doctoral faculty that 
interacted with the respondents, the instructions on the survey may not have been clear enough in specifying this. The instructions on the survey read "Please use your perspective when rating your professors' behaviors in regard to each of the following situations by circling your response.” Subjects may have been experiences that were excluded experiences from this data set because it was not clear if the respondent should take past and present doctoral faculty into consideration when filling out the survey.

One of the most frequent clarifications made by the respondents of the survey regarded the $1=$ never and N/A = not applicable option on the "Occurs in program scale.” One respondent stated "The distinction between never and not applicable was difficult. Seems like a messy option to give folks.” This researcher agrees with this statement, and as it was mentioned in Chapter II, the responses in the N/A category are collapsed into the "never" category.

Other respondents were hesitant to discuss and/or report behaviors that they did not witness first hand. As one respondent stated "Most of my "NA" responses are due to not knowing what is happening behind closed doors. I have no idea whether many of these things occur or not. I can only report on what I know for sure.” Another respondent similarly stated, “This survey was difficult to complete because I don’t know the specific behavior of each faculty member. My guess is that if someone acts unethically it won’t be common knowledge for the department.”

Several respondents commented on specific questions in the survey. For example, one respondent states “\#62 - Define "off-color” as people may have varying interpretations of this phrase." This researcher perceived the term "off-color" as a joke that is not appropriate and/or makes others feel uncomfortable. If this question is used in 
future research, it may have to be clarified so that some respondents can comprehend the question. Another respondent noted "Question \# 36 \& 39 ask about disclosing personal information. Some courses, such as a group therapy course may encourage this. However, it is always clearly stated in the syllabus.” This respondent makes a good point in that many of the questions could depend on the contextual factors in which the behavior has taken place in. One respondent speaks to this by stating "I find it hard to rate some items without having detailed info on the specific scenario because so much of ethics depends on the specifics.” Although presenting scenarios would be helpful when attempting to clarify the context in which the behavior has taken place in, doing so for each item in the survey would likely make it too long to complete. An alternative to presenting lengthy scenarios may be to present short, critical incidents to elicit results. Further, scenarios reflecting major categories of unethical behavior could be presented. Both of these suggestions could reduce the length of the survey while also helping to clarify the question.

A final clarification that was made by several respondents was that some of the behaviors listed on the survey were unprofessional and not unethical. One respondent sums up these comments by saying, "There were several items that felt more as if they reflected inappropriate/ unprofessional behavior but not technically unethical. Without getting out the APA Code of Ethical is was difficult to draw that line on some items.”

\section{Suggestions}

There are several helpful suggestions made by the respondents of this survey. One respondent stated, "It would be interesting to survey faculty members too and see if their perceptions about ethics match those of the students.” As this researcher previously 
mentioned in Chapter 1 of this paper, a similar study was completed on the perceptions of undergraduate faculty and students with regard to dual relationships (Holmes, Rupert, Ross, and Shapera, 1999). Although a project of this scope was beyond what this researcher was prepared to commit to, it would be interesting to see how doctoral faculty rate their behavior when compared to their students. Another suggestion concerned research and publishing and elaborated on this by stating:

I think another question about ethics in a psychology department that is important is whether or not professors who publish more research are given less consequences for unethical behavior. The answer in my department is yes, proportionately, the more you publish the less trouble you get in.

Similarly, another respondent stated:

You should include more about authorship credit. Many professors assume authorship credit on all work their supervisees publish, with little or no concern for what APA guidelines have to say about this. Further, researchers (faculty included) are too concerned with publishing that they conduct highly unethical research quite often. (e.g. “chopping up” a study into a number of publications, and testing hypotheses that are not discussed because they were non-significant). Two additional suggestions with regard to racial discrimination were made. As one respondent stated, "Your survey does not deal with racial discrimination or inadequate applications of multicultural counseling competencies requirements in courses, research, and clinical work. You should include a few questions that touch on these subjects.” Another respondent also stated, "You need a question about the preferential treatment of other students based on students' minority status, i.e., ethnic minorities receive 
preferential treatment.” A final respondent also had an interesting comment that relates to how culture is perceived differently in western society:

Questions regarding gift giving stood out to me. In my culture gift giving is appropriate and ethical. A gift is a representation of deep appreciation and respect. In western culture it continues to be unethical. This practice can and is demeaning to cultures that use gift giving as a token of appreciation.

\section{Limitations and Future Research}

There are several limitations to the current study. It is impossible to control and/or account for a respondent's anxiety when reporting what they perceive to be unethical behavior of their faculty. As discussed in Chapter I, faculty members have abused the power differential in the faculty-student relationship (Kitchener, 1988; Pope, 1991; Gottlieb, 1993; Biaggio et al., 1997). This power differential has a tremendous impact on students, often making them feel guilty and/or embarrassed if they were involved in the ethical violation (Knabe, B.B., 1992). These feelings may have caused a student not to participate in the survey or to give socially desirable responses. Some training directors may have chosen not to participate because they may have felt that their program could be identified in the survey.

Part of this study was to gather data on a wide range of behaviors that may be occurring in counseling psychology and clinical psychology doctoral programs. Gathering data on such complex and often ambiguous issues can be difficult (Lamb, Catanzaro, and Moorman, 2003). This is particularly true if a respondent of the survey believed the questions are too general. In fact, this type of variation caused by the questions on the survey may have a significant impact on the internal validity of the 
study. Further, when students are reporting behaviors they perceive to be unethical, these accounts may have been based on gossip, and/or hearsay, and could be inaccurate. Future research should focus on students' direct knowledge of unethical events. Students may have also perceived the same behavior differently than their colleagues or may have responded differently to the choices provided on the likert-scale. For example, a respondent could perceive their definition of "fairly often" or "very often” differently from others.

Doctoral students who were solicited to take part in this study were in their last semester before going on internship. The impetus for this decision was 1) To ensure that the students have had the opportunity to learn about psychology ethics and ethical decision-making by having completed the majority of their coursework and 2) Surveying students who are ready to go on their internship will likely have spent the most time with their faculty members, and therefore have had more opportunity to observe or hear reports about their behavior. However, by narrowing the population to these students, this researcher may have excluded other students who may have observed unethical behaviors not witnessed by the respondents as well as drastically reducing the sample size.

This sample size (125) has a significant impact on the external validity of this study. By not having a large sample, researchers must exercise caution when generalizing these findings to doctoral students outside of this study. For future research this researcher would suggest allowing all doctoral students within programs to respond to the survey, instead of attempting to restrict the sample to those in their last semester before going on internship. 
Internal validity is also negatively impacted by the small sample size as power is significantly reduced. Howell (2002) states “Our discussion of power illustrates that reasonably large sample sizes are almost a necessity if one is to run experiments with any decent chance of rejecting Ho, when it is in fact false and the effect is small.” He goes on to say that for power $=.80$, alpha $=.05$ and with a small effect size, total sample sizes required would be approximately 196 . The sample sizes for the current research which was considerably less than 196 had a significant impact on power, as well as an increase in the experiment-wise error rate when the MANOVA was not significant.

Throughout chapter four suggestions for future research have been discussed. However, the students' comments also yielded important suggestions on what type of questions should be added to the survey for future research. For example, several respondents mentioned that there were not enough questions on research and cultural diversity. This researcher agrees with this observation. There are two questions in the cultural diversity category and three in the research category. For future research, questions need to be added to these categories. For example, with regard to cultural diversity more questions need to touch upon issues of discrimination due to one’s ethnicity, as well as courses that do not adequately cover multicultural issues in their curriculum. When considering adding additional questions that relate to research, questions that should be included might address issues of incompetent supervision, inadequate supervision, supervision abandonment, intrusion of supervisor values, abusive supervision, exploitive supervision and dual relationships.

Further, many of the questions on the survey are unprofessional but not unethical. For future research the unprofessional questions could be reduced and replaced with 
behaviors that are unethical. For the purpose of having another informal check of reliability, questions that are clearly ethical and elicit similar responses could also be included.

The anecdotal responses were also helpful by revealing several ideas for future research. For example, one respondent asserted that in academia there is a perception that tenured faculty can do no wrong. Future research could investigate whether or not there are any differences in the ethical behavior of tenured faculty vs. non-tenured faculty. Although the current study did not inquire into these differences, results from the demographic portion of the survey suggest that the respondents believe full-time faculty to violate more psychology ethics than part-time faculty, and that male faculty are believed violate more psychology ethics than female faculty. With regard to gender, the current results for the demographic portion of the survey also support Hammel and colleagues (1996) contention that men violate psychology ethics more than women.

Another respondent asserts that the more publications a faculty member has, the less consequences they have for behaving unethically. In fact, Van Lange and Rusbult (1997) investigated a similar issue. The authors of this study examined social psychologists' beliefs with regard to the probability of self and others to engage in desirable and undesirable research practices. Their results revealed that the probability of undesirable actions by both self and others is perceived to be greater under conditions of low rather than high-perceived traceability. In other words, when others within their field are believed not to verify the appropriateness of the actions, undesirable research practices are more likely to occur. The authors also note that this finding was only observed among faculty members, but not among graduate students with less research 
experience. Future research could continue to investigate these issues, as well as inquire into whether or not psychology faculty who bring in more grant money are perceived to be more or less ethical than those who do not.

A final comment in the anecdotal findings section that spurred an idea for future research concerned the sexual harassment of doctoral students by doctoral students. In order to further investigate this issue future research to conduct a comprehensive investigation of all possible ethical violations, both academic and clinical, of psychology doctoral students as well as faculty. Further, this research could inquire if those students who are violating APA ethics in either a clinical or academic setting were educated by an unethical faculty person or persons. This could be accomplished by including a question in the demographic section that stated "throughout the course of your doctoral program, have you been trained by an unethical psychologist.” 


\section{REFERENCES}

American Psychological Association. (1979). Criteria for the accreditation of doctoral training programs and internships in professional psychology. Washington, DC: Author.

American Psychological Association. (1990). Ethical principles of psychologists. American Psychologist, 45, 390-395.

American Psychological Association. (2002). Ethical principles of psychologists and code of conduct, American Psychologist, 57, 1060-1073.

American Psychological Association. (2003a). Subfields in psychology. Retrieved on November 11, 2003, from www.apa.org/

American Psychological Association. (2003b). Guidelines and principles for accreditation of programs in professional psychology, Retrieved on November 11, 2003, from www.apa.org/

American Psychological Association. (2004). Graduate Study in Psychology. Washington, DC: Author.

Bartell, P., \& Rubin, L. (1990). Dangerous liaisons: Sexual intimacies in supervision. Professional Psychology: Research and Practice, 21, 442-450.

Bechtoldt, H., Wyckoff, L.A., Pokrywa, M.L., Campbell, L.F., \& Norcross, J.C. (2000). Theoretical orientations and employment settings of clinical and counseling psychologists: A comparative study. Poster presented at the $71^{\text {st }}$ annual convention of the Eastern Psychological Association, Baltimore, MD. 
Biaggio, M., Paget, T.L., \& Chenoweth, M.S. (1997). A model for ethical management of faculty-student dual relationships. Professional Psychology: Research and Practice, 28, 184-189.

Blevins-Knabe, B. (1992). The ethics of dual relationships in higher education. Ethics and Behavior, 2, 151-163.

Bowman, V.E., Hatley, L.D., \& Bowman, R.L. (1995). Faculty-student relationships: The dual role controversy. Counselor Education and Supervision, 34, 232-242.

Brems, C., \& Johnson, M.E. (1996). Comparison of Ph.D. programs in clinical and counseling psychology. The Journal of Psychology, 130, 485-495.

Brems, C. \& Johnson, M.E. (1997). Comparison of recent graduates of clinical versus counseling psychology programs. The Journal of Psychology, 131, 91-99.

DePalma, N., \& Drake, R. (1956). Professional ethics for graduate students in psychology, American Psychologist, 11, 554-557.

Glaser, R.D., \& Thorpe, J. (1986). Unethical intimacy: A survey of sexual contact and advances between psychology educators and female graduate students. American Psychologist, 41, 43-51.

Gottlieb, M.C. (1993). Avoiding exploitive dual relationships: A decision-making model. Psychotherapy, 30, 41-48.

Goodstein, L.D. (1981). Ethics are for academics too! Professional Psychology: Research and Practice, 12, 191-193.

Goodyear, R.K., Crego, C.A., \& Johnston, M.W. (1992). Ethical issues in the supervision of student research: A study of critical incidents. Professional Psychology: Research and Practice, 23, 203-210. 
Hammel, G.A., Olkin, R. \& Taube, D.O. (1996). Student-educator sex in clinical and counseling psychology doctoral training. Professional Psychology: Research and Practice, 27, 93-97.

Holmes, D.L., Rupert, P.A., Ross, R.S., \& Shapera, W.E. (1999). Student perceptions of dual relationships between faculty and students. Ethics and Behavior, 9, 79-107.

Howell, D.A. (2002). Statistical Methods for Psychology ( $5^{\text {th }}$ ed.). Pacific Grove, CA: Duxbury.

Jackson, H., \& Nuttall, R. (2001). A relationship between childhood sexual abuse and professional sexual misconduct. Professional Psychology: Research and Practice, 32. 200-204.

Jordan, A.E., \& Meara, M.N. (1990). Ethics and the professional practice of psychologist: The role of virtues and principles. Professional Psychology: Research and Practice, 21, 107-114.

Jorgensen, G.T., \& Weigel, R.G. (1973). Training psychotherapists: Practices regarding ethics, personal growth, and locus of responsibility. Professional Psychology: Research and Practice, 4, 23-27.

Keith-Spiegel, P.C. (1994). Teaching psychologists and the new APA ethics code: Do we fit in? Professional Psychology: Research and Practice, 25, 362-368.

Keith-Spiegel, P.C., Tabachnick, B.G., \& Allen, M. (1993). Ethics in academia: Students’ views of professors’ actions. Ethics and Behavior, 3, 149-162.

Kimmel, A.J. (1988). Ethics and values in applied social research. Newbury Park, CA: Sage. 
Kitchener, K.S. (1988). Dual role relationships: What makes them so problematic? Journal of Counseling and Development, 67, 217-221.

Kitchener, K.S. (1992). Psychologist as teacher and mentor: Affirming ethical values throughout the curriculum. Professional Psychology: Research and Practice, 23, 190-195.

Knabe, B.B. (1992). The ethics of dual relationships in higher education. Ethics \& Behavior, 2(3), 151-163.

Kolbert, J.B., Morgan, B., \& Brendel, J.M. (2002). Faculty and student perceptions of dual relationships within counselor education: A qualitative analysis. Counselor Education and Supervision, 41, 193-206.

Lamb, D.H., \& Catanzaro, S.J. (1998). Sexual and nonsexual boundary violations involving psychologists, clients, supervisees, and students: Implications for professional practice. Professional Psychology: Research and Practice, 29, 498503.

Lamb, D.H., Catanzaro, S.J., \& Moorman, A.S. (2003). Psychologists reflect on their sexual relationships with clients, supervisees, and students: Occurrence, impact, rationales, and collegial intervention. Professional Psychology: Research and Practice, 34(1), 102-107.

Mayne, T.J., Norcross, J.C., \& Sayette, M.A. (2000). Insider's guide to graduate programs in clinical and counseling psychology (2000-2001 ed). New York: Guilford. 
McGaha, S., \& Minder, C. (1993). Factors influencing performance on the Examination for Professional Practice in Psychology (EPPP). Professional Psychology: Research and Practice, 24, 107-109.

Newmark, C.S., \& Hutchins, T.C. (1981). Survey of professional education in ethics in clinical psychology internship programs. Journal of Clinical Psychology, 37, 681-683.

Norcross, J.C., Sayette, M.A., Mayne, M.A., Karg, T.J., \& Turkson, M.A. (1998). Selecting a doctoral program in professional psychology: Some comparisons among PhD counseling, PhD clinical and PsyD clinical psychology programs. Professional Psychology: Research and Practice, 29, 609-614.

Pan, G. (1999). On a levene type test for equality of two variances. Journal of Statistical Computation Simulation, 63, 59-71.

Peterson, R. (1993). A meta-analysis of cronbach’s coefficient alpha. Journal of Consumer Research, 21, 381-391.

Pittenger, D.J. (1994). The cross-disciplinary ethical responsibilities of psychology faculty. Ethics \& Behavior, 4, 199-208.

Podbelski, J., \& Weisgerber, K. (1989). Differences in moral sensitivity in master's level counselors. Paper presented at the Annual Meeting of the American Psychological Association, New Orleans.

Pope, K.S. (1991). Dual relationships in psychotherapy. Ethics \& Behavior, 1, 21-34. Pope, K.S., Schover, L.R., \& Levenson, H. (1980). Sexual behavior between clinical supervisors and trainees: Implications for professional standards. Professional Psychology: Research and Practice, 11, 157-162 
Pope, K.S., Tabachnick, B.G., \& Keith-Spiegel, P. (1986). Sexual attraction to clients: The human therapist and the (sometimes) inhuman training system. American Psychologist, 41, 147-158.

Pope, K.S., Tabachnick, B.G., \& Keith-Spiegel, P. (1987). Ethics of practice: The beliefs and behaviors of psychologists as therapists. American Psychologist, 42, 993-1006.

Pope, K.S., \& Vetter, V.A. (1992). Ethical dilemmas encountered by members of the American Psychological Association: A national survey. American Psychologist, 47, 397-411.

Rest, J.R. (1982). Research on moral development: Implications for training counseling psychologists. The Counseling Psychologist, 12, 19-29.

Ross, M.J., Holzman, L.A., Handal, P.J., \& Gilner, F.H. (1991). Performance on the Examination for the Professional Practice of Psychology as a function of specialty, degree, administrative housing, and accreditation status. Professional Psychology: Research and Practice, 22, 347-350.

Stadler, H. \& Paul, R.D. (1986). Counselor educators’ preparation in ethics. Journal of Counseling and Development, 64, 328-330.

Stevens, J.P. (1992). Applied multivariate statistics for the social sciences ( $3^{\text {rd }}$ ED.). Lawrence Erlbaum Associates, Mahwah, NJ.

Stone, AA., Turkkan, J.S., Bachrach, C.A., Jobe, J.B., Kurtzman, H.S., \& Lain, V.S. (2000). The science of self-report: Implications for research and practice. Mahwah, NJ: Lawrence Erlbaum Associates. 
Tabachnick, B.G., Keith-Spiegel, \& Pope, K.S. (1991). Ethics of teaching: Beliefs and behaviors of psychologists as educators. American Psychologist, 46, 506-515.

Tipton, R.M. (1983). Clinical and counseling psychology: A study of roles and functions. Professional Psychology: Research and Practice, 14, 837-846.

Tubbs, P., \& Pomerantz, A.M. (2001). Ethical behaviors of psychologists: Changes since 1987. Journal of Clinical Psychology, 57, 395-933.

Tymchuk, A.J. (1985). Ethical decision-making and psychology students’ attitudes toward training in ethics. Professional Practice of Psychology, 6, 219-232.

Tymchuk, A.J., Drapkin, R., Major-Kingsley, S., Ackerman, A.B., Coffman, E.W., \& Baum, M.S. (1979). Survey of training in ethics in APA-approved clinical psychology programs. American Psychologist, 34, 1168-1170.

Van Lange, P.A.M. \& Rusbult, C.E. (1997). Dilemmas of academic practice: Perceptions of superiority among social psychologists. European Journal of Social Psychology, 27, 675-685.

Wilson, L.S. \& Ranft, V.A. (1993). The state of ethical training for counseling psychology doctoral students. The Counseling Psychologist, 21, 445-456.

Woody, J.D. (1990). Resolving ethical concerns in clinical practice: Toward a pragmatic model. Journal of Marital and Family Therapy, 16, 133-150.

Zook, A. II. (1989). On the merger of clinical and counseling psychology. Professional Psychology: Research and Practice, 18, 4-5. 


\section{APPENDIX A}

January 29, 2004

Dear Training Director:

My name is Philip Cromer, I am a doctoral candidate in Counseling Psychology at West Virginia

University. I am conducting research for my dissertation that will evaluate the perceptions of counseling psychology doctoral students, versus the perceptions of clinical psychology doctoral students in regard to their faculty's ethical behavior. Improving the understanding of how students view their educators may help to guide faculty as role models.

I am requesting your help in distributing the enclosed packets to the clinical or counseling psychology doctoral students. For example, students who are currently preparing to go on internship this year should receive packets. Students who will be preparing to go on internship this time next year should also receive packets. Each packet contains the attached demographic questionnaire and the students' perceptions survey, which has been reviewed by several expert reviewers. In addition, many of the survey items were previously used by Kenneth S. Pope, Barbara G. Tabachnick, and Patricia Keith-Spiegel in their study of psychology students' perceptions of faculty ethical behavior.

The estimated amount of time to complete the demographic questionnaire and the survey is approximately 20-30 minutes. To correspond with the human subject regulations at West Virginia University participation must be voluntary, and students can decide to discontinue the survey at any time. All results from the survey will remain confidential, and returning the survey will indicate informed consent. There is no way a student or their program can be identified in this study. When the results of this investigation are posted on the internet, I will send you the address where they can be viewed. Thank you for your time.

Sincerely,

Philip Cromer

Doctoral Candidate, West Virginia University

Correspondence may be addressed to:

Philip Cromer

872 Independence Hill Village

Morgantown, WV 26505

(304)598-3444
Dissertation Chairperson

Robert P. Marinelli, Ed.D.

Dept. of Counseling, Rehabilitation Counseling, and Counseling Psychology

P.O. Box 6122

Morgantown, WV 26505 
January 29, 2004

Doctoral Students' Perceptions of Their Faculty’s Ethical Behavior

Dear Colleague:

\section{Introduction}

My name is Philip Cromer, I am a doctoral candidate in Counseling Psychology at West Virginia University. I am conducting research for my dissertation under the supervision of Robert Marinelli, Ed.D. My research will evaluate the perceptions of counseling psychology

doctoral students, versus the perceptions of clinical psychology doctoral students in regard to their faculty's ethical behavior.

\section{Purpose of the Study}

I hope that improving the understanding of how students view their educators may help to guide faculty as role models.

\section{Description of Procedures}

I am requesting your help in gathering data on a variety of ethical issues. Enclosed is a demographic questionnaire and the students' perceptions survey that should take you only 20-30 minutes to complete. Please complete the survey, and return it to me in the postage paid envelope provided for you. Several expert reviewers have reviewed these instruments. In addition, many of the survey items were previously used by Kenneth S. Pope, Barbara G. Tabachnick, and Patricia Keith-Spiegel in their study of psychology students' perceptions of faculty ethical behavior.

\section{Risks and Discomforts}

There are no known or expected risks from participating in this study, except for the potential anxiety associated with answering the questions on the survey.

\section{Alternatives}

Your participation in this study is entirely voluntary, and your return of the survey will indicate informed participation.

\section{Benefits}

Although this study may not have a direct benefit to you, the knowledge gained from your participation may be of benefit to others.

\section{Contact Persons}

Philip Cromer, M.A.

872 Independence Hill Village

Morgantown, WV 26505

(304) 598-3444

\section{Confidentiality}

Any information obtained as a result of this research will be kept as confidential as legally possible. There is no way a student or their program can be identified in this study. When the results of this investigation are posted on the internet, I will send your training director the address where they can be viewed.

\section{Voluntary Participation}

Participation in this study is voluntary. Although complete data sets are my goal, you are free to not answer any of the individual questions in the survey. If you decide not to participate in this investigation, please return the blank survey. Thank you for your time.

Sincerely,

Philip Cromer, M.A.

Dissertation Chairperson

Robert P. Marinelli, Ed.D.

Dept. of Counseling, Rehabilitation

Counseling, and Counseling Psychology

P.O. Box 6122

Morgantown, WV 26505

(304) 293-3807
Office of Research Compliance

304-293-7073 
February 16, 2004

Dear Training Director,

My name is Philip Cromer and I am the doctoral candidate in Counseling Psychology at West Virginia University who requested your help in distributing packets containing a demographic questionnaire, and the students' perception survey to the counseling psychology or clinical psychology doctoral students in your program. Students who complete these measures should be in their last semester prior to their internship. Could you please remind these students that if they have not completed the survey to return it to me in their postage paid envelope? This follow-up letter is being sent to each site that was randomly selected because there is no way to identify programs that did, or did not, participate in this investigation. Once again, thank you for your time and help.

Sincerely,

Philip Cromer

Doctoral Candidate, West Virginia University 
Please use your perspective when rating your professors' behavior in regard to each of the following situations by circling your response. If the behavior has not occurred or if you don't know if it has occurred in your program, please circle "N/A" for Not Applicable. Whether or not the behavior has occurred in your program, please rate the behavior as ethical or unethical in the last column. Please be honest in your responses, all questionnaires will be kept confidential.

Rating Codes:

Occurs in program? 1=Never $2=$ =Rarely $3=$ Sometimes $4=$ =Fairly often $5=$ Very often

Is it ethical? $\quad 1=$ No $2=$ Under rare circumstances $3=$ Don't know/not sure $4=$ Under most circumstances $5=$ Yes

Occurs in program? Is it ethical?

\begin{tabular}{|l|l|l|l|l|l|l|} 
1. Ignoring strong evidence of student's cheating. & 1 & 2 & 3 & 4 & 5 & N/A \\
\hline
\end{tabular}

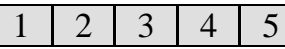

2. Dating a student.

\begin{tabular}{l|l|l|l|l|l|}
\hline & 2 & 3 & 4 & 5 & N/A \\
\hline
\end{tabular}

3. Asking small favors (such as a ride home) from students.

\begin{tabular}{|l|l|l|l|l|l|}
\hline & 2 & 3 & 4 & 5 & N/A \\
\hline
\end{tabular}

4. Hugging a student.

\begin{tabular}{l|l|l|l|l|l|}
1 & 2 & 3 & 4 & 5 & N/A \\
\hline
\end{tabular}

5. Accepting a student's expensive gift.

\begin{tabular}{|l|l|l|l|l|l|}
1 & 2 & 3 & 4 & 5 & N/A \\
\hline
\end{tabular}

6. Teaching classes when too distressed to be effective.

\begin{tabular}{|l|l|l|l|l|l|}
\hline & 2 & 3 & 4 & 5 & N/A \\
\hline
\end{tabular}

7. Becoming sexually involved with a student.

\begin{tabular}{|l|l|l|l|l|l|}
\hline & 2 & 3 & 4 & 5 & N/A \\
\hline
\end{tabular}

8. Lending money to a student.

\begin{tabular}{|l|l|l|l|l|l|}
\hline 1 & 2 & 3 & 4 & 5 & N/A \\
\hline
\end{tabular}

9. Accepting a student's invitation to a party.

\begin{tabular}{|l|l|l|l|l|l|}
1 & 2 & 3 & 4 & 5 & N/A \\
\hline
\end{tabular}

10. Selling goods (such as a car or books) to a student.

\begin{tabular}{|l|l|l|l|l|l|}
1 & 2 & 3 & 4 & 5 & N/A \\
\hline
\end{tabular}

11. Being sexually attracted to a student.

\begin{tabular}{|l|l|l|l|l|l|}
\hline 1 & 2 & 3 & 4 & 5 & N/A \\
\hline
\end{tabular}

12. Teaching material that they don't know much about.

\begin{tabular}{|l|l|l|l|l|l|}
\hline & 2 & 3 & 4 & 5 & N/A \\
\hline
\end{tabular}

13. Teaching that homosexuality is a mental sickness.

\begin{tabular}{|l|l|l|l|l|l|}
\hline 1 & 2 & 3 & 4 & 5 & N/A \\
\hline
\end{tabular}

14. Accepting a student’s inexpensive gift (e.g., worth less than \$5).

\begin{tabular}{|l|l|l|l|l|l|}
\hline 1 & 2 & 3 & 4 & 5 & N/A \\
\hline
\end{tabular}

15. Making deliberate or repeated sexual comments, gestures, or physical contact toward a student that are unwanted by the student.

\begin{tabular}{|l|l|l|l|l|l|}
1 & 2 & 3 & 4 & 5 & N/A \\
\hline
\end{tabular}

16. Teaching while under the influence of alcohol.

\begin{tabular}{|l|l|l|l|l|l|}
\hline 1 & 2 & 3 & 4 & 5 & N/A \\
\hline
\end{tabular}

17. Teaching that certain races are intellectually inferior.

\begin{tabular}{|l|l|l|l|l|l|}
\hline 1 & 2 & 3 & 4 & 5 & N/A \\
\hline
\end{tabular}

18. Encouraging students to volunteer to participate in their research projects as "subjects".

\begin{tabular}{|l|l|l|l|l|l|}
\hline 1 & 2 & 3 & 4 & 5 & N/A \\
\hline
\end{tabular}

19. Having students be research participants as part of a course requirement (with no alternative way of satisfying the class requirement).

\begin{tabular}{|l|l|l|l|l|l|}
1 & 2 & 3 & 4 & 5 & N/A \\
\hline
\end{tabular}

20. Teaching while under the influence of alcohol, cocaine, or some other illegal drug.

\begin{tabular}{|l|l|l|l|l|l|}
\hline 1 & 2 & 3 & 4 & 5 & N/A \\
\hline
\end{tabular}

\begin{tabular}{|c|c|c|c|c|}
\hline 1 & 2 & 3 & 4 & 5 \\
\hline 1 & 2 & 3 & 4 & 5 \\
\hline 1 & 2 & 3 & 4 & 5 \\
\hline 1 & 2 & 3 & 4 & 5 \\
\hline 1 & 2 & 3 & 4 & 5 \\
\hline 1 & 2 & 3 & 4 & 5 \\
\hline 1 & 2 & 3 & 4 & 5 \\
\hline 1 & 2 & 3 & 4 & 5 \\
\hline 1 & 2 & 3 & 4 & 5 \\
\hline 1 & 2 & 3 & 4 & 5 \\
\hline 1 & 2 & 3 & 4 & 5 \\
\hline 1 & 2 & 3 & 4 & 5 \\
\hline 1 & 2 & 3 & 4 & 5 \\
\hline 1 & 2 & 3 & 4 & 5 \\
\hline 1 & 2 & 3 & 4 & 5 \\
\hline 1 & 2 & 3 & 4 & 5 \\
\hline 1 & 2 & 3 & 4 & 5 \\
\hline 1 & 2 & 3 & 4 & 5 \\
\hline 1 & 2 & 3 & 4 & 5 \\
\hline
\end{tabular}




\section{Rating Codes:}

Occurs in program? 1=Never $2=$ =Rarely $3=$ =Sometimes $4=$ =Fairly often $5=$ =ery often

Is it ethical? $\quad 1=$ No $2=$ =Under rare circumstances $3=$ Don't know/not sure $4=$ =Under most circumstances $5=$ Yes

21. Allowing how much a student is liked to influence what grade the student gets.

\begin{tabular}{|l|l|l|l|l|l|}
\hline & Occurs in program? \\
\hline
\end{tabular}

22. Telling a student "I’m sexually attracted to you".

23. Using university time, funds, or resources to create a scholarly textbook then requiring it for their classes.

24. Assigning unpaid students to carry out work for the professors that has little educational value for the students.

\begin{tabular}{l|l|l|l|l|l|}
1 & 2 & 3 & 4 & 5 & N/A \\
\hline
\end{tabular}

\begin{tabular}{|l|l|l|l|l|l|}
1 & 2 & 3 & 4 & 5 & N/A \\
\hline
\end{tabular}

\begin{tabular}{|l|l|l|l|l|l|}
1 & 2 & 3 & 4 & 5 & N/A \\
\hline
\end{tabular}

25. Privately tutoring students in the department for a fee.

\begin{tabular}{|l|l|l|l|l|l|}
1 & 2 & 3 & 4 & 5 & N/A \\
\hline
\end{tabular}

26. Taking advantage of a student’s offer such as getting wholesale prices at a parent's store.

\begin{tabular}{|l|l|l|l|l|l|}
1 & 2 & 3 & 4 & 5 & N/A \\
\hline
\end{tabular}

27. Criticizing all theoretical approaches except those the professor personally prefers.

\begin{tabular}{|l|l|l|l|l|l|}
1 & 2 & 3 & 4 & 5 & N/A \\
\hline
\end{tabular}

28. Using cocaine or other illegal drugs in their personal (nonteaching) life.

\begin{tabular}{|l|l|l|l|l|l|}
1 & 2 & 3 & 4 & 5 & N/A \\
\hline
\end{tabular}

29. Insulting or ridiculing a student in the student's presence.

\begin{tabular}{|l|l|l|l|l|l|}
\hline 1 & 2 & 3 & 4 & 5 & N/A \\
\hline
\end{tabular}

30. Ignoring unethical behavior committed by their colleagues.

\begin{tabular}{|l|l|l|l|l|l|}
\hline 1 & 2 & 3 & 4 & 5 & N/A \\
\hline
\end{tabular}

31. Becoming sexually involved with a student after the class is over and the grades have been assigned.

\begin{tabular}{|l|l|l|l|l|l|}
1 & 2 & 3 & 4 & 5 & N/A \\
\hline
\end{tabular}

32. Picking their favorite students to do projects with them.

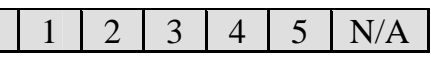

33. Agreeing to write a recommendation letter for a student, but not getting it in until 2 weeks past the deadline.

\begin{tabular}{|l|l|l|l|l|l|}
1 & 2 & 3 & 4 & 5 & N/A \\
\hline
\end{tabular}

34. Flirting with students.

\begin{tabular}{|l|l|l|l|l|l|}
\hline & 2 & 3 & 4 & 5 & N/A \\
\hline
\end{tabular}

35. Giving every student a high grade regardless of the quality of their work.

\begin{tabular}{l|l|l|l|l|l|}
1 & 2 & 3 & 4 & 5 & N/A \\
\hline
\end{tabular}

36. Setting up a course so that students are encouraged to share aspects of their very personal life in class.

\begin{tabular}{|l|l|l|l|l|l|}
1 & 2 & 3 & 4 & 5 & N/A \\
\hline
\end{tabular}

37. Announcing exam grades of each student, by name, in front of the class.

38. Accepting current students as psychotherapy clients in a professor's private practice.

39. Requiring students to disclose highly personal information in a group discussion class (e.g., the student who remains silent or "closed up" is graded down for that.)

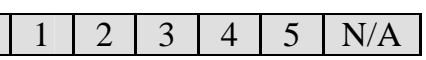

\begin{tabular}{|l|l|l|l|l|l|}
1 & 2 & 3 & 4 & 5 & N/A \\
\hline
\end{tabular}

\begin{tabular}{|l|l|l|l|l|}
\multicolumn{5}{c|}{ Is it ethical? } \\
\hline & 2 & 3 & 4 & 5 \\
\hline
\end{tabular}

\begin{tabular}{|l|l|l|l|l|}
\hline 1 & 2 & 3 & 4 & 5 \\
\hline 1 & 2 & 3 & 4 & 5 \\
\hline
\end{tabular}

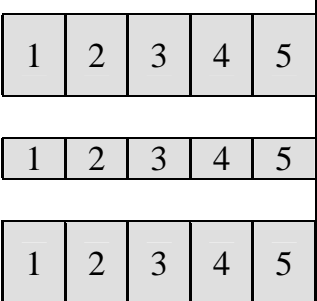

\begin{tabular}{|l|l|l|l|l|}
\hline 1 & 2 & 3 & 4 & 5 \\
\hline
\end{tabular}

\begin{tabular}{|c|c|c|c|c|}
\hline 1 & 2 & 3 & 4 & 5 \\
\hline 1 & 2 & 3 & 4 & 5 \\
\hline 1 & 2 & 3 & 4 & 5 \\
\hline 1 & 2 & 3 & 4 & 5 \\
\hline
\end{tabular}

\begin{tabular}{|l|l|l|l|l|}
\hline 1 & 2 & 3 & 4 & 5 \\
\hline 1 & 2 & 3 & 4 & 5 \\
\hline
\end{tabular}

\begin{tabular}{|c|c|c|c|c|}
\hline 1 & 2 & 3 & 4 & 5 \\
\hline 1 & 2 & 3 & 4 & 5 \\
\hline 1 & 2 & 3 & 4 & 5 \\
\hline 1 & 2 & 3 & 4 & 5 \\
\hline 1 & 2 & 3 & 4 & 5 \\
\hline
\end{tabular}

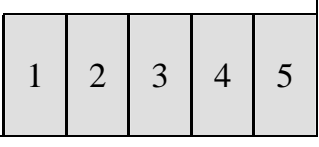

Next Page $\rightarrow$ 
Rating Codes:

Occurs in program? 1=Never $2=$ =Rarely $3=$ =Sometimes $4=$ Fairly often $5=$ Very often

Is it ethical? $\quad 1=$ No $2=$ Under rare circumstances $3=$ Don't know/not sure 4=Under most circumstances 5= Yes

Occurs in program? Is it ethical?

\begin{tabular}{|l|l|l|l|l|l|l|l|l|l|l|l|l|l|l|}
\hline 40. Failing to periodically update class content. & 1 & 2 & 3 & 4 & 5 & N/A & 1 & 2 & 3 & 4 & 5
\end{tabular}

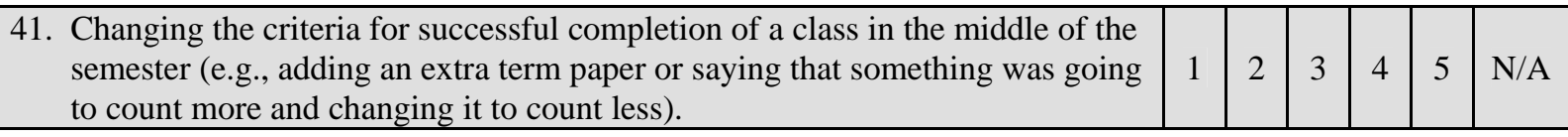

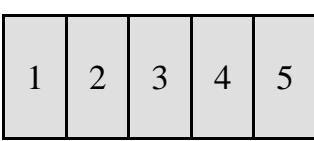

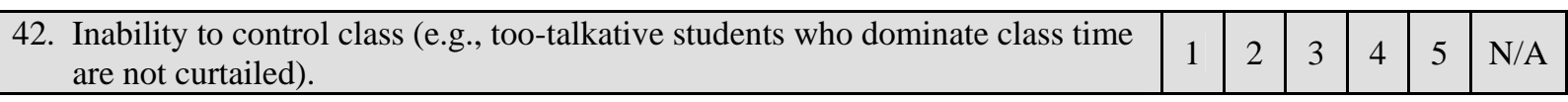

\begin{tabular}{|l|l|l|l|l|l|l|} 
43. Consistently letting class out 30, or more, minutes early. & 1 & 2 & 3 & 4 & 5 & N/A \\
\hline
\end{tabular}

\begin{tabular}{|l|l|l|l|l|l|l|} 
44. Writing comments on tests or assignments that are illegible. & 1 & 2 & 3 & 4 & 5 & N/A \\
\hline
\end{tabular}

45. Returns assignments promptly.

\begin{tabular}{|c|c|c|c|c|c|}
\hline 1 & 2 & 3 & 4 & 5 & N/A \\
\hline
\end{tabular}

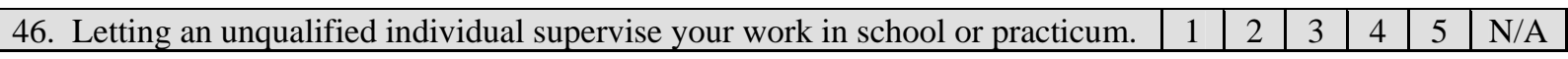

47. Giving testimonials in class (e.g., telling students to refer people to their private office or purchase their book).

\begin{tabular}{|l|l|l|l|l|l|}
\hline 1 & 2 & 3 & 4 & 5 & N/A \\
\hline
\end{tabular}

48. Demeaning a student publicly in class.

49. Inviting selected students to participate in a study group closed to other students.

\begin{tabular}{|l|l|l|l|l|l|}
\hline & 2 & 3 & 4 & 5 & N/A \\
\hline
\end{tabular}

\begin{tabular}{|l|l|l|l|l|l|}
\hline 1 & 2 & 3 & 4 & 5 & N/A \\
\hline
\end{tabular}

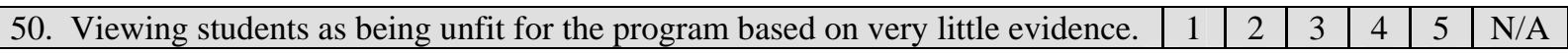

51. Using students as informants to report on the functioning of their class members.

52. Encouraging students to select field placement sites (e.g., practicum/ internship) for the instructor's personal benefit.

\begin{tabular}{|l|l|l|l|l|l|}
1 & 2 & 3 & 4 & 5 & N/A \\
\hline
\end{tabular}

\begin{tabular}{|l|l|l|l|l|l|}
1 & 2 & 3 & 4 & 5 & N/A \\
\hline
\end{tabular}

53. Consistently being unavailable for students during office hours.

\begin{tabular}{|l|l|l|l|l|l|}
\hline & 2 & 3 & 4 & 5 & N/A \\
\hline
\end{tabular}

54. Consistently returning e-mails and/or phone calls to students more than a week late or not at all.

\begin{tabular}{|l|l|l|l|l|l|}
1 & 2 & 3 & 4 & 5 & N/A \\
\hline
\end{tabular}

55. Frequently missing class for weather related problems when class members who have much worse driving conditions are able to attend.

\begin{tabular}{|l|l|l|l|l|l|}
\hline 1 & 2 & 3 & 4 & 5 & N/A \\
\hline
\end{tabular}

56. Not notifying class members in advance of their class cancellation when not in emergency situation and prior notice could have been given.

\begin{tabular}{|l|l|l|l|l|l|}
1 & 2 & 3 & 4 & 5 & N/A \\
\hline
\end{tabular}
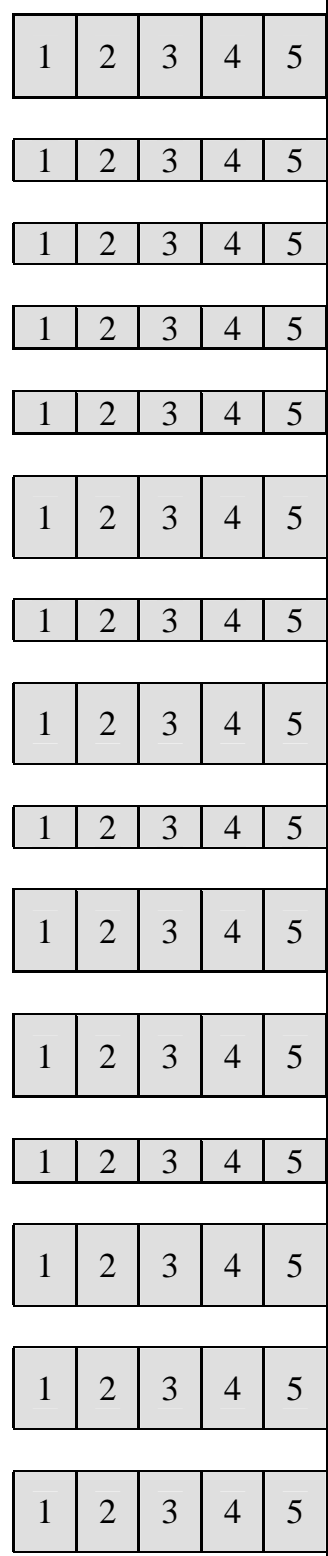

57. Given preference to students based on their physical appearance and/or gender.

\begin{tabular}{|l|l|l|l|l|l|}
1 & 2 & 3 & 4 & 5 & N/A \\
\hline
\end{tabular}




\begin{tabular}{|c|c|c|c|c|c|c|c|c|c|c|c|}
\hline 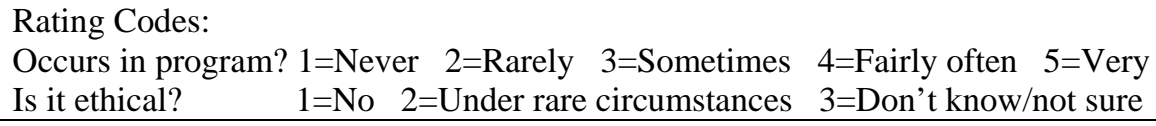 & often $4=\mathrm{U}$ & hde & nos & $\mathrm{tci}$ & um & tances & $5=$ Yes & & & & \\
\hline & & $\overline{\mathrm{Occ}}$ & rs i & $\mathrm{pr}$ & gran & & & Is i & thi & & \\
\hline $\begin{array}{l}\text { 58. Giving a student advice in areas in which the professor is not really qualified } \\
\text { to offer advice. }\end{array}$ & 1 & 2 & 3 & 4 & 5 & N/A & 1 & 2 & 3 & 4 & 5 \\
\hline 59. Talking to student (in private) about another student's personal problems. & 1 & 2 & 3 & 4 & 5 & N/A & 1 & 2 & 3 & 4 & 5 \\
\hline 60. Talking to students (in private) about their own personal problems. & 1 & 2 & 3 & 4 & 5 & N/A & 1 & 2 & 3 & 4 & 5 \\
\hline 61. Being more friendly to some students than to others. & 1 & 2 & 3 & 4 & 5 & N/A & 1 & 2 & 3 & 4 & 5 \\
\hline 62. Telling "off-color" jokes in class. & 1 & 2 & 3 & 4 & 5 & N/A & 1 & 2 & 3 & 4 & 5 \\
\hline 63. Taking publishing credit for work they were not involved with. & 1 & 2 & 3 & 4 & 5 & N/A & 1 & 2 & 3 & 4 & 5 \\
\hline 64. Demeaning a student in a faculty meeting or discussion. & 1 & 2 & 3 & 4 & 5 & N/A & 1 & 2 & 3 & 4 & 5 \\
\hline 65. Occasionally 5 minutes late to class. & 1 & 2 & 3 & 4 & 5 & N/A & 1 & 2 & 3 & 4 & 5 \\
\hline 66. Plagiarizes material. & 1 & 2 & 3 & 4 & 5 & N/A & 1 & 2 & 3 & 4 & 5 \\
\hline 67. Occasionally unkempt in class & 1 & 2 & 3 & 4 & 5 & N/A & 1 & 2 & 3 & 4 & 5 \\
\hline
\end{tabular}

Please use this space to comment on any additional experiences you have had related to the content of this survey. You may also use this space to comment on any part of the survey you feel needs clarification. Thank you for your time and comments. 


\section{DEMOGRAPHICS}

Please circle only one response for each of the following questions:

1. What is your field of study? A. Counseling psychology

B. Clinical Psychology

2. Is your program APA approved?
A. Yes
B. No

3. Does your program require a separate course in ethics?
A. Yes (If yes, answer 3a)
B. No

3a. Have you taken it?
A. Yes

B. No

4. What is your gender?

A. Male

B. Female

5. Do you feel you have adequate knowledge of psychology ethics?
A. Yes
B. No

6. Have you taken a course in ethics as an undergraduate or graduate student?
$\underline{\text { Undergrad }}$
Graduate
A. Yes
A. Yes
B. No
B. No

7. What is your race/ethnicity?
A. African American
D. Caucasian American
G. Other:

B. Native American

E. Hispanic/Latino

C. Asian American

F. Pacific Islander

8. What year of your program are you currently in?
A. 1
B. 2
C. 3
D. 4
E. 5
F. 6
G. 7

9. What is your age?
A. $18-25$
B. 26-33
C.34-41
D. $42-49$
E. 50 or above

10. What degree will you receive upon completion of your program?
A. Ph.D.
B. Ed.D.
C. Psy.D.

11. Does the administration in your department tolerate unethical behavior?
A. Yes
B. No
C. Not sure

12. Does the administration of the college in which your department is housed tolerate unethical behavior?
A. Yes
B. No
C. Not sure

13. Please estimate your program's provision of opportunities to be educated about ethics by circling one of the following numbers:

$\begin{array}{ccccc}\text { Extensive } & & \text { Some } & & \text { None } \\ 1 & 2 & 3 & 4 & 5\end{array}$

Please describe the educational experiences to which you were exposed: 
Students’’ Perceptions, 127

14. Please estimate the opportunities to be educated about ethics prior to entering your doctoral program:

Extensive

1 $2 \quad$ Som

$\begin{array}{cc}\text { Some } \\ 3 & 4\end{array}$

None

5

Please describe the educational experiences to which you were exposed:

\section{Please fill in your response for the following questions:}

15. Please estimate the number faculty involved in your doctoral program:

A. Full-time

B. Part-time

16. Please estimate how many of your male and female full-time professors, in your doctoral program, have violated any psychology ethics:

A. Males

B. Females

17. Please estimate how many of your male and female part-time professors, in your doctoral program, have violated any psychology ethics:

A. Males

B. Females

18. In what field(s) is your masters degree in?

19. In what field(s) is your undergraduate degree in?

20. Please estimate the number of students in your doctoral program:

21. Please estimate your years of clinical experience: 